\title{
A LOW-COST LOOP MEASUREMENT TOOL FOR DC-DC CONVERTERS
}

\author{
A Thesis \\ presented to \\ the Faculty of California Polytechnic State University, \\ San Luis Obispo
}

\author{
In Partial Fulfillment \\ of the Requirements for the Degree \\ Master of Science in Electrical Engineering
}

by

Shouee Brian Lin

October 2015 
(C) 2015

Shouee Brian Lin

ALL RIGHTS RESERVED 


\section{COMMITTEE MEMBERSHIP}

TITLE:

AUTHOR:

DATE SUBMITTED:

COMMITTEE CHAIR:

COMMITTEE MEMBER:

COMMITTEE MEMBER
A Low-Cost Loop Measurement Tool For DC-DC Converters

Shouee Brian Lin

October 2015

Taufik, Ph.D.

Professor of Electrical Engineering

Vladimir Prodanov, Ph.D.

Associate Professor of Electrical Engineering

Xiao-Hua (Helen) Yu, Ph.D.

Professor of Electrical Engineering 


\section{ABSTRACT}

\section{A Low-Cost Loop Measurement Tool For DC-DC Converters}

\section{Shouee Brian Lin}

Loop measurements are very important in evaluating dynamic performance of DC-DC converters. In this thesis, a small loop measurement tool as a low-cost alternative to a network analyzer is proposed. The tool is particularly useful when a network analyzer is not always available for use, for example when engineers are working on-site with customers or when a network analyzer is not affordable due to their relatively high cost. The design, simulation, and hardware implementation of the inexpensive loop measurement tool will be presented in this thesis. Results from computer simulation and hardware prototype demonstrate the ability of the proposed tool to perform phase margin, gain margin, and cross-over frequency measurements of DC-DC converters. These results are then shown to be comparable with those obtained from a network analyzer. The procedure used to perform loop measurements with the proposed tool will be explained. Limitations in the operation as well as further improvements to enhance the performance of the proposed tool will also be discussed. 


\section{ACKNOWLEDGMENTS}

I would like to thank my parents for their encouragement during my time at Cal Poly. Without their support, these past five years would have been much more difficult. It is because of them that my pursuing a Bachelor's and Master's degree in Electrical Engineering have been made possible.

Of course I would also like to thank my advisor Dr. Taufik for his support and mentorship. The genuine interest and passion he exudes through his teaching has been a source of inspiration to me, especially in the field of power electronics. Dr. Taufik's guidance has been an integral part of the thesis and I greatly appreciate everything he has done for me. I only wish I did better in his classes!

I would also like to give thanks to my peers who have helped me throughout the years here at Cal Poly. I want to thank Ken Huynh for being not only a model student I could look to for help, but also for being one of my best friends in and out of school. I would also like to thank Colleen Cheung for being the most reliable study buddy I have had in school; without you, I might not have made it to this point. Also, I would also like to thank Owen Jong, Austin Luan, and Michael $\mathrm{Wu}$ for taking time out of their days to give advice and technical help.

Lastly, I would like to give thanks to Mr. Li and Mr. Zhang from Linear Technology for their role in my thesis. Without their guidance and approval, I literally would not have been able to write this thesis. 


\section{TABLE OF CONTENTS}

\section{Page}

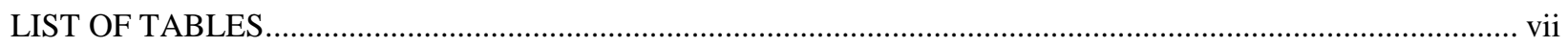

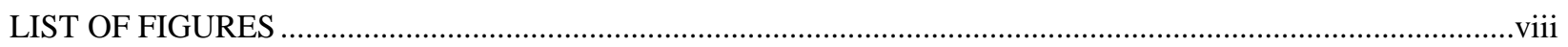

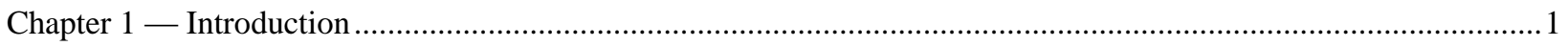

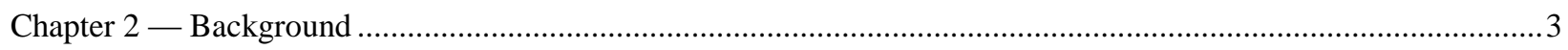

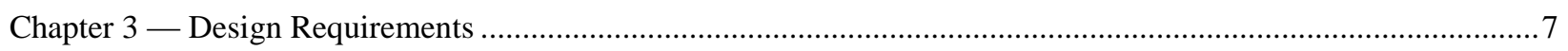

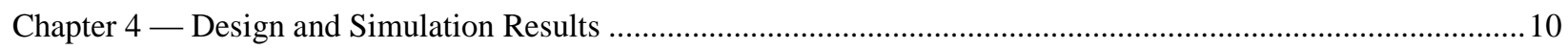

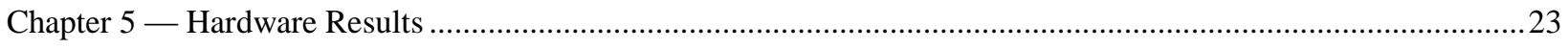

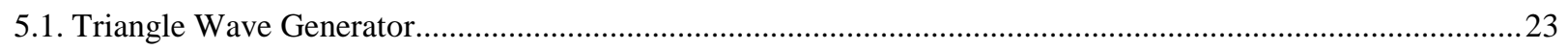

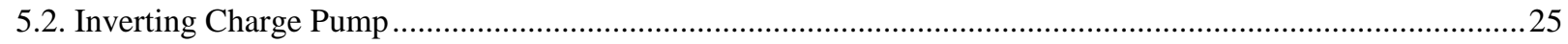

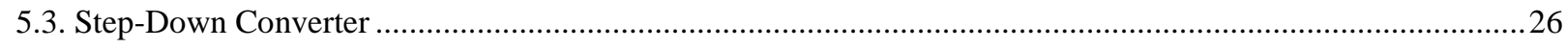

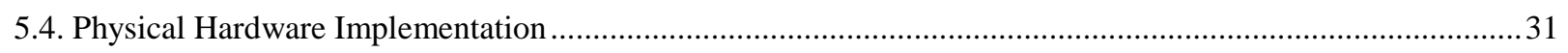

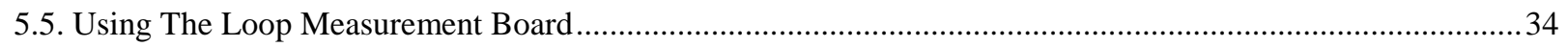

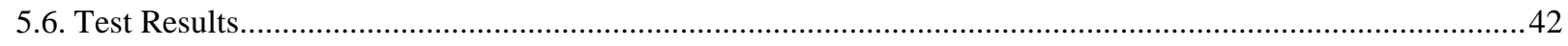

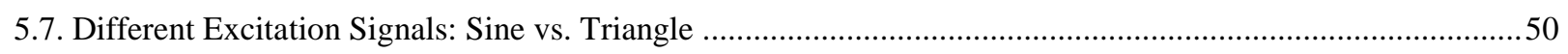

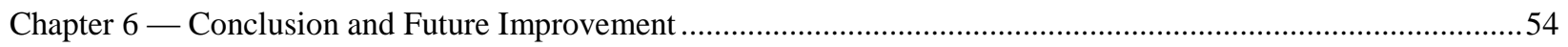

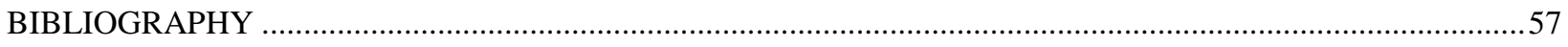

\section{APPENDICES}

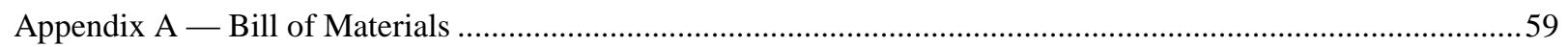


TABLE 4-1: CALCULATED VALUES FOR TRIANGLE WAVE GENERATOR …………...............................18

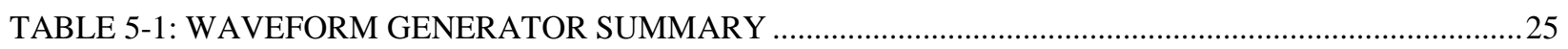

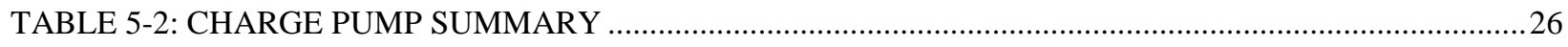

TABLE 5-3: OUTPUT VOLTAGES AND EFFICIENCIES FOR PERCENT LOAD TEST OF STEP- DOWN

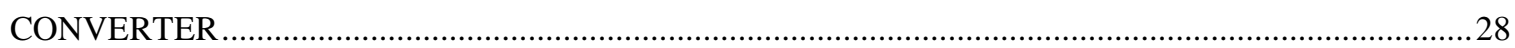

TABLE 5-4: LOOP MEASUREMENT RESULTS FOR 1409A BOOST CIRCUIT VIN = 7V ...........................45

TABLE 5-5: LOOP MEASUREMENT RESULTS FOR 1409A BOOST CIRCUIT VIN = 12V ….........................47

TABLE 5-6: LOOP MEASUREMENT RESULTS FOR 1829A BOOST CIRCUIT VIN = 12V …......................50

TABLE 5-7: DIFFERENT EXCITATION, SINE VS. TRIANGLE ................................................................53 


\section{LIST OF FIGURES}

Figure

FIGURE 1-1: EXAMPLE REGULATOR [3]

FIGURE 2-1: EXAMPLE OF DESIRED LOOP CHARACTERISTICS FOR DC-DC CONVERTER ......

FIGURE 2-2: EXAMPLE OF A SYSTEM WITH NEGATIVE FEEDBACK [4] ................................................. 5

FIGURE 2-3: EXAMPLE OF WHERE SIGNAL INJECTION TAKES PLACE FOR DC-DC CONVERTERS .......6

FIGURE 3-1: EXAMPLE NETWORK ANALYZER SETUP ….....................................................................

FIGURE 4-1: LINEAR MODEL OF BUCK CONVERTER (LEFT) AND SIGNAL INJECTION CIRCUITRY

(RIGHT)

FIGURE 4-2: SIMULATED WAVEFORMS OF TP1 (GREEN) AND TP2 (BLUE) WITH SIGNAL

FREQUENCY $=180 \mathrm{KHZ}$

FIGURE 4-3: SIMULATED WAVEFORMS OF TP1 (GREEN) AND TP2 (BLUE) WITH SIGNAL

FREQUENCY $=150 \mathrm{KHZ}$

FIGURE 4-4: SIMULATED WAVEFORMS OF TP1 (GREEN) AND TP2 (BLUE) WITH SIGNAL

FREQUENCY $=210 \mathrm{KHZ}$

FIGURE 4-5: SINE WAVE GENERATOR SCHEMATIC.

FIGURE 4-6: TRIANGLE WAVE GENERATOR SCHEMATIC.

FIGURE 4-7: TRIANGLE WAVE GENERATOR WITH INVERTERING AMPLIFIER STAGE SCHEMATIC.. 15

FIGURE 4-8: TRIANGLE WAVE GENERATOR SCHEMATIC WITH INVERTING CHARGE PUMP . .17

FIGURE 4-9: SIMULATED TRIANGLE WAVEFORM . .19

FIGURE 4-10: TRANSFORMER TEST CIRCUIT. 19

FIGURE 4-11: RESULTS OF TRANSFORMER SIMULATION.

FIGURE 4-12: SIGNAL INJECTION CIRCUITRY SCHEMATIC 20

FIGURE 4-13: SCHEMATIC OF LOOP MEASUREMENT BOARD. 21

FIGURE 5-1: MINIMUM FREQUENCY WAVEFORM 23

FIGURE 5-2: MAXIMUM FREQUENCY WAVEFORM .24

FIGURE 5-3: CHARGE PUMP SCHEMATIC [12]. 25 


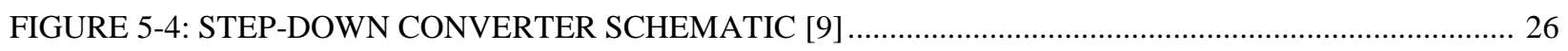

FIGURE 5-5: STEP-DOWN DC-DC CONVERTER TEST SET-UP ………………...............................................22

FIGURE 5-6: EFFICIENCY VS. LOAD FOR STEP-DOWN CONVERTER FOR VARIOUS INPUT

VOLTAGES

FIGURE 5-7: OUTPUT VOLTAGE PEAK-TO-PEAK RIPPLE AT FULL LOAD CONDITIONS (BOTTOM WAVEFORM) 30

FIGURE 5-8: TOP LAYER OF PCB FOR LOOP MEASUREMENT BOARD ……............................................. 32

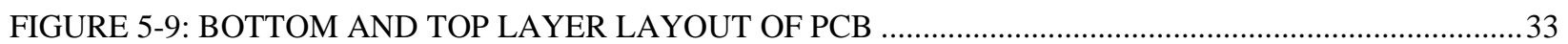

FIGURE 5-10: PCB LAYOUT SHOWING EXPOSED GROUND PLANES ……………………........................ 33

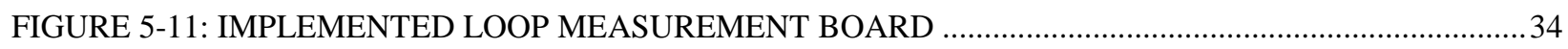

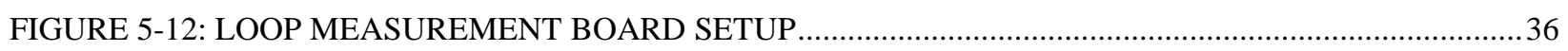

FIGURE 5-13: EXAMPLE WAVEFORM FOR PHASE MARGIN AND CROSSOVER FREQUENCY ................37

FIGURE 5-14: EXAMPLE WAVEFORM FOR FINDING GAIN MARGIN ……….......................................... 38

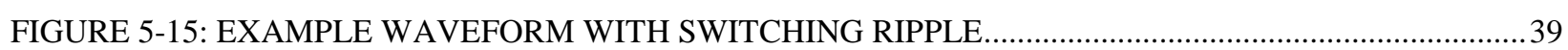

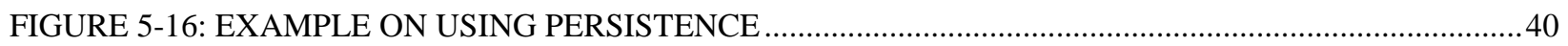

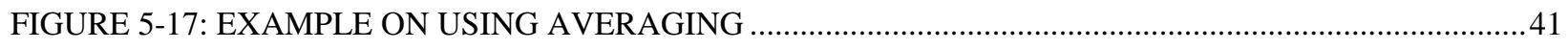

FIGURE 5-18: BODE PLOT OF 1409A BOOST AT VIN = 7V FROM NETWORK ANALYZER .........................42

FIGURE 5-19: BODE PLOT OF 1409A BOOST AT VIN = 12V FROM NETWORK ANALYZER ......................43

FIGURE 5-20: WAVEFORM USED TO MEASURE CROSSOVER FREQUENCY AND PHASE MARGIN

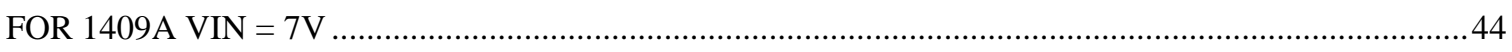

FIGURE 5-21: WAVEFORM USED TO MEASURE GAIN MARGIN FOR 1409A VIN = 7V .........................44

FIGURE 5-22: WAVEFORM USED TO MEASURE CROSSOVER FREQUENCY AND PHASE MARGIN

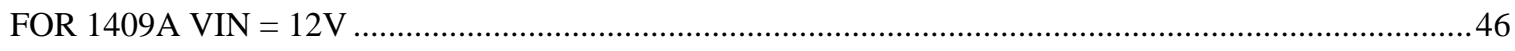

FIGURE 5-23: WAVEFORM USED TO MEASURE GAIN MARGIN FOR 1409A VIN = 12V ..........................46

FIGURE 5-24: BODE PLOT OF 1829A BUCK AT VIN = 12V FROM NETWORK ANALYZER ........................48

FIGURE 5-25: WAVEFORM USED TO MEASURE CROSSOVER FRQUENCY AND PHASE MARGIN

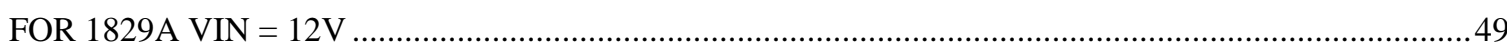

FIGURE 5-26: WAVEFORM USED TO MEASURE GAIN MARGIN FOR 1829A VIN = 12V .........................49 
FIGURE 5-27: BODE PLOT PRODUCED BY NETWORK ANALYZER ……..................................................51

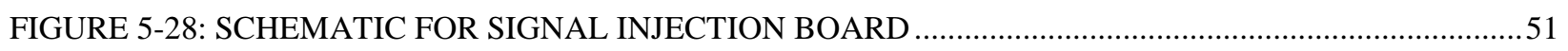

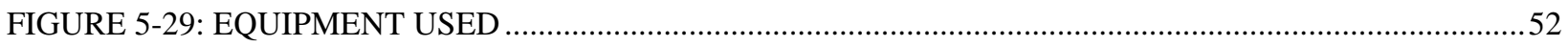

FIGURE 5-30: TEST SETUP TO COMPARE TRIANGLE AND SINE EXCITATION SIGNALS ........................52 


\section{Chapter 1 - Introduction}

Power electronics refers to the use of solid-state electronics with regards to the flow of electric energy. Different power electronics can be used for a variety of electrical conversions, including DC to DC, AC to DC, among others. When implementing and using power electronics, the main goal in the power conversion is to achieve high efficiency. Before the use of power electronics, other technologies such as linear electronics, while usually simple in usage, had relatively low power efficiency. Not only did these devices have potentially very low efficiency, they also had problems related to heat dissipation, as well as problems associated with weight and $\operatorname{cost}[14]$.

In recent years, with advances in electronics, especially with portable and small electronic devices, power electronics have seen increased use. New inventions in devices and systems have resulted in power electronics becoming more and more important. Many current day electronic systems require an ever increasing number of power rails and supply solutions [1]. DC-DC converters, a type of power electronic that converts a DC voltage level to another DC voltage level, have also seen increased usage in recent times.

DC-DC converters are an integral part of many systems nowadays due to their high efficiency. DC-DC converters also come with other benefits when compared to other types of converters, such as reduction in size and smaller footprint, less need for cooling, and a wider range of available output voltages without the need for a transformer [14].

However, despite their advantages, DC-DC converters are in general more difficult to design and implement than linear regulators. One major area of difficulty relates to the design of the DC-DC converter's control loop and compensation, which serve an important role in their operation. A typical DC-DC converter system, like one in Figure 1-1, takes in some input voltage, 
and the expectation is that the regulator outputs a voltage that is well controlled. How the converter produces a consistent output is through the design of a good control loop. The control loop and its design are vital, as the quality of the control loop determines the converter's transient response and stability. These factors in turn affect the converter's accuracy, efficiency, power density, and cost.

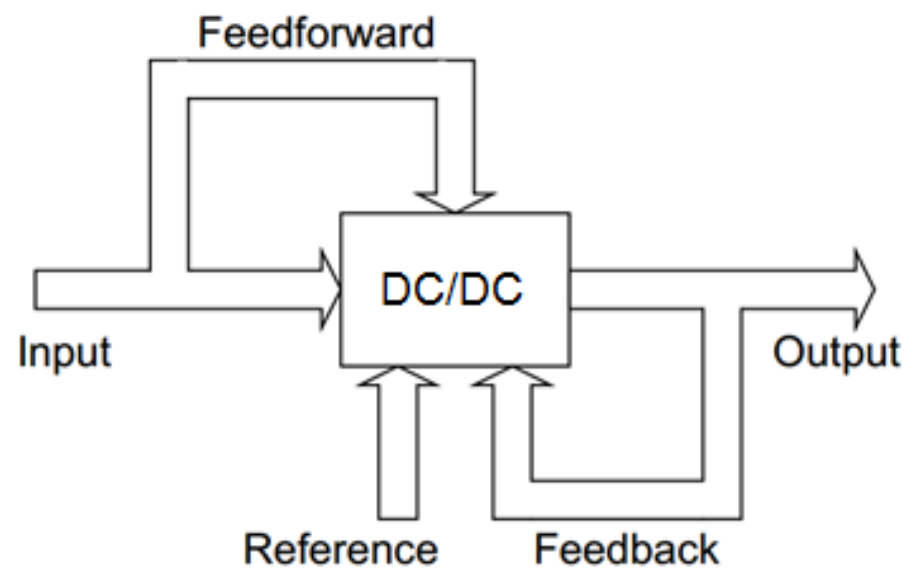

Figure 1-1: Example Regulator [3]

Typically, the control loop's frequency response is designed to allow for loop stability and an optimized transient response. For example, a DC-DC converter with a good control loop will respond well enough to load and line transients so its operation is not altered too dramatically. More specifically, having a good control loop in DC-DC converters partly means having an appropriate frequency response. The frequency response is represented by the gain margin, phase margin, and crossover frequency. The designer should allow for a sufficient amount of gain margin and phase margin, along with an appropriate cross-over frequency, for the converter to be stable and to respond well to transients. 


\section{Chapter 2 - Background}

As previously mentioned in chapter one, the control loops plays an integral role in a DCDC converter's functionality. When a DC-DC converter has a good control loop and is well compensated, the converter can be very stable and quiet. If a DC-DC converter does not have a well-designed control loop, the converter can have problems that include oscillations at the output, audible noise, and jitter on various waveforms. At the same time, if a converter is overcompensated, while it will be stable, it will also have a slower transient response. Thus, a DCDC converter ideally is compensated in such a way that it is both quiet and stable, while not being overcompensated so it still has a fast transient response [1].

When looking at a DC-DC converter, its loop stability margin and bandwidth become important parameters when determining stability. The bandwidth is seen through the crossover frequency, where the loop gain is unity $(0 \mathrm{~dB})$. The loop stability margin on the other hand can be specified through phase margin and gain margin. The gain margin is the difference between the loop gain and $0 \mathrm{~dB}$ at the frequency where the overall loop gain equals $-180^{\circ}$. The phase margin is the difference between the phase delay and $-180^{\circ}$ at crossover frequency. Figure $2-1$ shows a typical example of how a loop characteristic may look for a DC-DC converter. The designer of such a converter seeks to have a converter whose crossover frequency, phase margin, and gain margin are sufficient for adequate stability and good response to transients. For example, for a Step-Down Buck Converter, the phase margin should be somewhere between $45^{\circ}$ to $60^{\circ}$ while the gain margin would be between $6 \mathrm{~dB}$ and $12 \mathrm{~dB}$. When a control loop is designed, important parameters like phase margin and gain margin can be obtained through calculations or simulation. However, since simulations and hand calculations do not necessarily account for non-idealities 
that come from factors such as layout choice and component variation, lab/bench verification is required in the design as well.

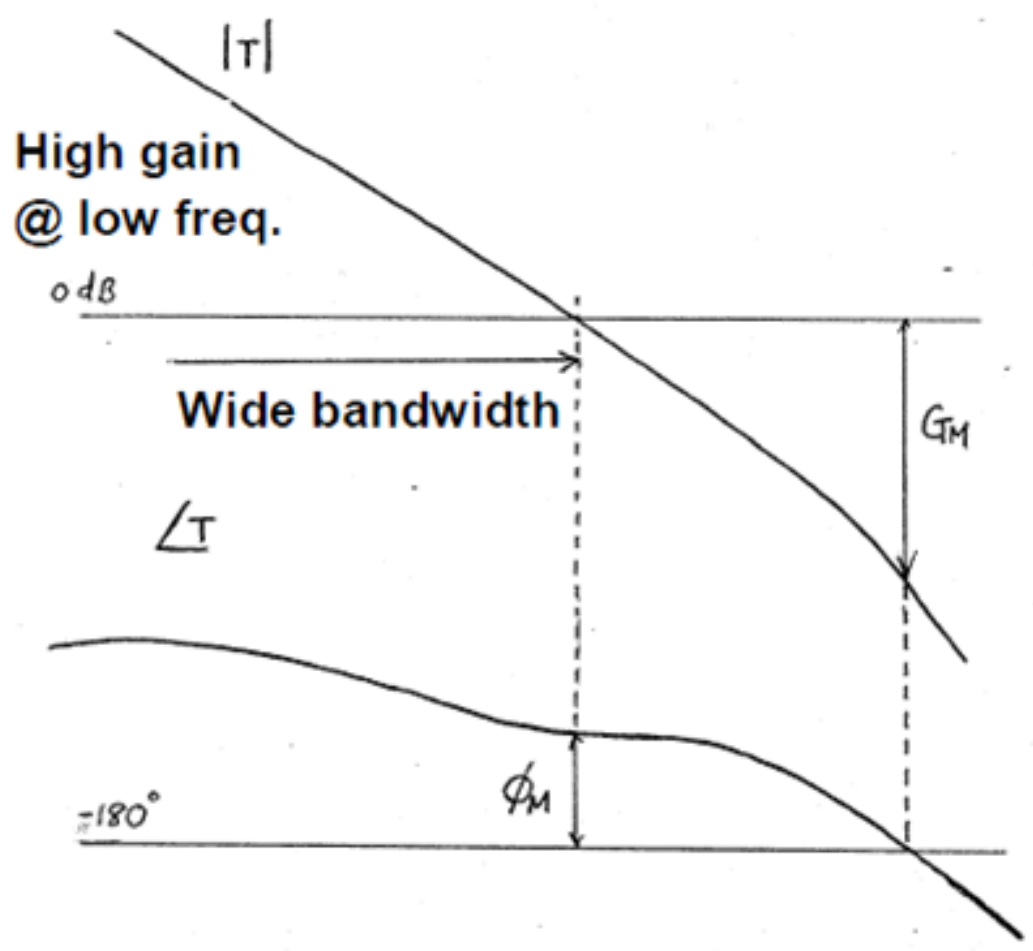

Figure 2-1: Example of Desired Loop Characteristics for DC-DC Converter

A network analyzer or frequency response analyzer is often used for the purpose of making loop measurements for electrical systems with electronics feedback. Network analyzers are the standard RF measurement devices, partly due to their precision as well as versatility. They can operate over a wide range of frequencies and can be used for various measurement tasks [5]. Network analyzers are an invaluable resource when designing a DC-DC converter's control loop as it allows for the measuring of phase and gain margin, as well as the crossover frequency. Thus, using a network analyzer, a converter's stability can be assessed. Most often times, a DC-DC converter will utilize a negative feedback loop, like one seen in Figure 2-2. Consequently, this is where the loop measurement takes place. 


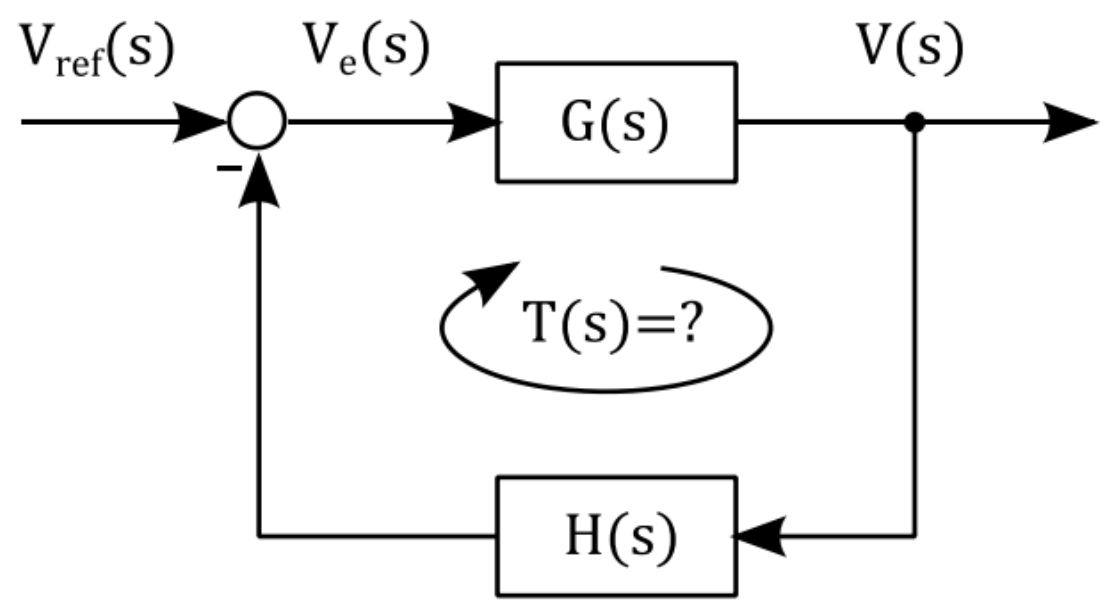

Figure 2-2: Example of a system with negative feedback [4]

A method that is often used to measure the loop gain of a DC-DC converter involves the use of voltage injection. Using an appropriately selected injection transformer, a perturbation signal is injected at a chosen point in the system's feedback loop. The network analyzer can then measure the loop response. To do this, resistor (usually somewhere from $10 \Omega$ to $50 \Omega$ ) is usually placed in the negative feedback loop. The injection transformer is then connected in parallel to the resistor for the perturbation signal to be injected. By doing this, the injection of the signal can be done without changing the DC-DC converter's DC bias [4].

So when a network analyzer is used to make loop measurements for a DC-DC converter, typically a perturbation signal is placed at points A and B, as shown in Figure 2-3. By monitoring the signals at points $\mathrm{A}$ and $\mathrm{B}$, the network analyzer can produce a Bode Plot point by point over a range of frequencies. From the plot vital pieces of information, such as the converter's bandwidth, phase margin, and gain margin, can be determined. 


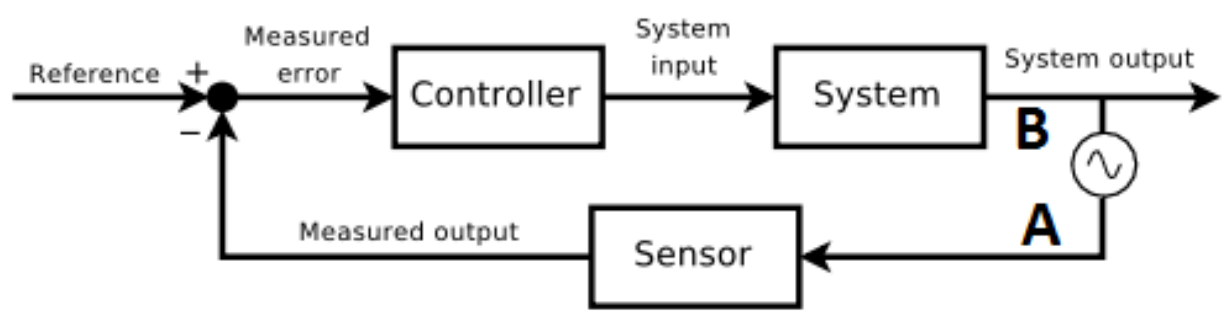

Figure 2-3: Example of where signal injection takes place for DC-DC converters

For all their advantages such as precision and flexible use, network analyzers have a number of disadvantages. Network analyzers can be very expensive, sometimes costing over 10,000 USD. The more flexible and complex the network analyzer, the more expensive it gets. Also, network analyzers are relatively large in size and heavy compared to some other pieces of lab equipment, such as the commonly used Fluke multimeters.

There are times when these disadvantages become severe limitations for electrical engineers. For example, sometimes an engineer may be in a situation where a network analyzer is not available. This may occur if the engineer is on site with customers that is using the engineer's DC-DC converter. While pieces of equipment like oscilloscopes are standard in most electrical engineering labs, sometimes network analyzers might not be available. Considering that network analyzers are not necessarily portable due to their size and weight, as well as the fact that they are rather expensive, it makes sense that not every engineer who needs a network analyzer will have one on hand.

Thus, the objective of this thesis is to provide a more portable and less expensive alternative to network analyzers. The hope is that by only including a network analyzer's core features for making loop measurements, both the cost and size of the alternative can be minimized. From this alterative, phase margin, gain margin, and crossover frequency will be able to be determined for DC-DC converters with the use of a network analyzer. 


\section{Chapter 3 - Design Requirements}

In order to creative a viable alternative to network analyzers that are used to measure a DCDC converter's loop characteristics, the alternative must be built with functionality that is similar to a network analyzer. At the same time, these measurements have to be done on a device that is small, portable, and inexpensive. As such, it becomes evident that that choices made in the design will be highly dependent on the system's requirements.

Bench network analyzers typically consist of signal generators, test sets, receivers, as well as processors and displays. These make bench network analyzers large in size as well as heavy, and are often used with the expectation that it will not be moved around often. There are relatively smaller network analyzers, but these often times require other peripherals that contribute to their immobility, as shown in Figure 3-1. For this thesis, the proposed loop measurement tool will be portable and therefore small in size and weight. More specifically, its dimension and weight should be less than 4"x4"x4" and 100 grams respectively such that the finished product will be able to be held by an adult's hand.

One major factor that makes network analyzers less accessible is their cost. Network analyzers can cost anywhere from several thousand dollars to tens of thousands of dollars. For example, Omicron's Bode 100 test unit currently costs approximately $\$ 5500$ while some of Agilent's products can cost more than $\$ 30,000$. To improve the accessibility of network analyzers, the proposed alternative to the network analyzer should be low cost; that is, it should cost no more than one-hundred dollars to produce. 


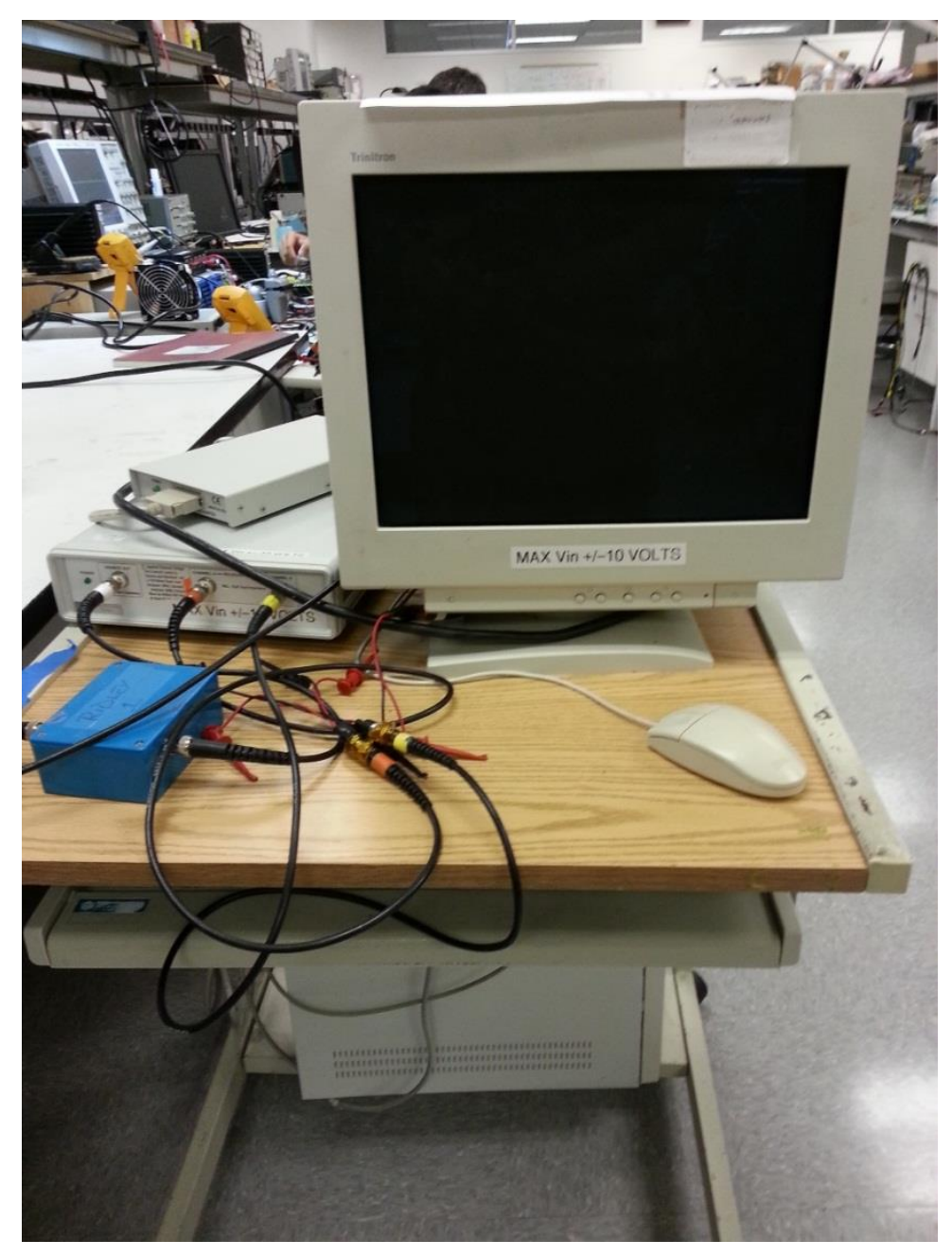

Figure 3-1: Example Network Analyzer Setup

Most network analyzers are able to operate within a certain range of frequencies. This specification determines what tests and measurements can be done on a given electrical system. For example, if the upper limit for a network analyzer is too low, various communications or RF systems may not be able to be tested. Many expensive network analyzers operate in a very wide range, which potentially contributes to the unit cost. For example, Agilent's E5063A-2H5 works up to $18 \mathrm{GHz}$. However, for the purpose of measuring a DC-DC converter's loop behavior, a much smaller range will suffice. In fact, measurement of DC-DC converter's crossover, gain margin, and phase margin will only require a network analyzer that operates below $1 \mathrm{MHz}$ frequency range. 
The proposed loop measurement tool will be specifically used for DC-DC converter loop measurements and therefore it will be designed to have a frequency range that goes from 0 to 1 MHz.

Another technical constraint of the proposed loop measurement tool is its input voltage rating. With many electronics nowadays working with low voltages, most notably below 24 VDC, a maximum operating input voltage of $50 \mathrm{VDC}$ will be chosen to keep the device practical. This implies that the DC-DC Converter being tested by the loop measurement tool must have a maximum output voltage of 50 VDC. In addition, the proposed loop measurement tool will be designed to be powered up by a single 5 VDC power supply; hence, keeping its operation simple. Alternately, the 5 VDC supply may also be provided via a micro USB to allow users to power up the loop measurement tool using a laptop which further increases the tool's potential mobility. To extend the flexibility of the proposed loop measurement tool, a third option is provided where a step-down regulator will be integrated within the tool. This will be particularly useful in the case where only one power supply is available which could become problematic if the DC-DC converter under test may require other than a 5 VDC power supply at its input. The only limitation to this option, however, is that the input voltage of the DC-DC converter under test has to be larger than 5 VDC. 


\section{Chapter 4 - Design and Simulation Results}

In this chapter, the design of the proposed alternative loop measurement tool will be described in detail. The goal is that the design of the measurement tool will fulfill the requirements that were previously specified in Chapter 3. The measurement tool has a few major components to it that require attention: how the signals are monitored, the waveform generator, and the isolation transformer. There needs to be proof that these measurements can be made, and that the signals can be monitored. To make the loop measurements, an AC signal must be outputted from the board onto the device under test. The isolation transformer must be chosen so that it will be suited for DC-DC converter measurements. Simulations, calculations, and design choices will be shown and explained in this chapter.

Before anything is designed or put together, there is a major question that needs to be addressed: can the change in the signals that were shown in Figure 2-3 be monitored? The idea needs to at least be simulated as a proof of concept, or that the idea is even viable. Figure 4-1 shows the LTSpice schematic for a simulation of the proof of concept. TP1 and TP2 are points in the converter's feedback loop that are often used by network analyzers to make loop measurements for DC-DC converters. While points TP1 and TP2 are used to inject signals into a DC-DC converter, TP3 and TP4 are points that will be used to monitor the two signals via BNC connectors.

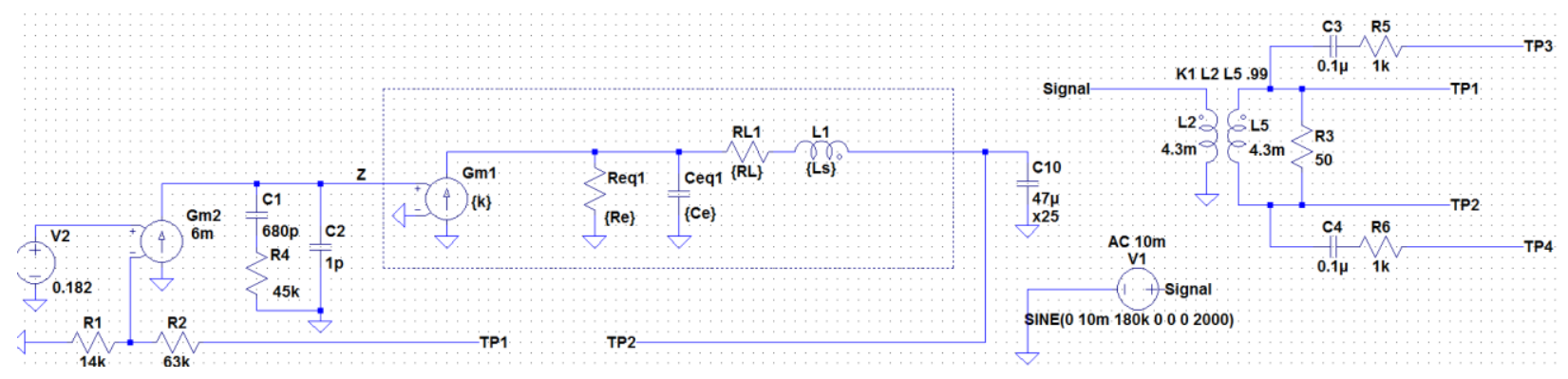

Figure 4-1: Linear Model of Buck Converter (Left) and Signal Injection Circuitry (Right) 
Using a linear model for a current-mode controlled step-down converter whose crossover frequency is known and signal injection circuitry, the goal is to see if the signal at points TP1 and TP2 can be monitored, and if changes in these signals can be seen when the AC signal frequency is varied. For the simulation, the converter's crossover frequency is $180 \mathrm{kHz}$. Thus, when a signal that has a frequency of $180 \mathrm{kHz}$ is outputted, the signals at TP1 and TP2 are expected to have approximately equal amplitudes. When the signal's frequency is not around $180 \mathrm{kHz}, \mathrm{TP} 1$ and TP2 should no longer have equal amplitudes.

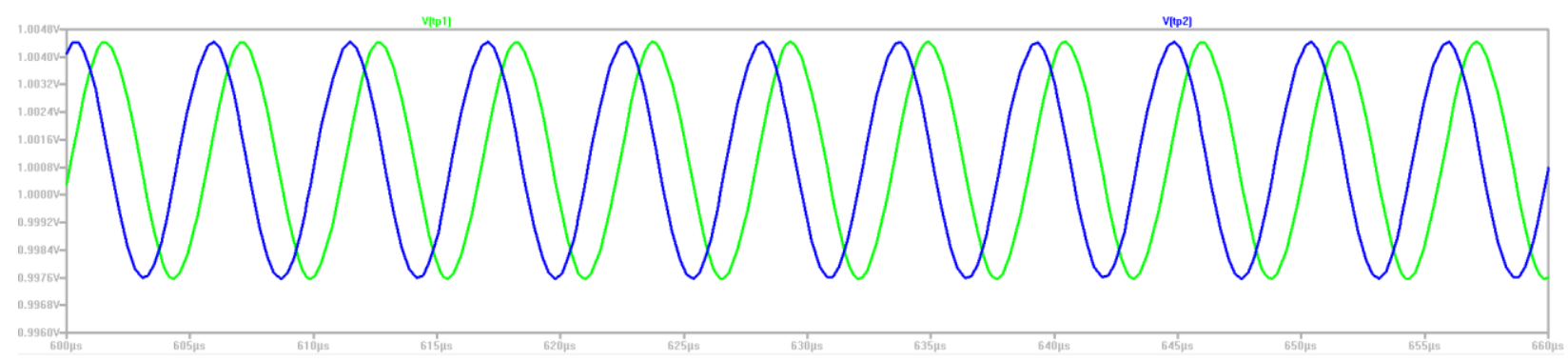

Figure 4-2: Simulated Waveforms of TP1 (Green) and TP2 (Blue) With Signal Frequency $=180 \mathrm{kHz}$ As seen in Figure 4-2, when the input AC signal has a frequency of $180 \mathrm{kHz}$, the amplitudes of TP1 and TP2 are the same. This is expected because at crossover frequency, the gain of the system is at unity, thus there should be no difference between the two signals.

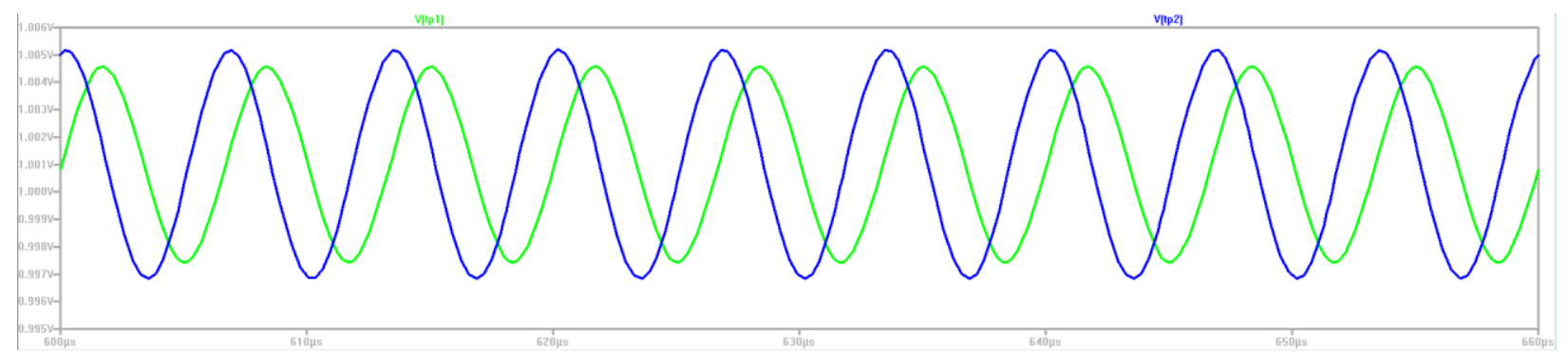

Figure 4-3: Simulated Waveforms of TP1 (Green) and TP2 (Blue) With Signal Frequency $=150 \mathrm{kHz}$ In the next simulation, the input $\mathrm{AC}$ signal is set to have a frequency of $150 \mathrm{kHz}$. As expected, the amplitudes of the two signals are not equal. Below crossover frequency, gain for a DC-DC converter is not at unity, so the signals are not expected to be equal. 


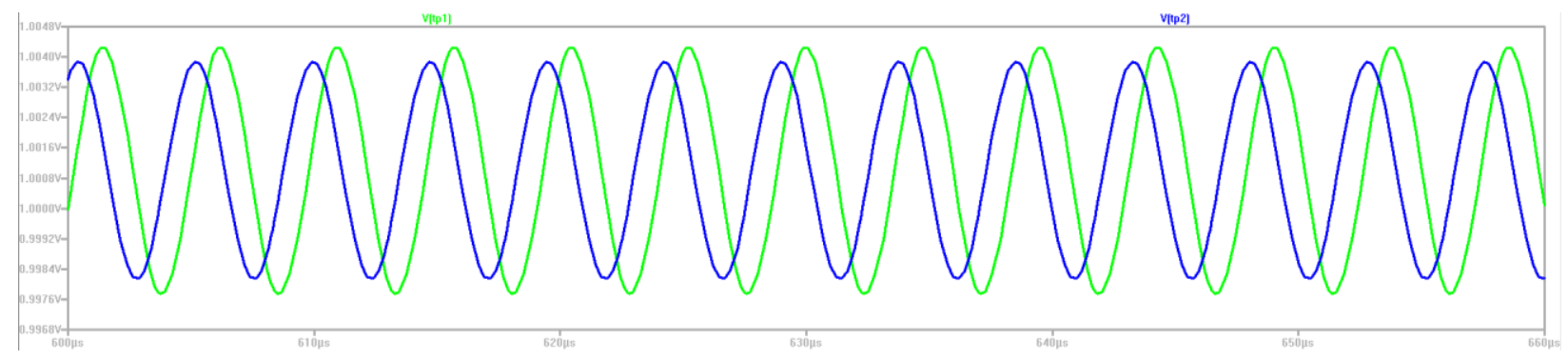

Figure 4-4: Simulated Waveforms of TP1 (Green) and TP2 (Blue) With Signal Frequency $=210 \mathrm{kHz}$

Similar to the previous simulation, a frequency that is not at a crossover frequency is used. When the AC signal is set to have a frequency of $210 \mathrm{kHz}$, the signals once again do not have equal amplitudes.

As these simulations show, the waveforms being monitored in the converter's feedback loop vary based on frequency. Also, these changes on each of the waveforms TP1 and TP2 can be monitored. Using these signals, information about a DC-DC converter's control loop can be obtained. From this, we know the concept is viable, and thus the next step is to design a waveform generator to provide the injected signal.

The waveform generator must meet certain requirements for the proposed loop measurement tool. As stated in Chapter 3, the loop measurement tool must have the ability to make measurements from $0 \mathrm{~Hz}$ to $1 \mathrm{MHz}$. This means that the waveform generator must be able to source an AC signal in this range. Also, having as small a footprint as possible is also a high priority for the waveform generator since the system itself is ideally as small in size as possible. When considering the circuit topology would provide the AC signal that would most appropriately fulfill the needs specified in Chapter 3, two particular circuits came into consideration. 


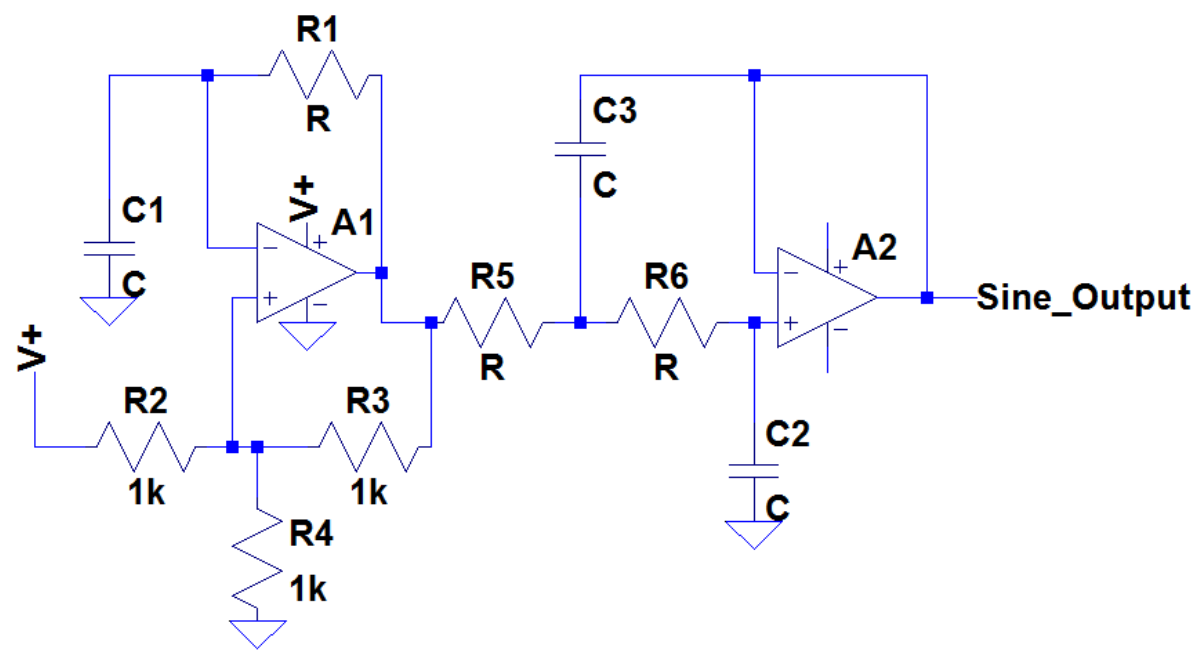

Figure 4-5: Sine Wave Generator Schematic [7]

The first circuit, seen in Figure 4-5, produces a sine wave with two op amps and a few resistors and capacitors. This sine wave generator is relatively simple as it does not require too many parts and only needs a handful of passive components. The first op amp labeled A1 outputs a square wave at a set frequency determined by $\mathrm{R} 1$ and $\mathrm{C} 1$. The op amp labeled $\mathrm{A} 2$ is used as a two-pole low pass filter that takes the square wave signal from A1's output. The filter is set to have a cut off frequency that is equal to the square wave, and removes most of the harmonic frequencies, leaving the fundamental frequency at the output of A2. A sine wave whose amplitude is around 87 percent of the peak of the square wave is outputted. The amplitude of the square wave is dependent on the amplifier's supply voltage and output swing specification [7]. Thus, the sine wave amplitude would track the amplifier's supply voltage. It can be shown that in sizing the components, these equations would be used:

$$
\begin{aligned}
& R 2=R 3=R 4 \\
& C 2=C 1 \\
& C 3=2 C 1
\end{aligned}
$$




$$
\begin{aligned}
& R I=\frac{\frac{1}{2} F}{0.693 \cdot C 1} \\
& R 6=R 5 \\
& R 5=\frac{1}{8.8856 \cdot F \cdot C 1}
\end{aligned}
$$

The second circuit under consideration is a triangle square wave that uses two op amps and a smaller number of resistors and a capacitor. In this circuit, using the op amp labeled U1 as a comparator, a square wave appears on the output. The square wave goes into U2, which is configured as an integrator, which then outputs a triangle wave. The values of resistors R1 and R2 set the comparator's hysteresis. The frequency of the square and triangle waves are dependent on the values of resistor $\mathrm{R} 3$ and capacitor $\mathrm{C} 1$. To vary the frequency of the waveform, potentiometers could be placed for resistor R3.

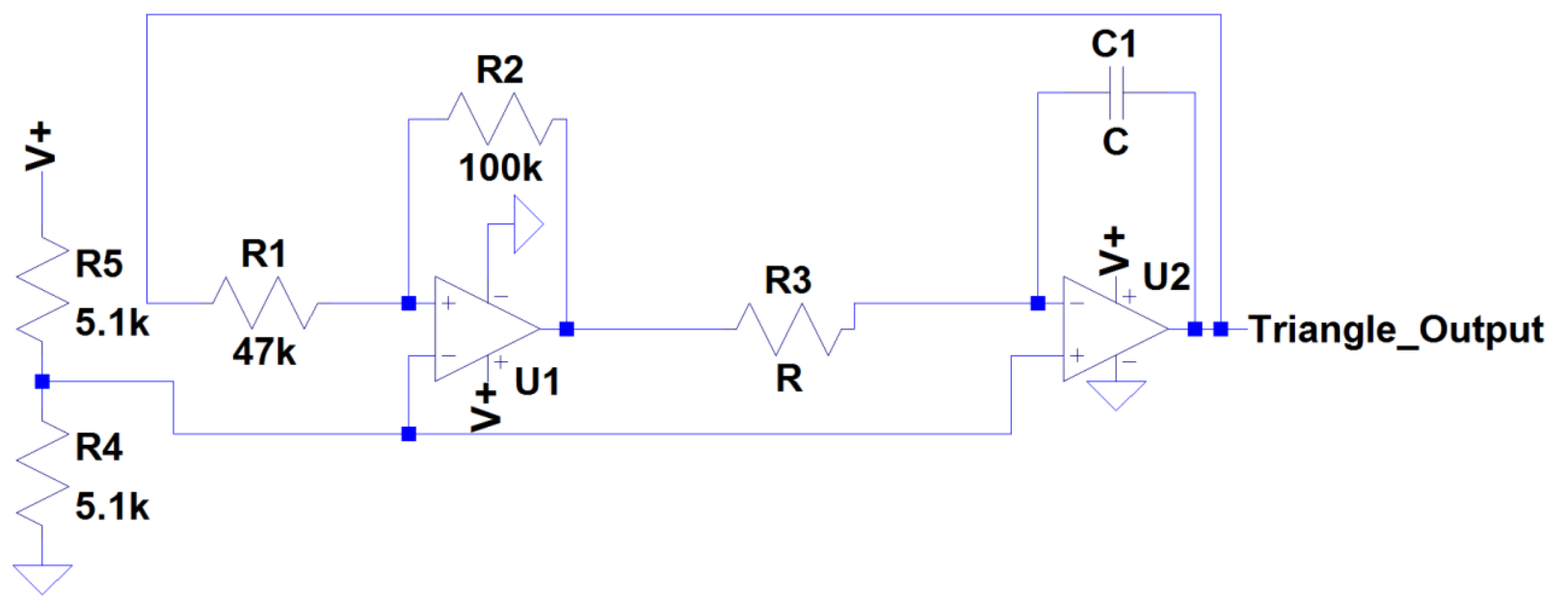

Figure 4-6: Triangle Wave Generator Schematic

It can be shown that to size $\mathrm{R} 3$ and $\mathrm{C} 1$ in order to set frequency:

$$
F=(0.5) \frac{1}{R 3 \cdot C 1}
$$


Due to the triangle wave generator using three less passive components than the sine wave generator, the triangle wave generator was chosen to be the AC signal generator for the loop measurement tool. Although network analyzers typically use a sine wave, the same measurements can be done with a triangle wave. For a triangle wave, the fundamental component is dominant and the higher order components fall off quickly. Therefore, the use of a triangle signal is not expected to cause problems when making loop measurements. Since the loop measurement tool must be as small as possible to be portable, the topology with the smaller footprint was chosen. Other circuits were not considered due to the need to vary the frequency from $0 \mathrm{~Hz}$ to $1 \mathrm{MHz}$. There are of course other circuits that can produce variable sine or triangle waves, but the triangle wave generator seen in Figure 4-6 was found most appropriate.

For different DC-DC converters with different output voltages, the signal required to make loop measurements will vary as well. Thus, another stage will need to be added on to the signal generator that will allow for the amplitude of the signal to change. Therefore, the triangle waveform generator circuit was modified in order to accompany this need.

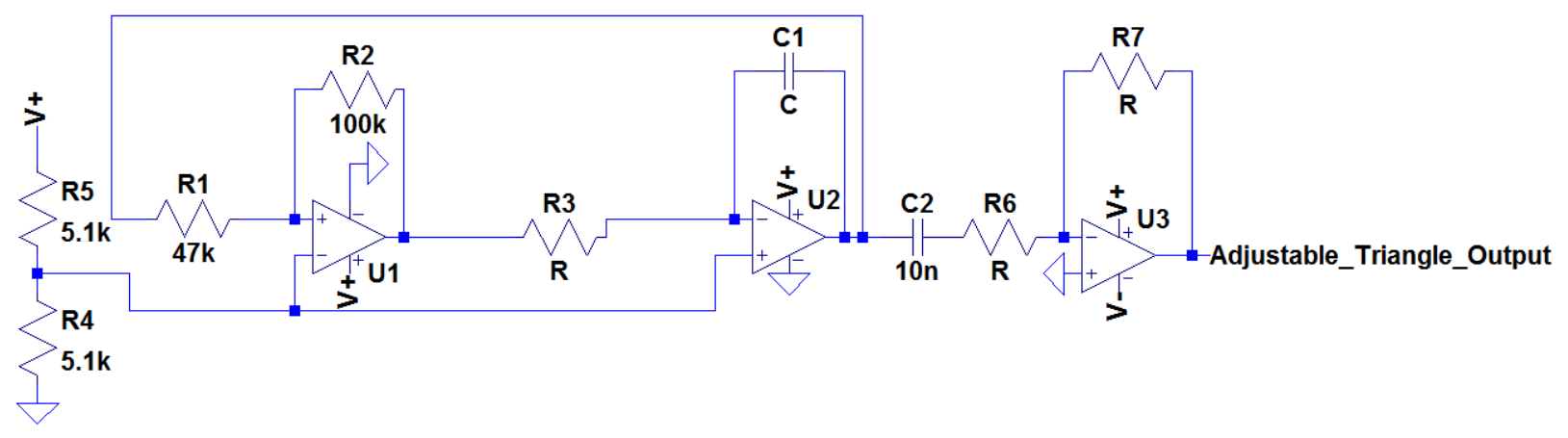

Figure 4-7: Triangle Wave Generator With Inverting Amplifier Stage Schematic

The second stage utilizes an op amp, labeled U3, as an inverting amplifier. The capacitor C2 is used for DC blocking to ensure a symmetric triangular signal. An inverting amplifier was 
chosen due to its simplicity and low part count. The output for the inverting amplifier stage can be shown to be:

$$
V_{\text {OUT }}=\left(-V_{I N}\right) \frac{R 7}{R 6}
$$

In order to determine the $\mathrm{V}_{\text {OUT }}$ and $\mathrm{V}_{\text {IN }}$ range, $\mathrm{R} 3, \mathrm{C} 1, \mathrm{R} 6$, and $\mathrm{R} 7$ all need to be determined. Before these component values can be calculated however, the proper op amps must be chosen. For U1 and U2, the LT1722 single low noise precision op amp was chosen. This op amp was chosen for a variety of reasons. First, it can come in a small S8 8-lead package, meaning that it is easy to use as well as small in size, which keeps the system's footprint small. The LT1722 is also low noise, low power, and high speed; according to its datasheet. It has a GBW (gain-bandwidth product) of $180 \mathrm{MHz}$, meaning that the device falls to unity gain at $180 \mathrm{MHz}$, and slew-rate of $70 \mathrm{~V} / \mu \mathrm{S}$ when operating from a single 5V supply. Having a high GBW means that there should be no worries about whether or not the op amp can operate at the frequencies the loop measurement device must operate at. The slew-rate of $70 \mathrm{~V} / \mu \mathrm{S}$ means that the op amp is able to change its output voltage by $70 \mathrm{~V}$ for every microsecond. The op amp's slew-rate and GBW thus make it more than fast enough for the loop measurement tool. It is also tolerant of less than ideal layouts, which gives some flexibility in its use [8]. For U3, the inverting amplifier, the LT1206 was chosen. The LT1206 op amp was chosen for its high bandwidth, which is $36 \mathrm{MHz}\left(\mathrm{A}_{V}=1\right)$ according to its datasheet, as well as its slew-rate of $900 \mathrm{~V} / \mu \mathrm{S}$. Like the LT1722, it can also come in a S8 8-lead package, making it easy to use. It should also be noted that $\mathrm{U} 3$ should run off a $-5 \mathrm{~V}$ rail as well as a $+5 \mathrm{~V}$ rail in order to produce an $\mathrm{AC}$ waveform that is centered around ground. To produce the $-5 \mathrm{~V}$ rail, the LT1983-5, an inverting charge-pump, was chosen. The charge-pump comes in a small S6 6Lead SOT23 package, keeping the system size small. Also, including bypass capacitors, the charge 
pump just needs a total of three external capacitors to provide the $-5 \mathrm{~V}$ output. The requirement for the charge pump is that its output must be within $5 \%$ of $-5 \mathrm{~V}$.

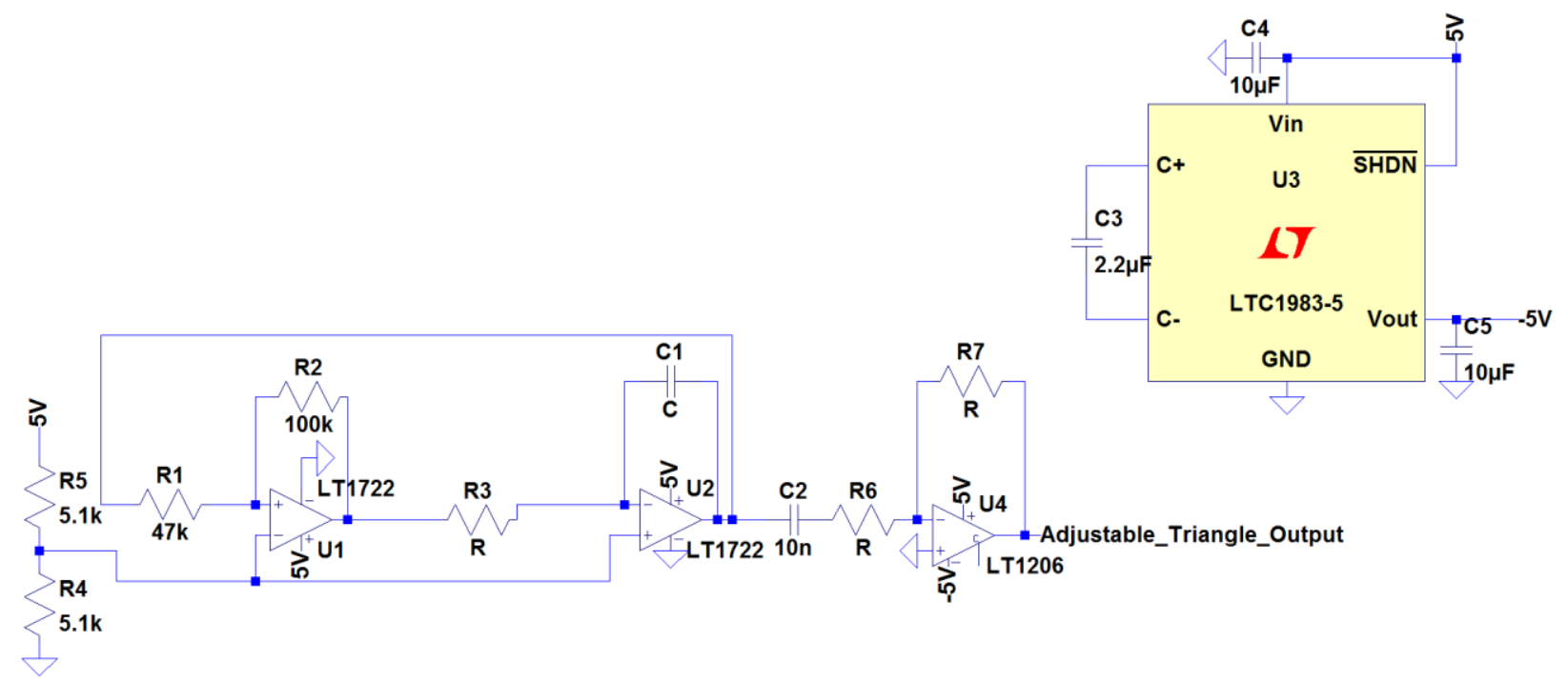

Figure 4-8: Triangle Wave Generator Schematic with Inverting Charge Pump

Figure 4.8 shows the complete schematic for the variable triangle wave generator, with the exception of component values for R3, C1, R6, and R7. As stated in Chapter 3, the frequency range for the waveform generator should be from 0 to $1 \mathrm{MHz}$. Using this frequency requirement in conjunction with equation 4.7 and setting $\mathrm{C} 1$ to $10 \mathrm{nF}, \mathrm{R} 3$ needs to be $50 \Omega$ to reach $1 \mathrm{MHz}$. Since the formula does not allow for R3 to be calculated for a frequency of $0 \mathrm{~Hz}, \mathrm{R} 3$ was calculated to be $50 \mathrm{~K} \Omega$ for a frequency of $1000 \mathrm{~Hz}$ for the lower bound. Not being able to get the signal to be $0 \mathrm{~Hz}$ is acceptable, as it is more important that the waveform generator can output higher frequency signals. In most cases, DC-DC converters do not have too many important loop measurements below $1 \mathrm{kHz}$. This is not always the case, but a frequency range of $1 \mathrm{kHz}$ to $1 \mathrm{MHz}$ is admissible for this particle application. Since the loop measurement device will need to be able to adjust the signal's frequency, a $50 \mathrm{~K} \Omega$ potentiometer will be used for R3. 
Next comes the calculation for R6 and R7, the resistors for the inverting amplifier. The loop measurement tool needs to be able to make measurements on DC-DC converters that output up to $50 \mathrm{~V}$. For these measurements, an injection signal of less than $400 \mathrm{mV}_{\mathrm{pk}-\mathrm{pk}}$ should be adequate, thus, these resistor values are determined by the maximum voltage it must reach, which in this case is $400 \mathrm{mV}_{\mathrm{pk} \text {-pk. }}$. In the datasheet for the $\mathrm{LT} 1206$, the forward resistor, $\mathrm{R} 7$, should be set to a lower value (a resistance below $1 \mathrm{k} \Omega$ ) in order to utilize the part correctly. In accordance with the datasheet, R7 is set to be $715 \Omega$. Using equation 4.8 , R6 is calculated to be $13.5 \mathrm{k} \Omega$.

Table 4-1: Calculated values for Triangle Wave Generator

\begin{tabular}{|c|c|}
\hline Component & Value \\
\hline C1 & $10 \mathrm{nF}$ \\
\hline R3 & $0 \Omega-50 \mathrm{k} \Omega$ \\
\hline R6 & $0 \Omega-7 \mathrm{k} \Omega$ \\
\hline R7 & $715 \Omega$ \\
\hline
\end{tabular}

Table 4-1 summarizes the component values calculated to create a triangle waveform that can vary from $1 \mathrm{kHz}$ to $1 \mathrm{MHz}$ and that can go up to $400 \mathrm{mV}_{\mathrm{pk}-\mathrm{pk}}$. Later while testing in hardware, $\mathrm{R} 6$ was changed to be a $5 \mathrm{~K} \Omega$ potentiometer in series with a $2 \mathrm{~K} \Omega$ resistor. These changes will be explained in Chapter 5. To see if this design is viable, a simulation was run in LTspice. Figure 4.9 shows a sample triangular waveform. 


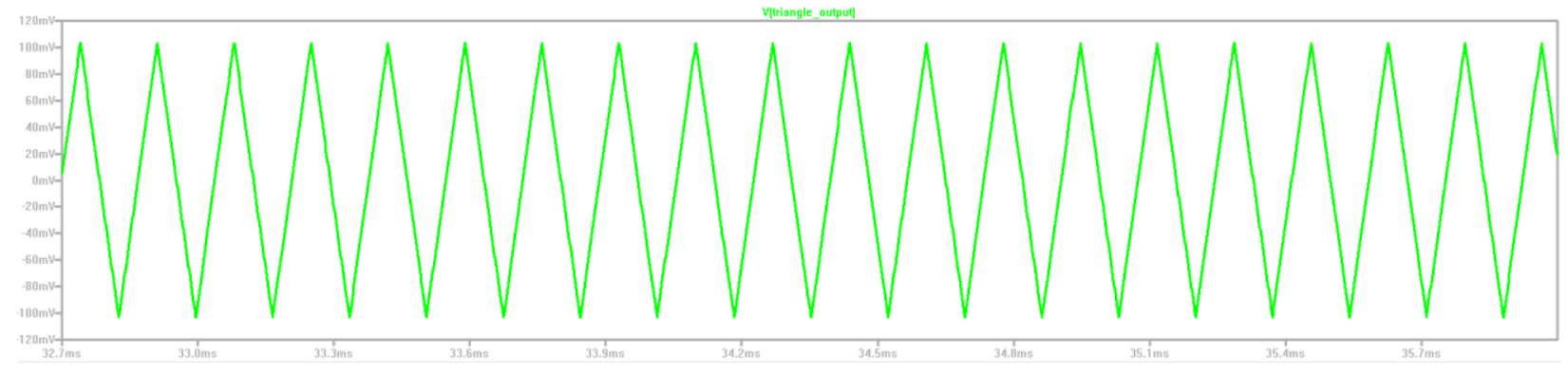

Figure 4-9: Simulated Triangle Waveform

The next important step in the design of the loop measurement tool is the selection of the transformer. The selection of the transformer matters because if a transformer with too low a magnetizing inductance is chosen, for instance $1 \mathrm{mH}$, lower frequencies become attenuated. If the magnetizing inductance is too high, the leakage inductance would attenuate the higher frequencies. The transformer's transfer characteristics do not matter as much because the measurements are taken on the secondary side of the transformer.

To choose an appropriately valued transformer, a simulation was done on LTspice where a model of a transformer steps through several values of magnetizing inductance. A leakage inductance of $2 \%$ was assumed. The circuit used in the simulation shown in Figure 4-10.

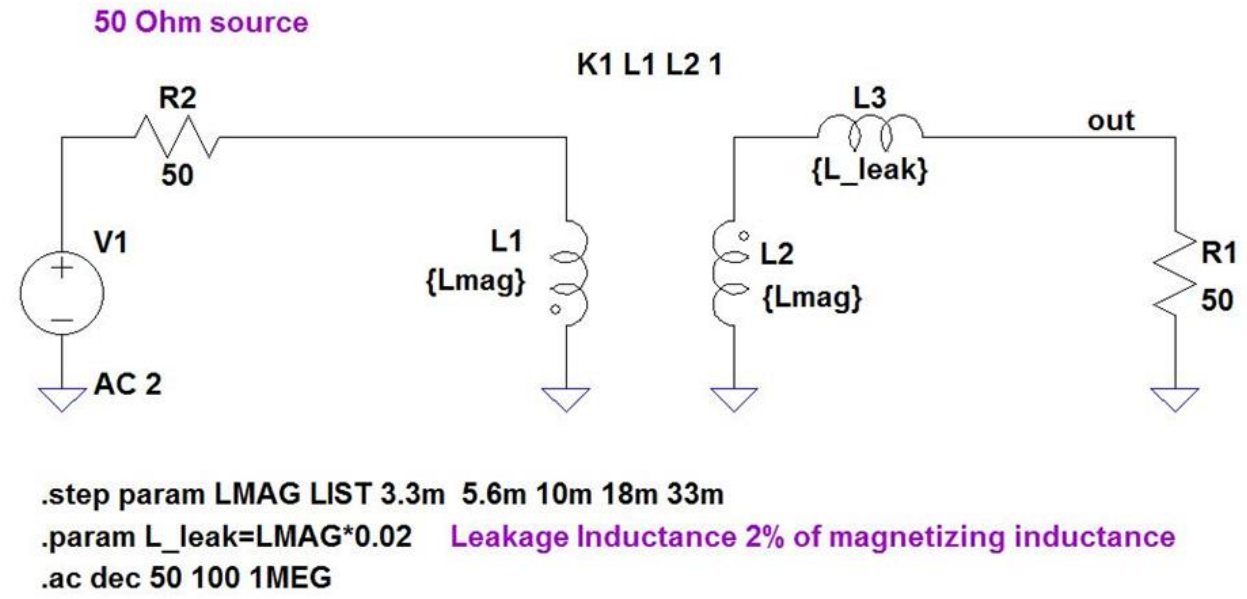

Figure 4-10: Transformer Test Circuit

The results are shown in Figure 4-11: 


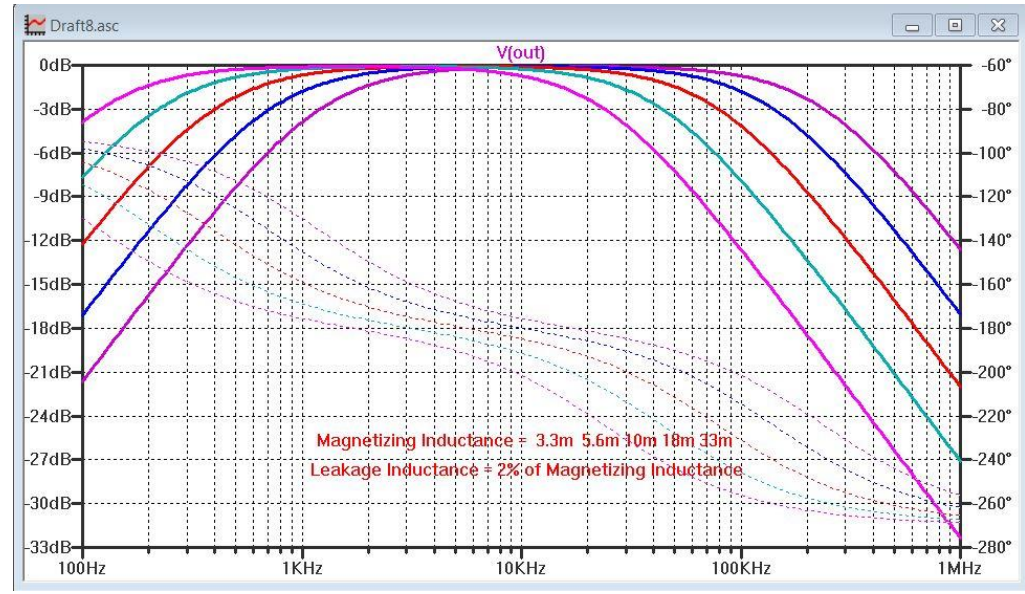

Figure 4-11: Results of Transformer Simulation

From the simulation, the $10 \mathrm{mH}$ trace (red) would best fit the needs of the measurement tool. However, the selected transformer that will be used in hardware implementation will be based on what transformer is available. At the time when the hardware was implemented, a transformer with a magnetizing inductance value of $4.3 \mathrm{mH}$ was used.

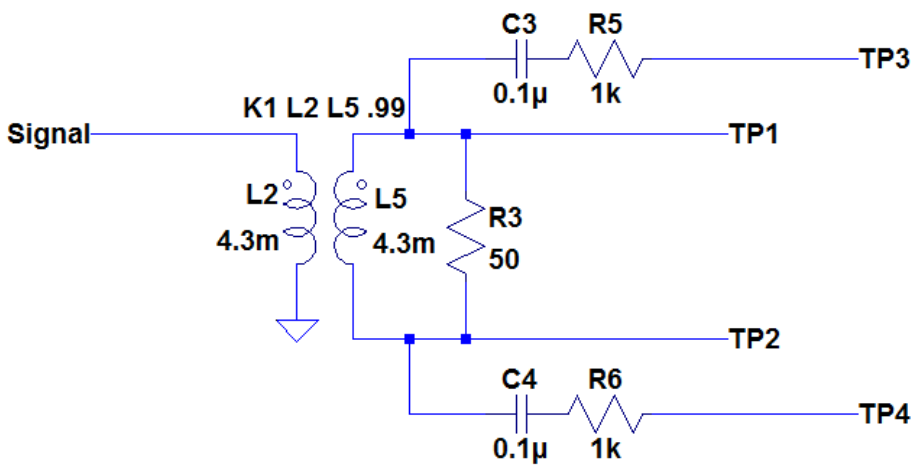

Figure 4-12: Signal Injection Circuitry Schematic

Figure 4-12 shows the schematic for the signal injection circuitry. TP1 and TP2 are where the signals get injected into the DC-DC converter. TP3 and TP4 are where the signals are monitored. The series resistors and capacitors on TP3 and TP4 are to protect the oscilloscope used with the loop measurement tool if the output of the DC-DC converter shorts. Capacitors C4 and C3 are also used to block the DC voltage from the DC-DC converter's output. The capacitors will 
be rated at $50 \mathrm{~V}$, thus allowing for the measurement of converters that output up to $50 \mathrm{~V}$. The $50 \Omega$ resistor breaks the DC-DC converter's feedback path. This is done to electrically separate the injection points TP1 and TP2.

The next requirements that need to be met are the alternative ways of powering up the loop measurement tool. Normally, the loop measurement tool can be powered with a single $5 \mathrm{~V}$ supply. As stated in the previous chapter, the loop measurement should also be able to be powered by connecting to a laptop through a micro USB connection. The loop measurement board should also have the option of being powered with higher voltages than $5 \mathrm{~V}$.

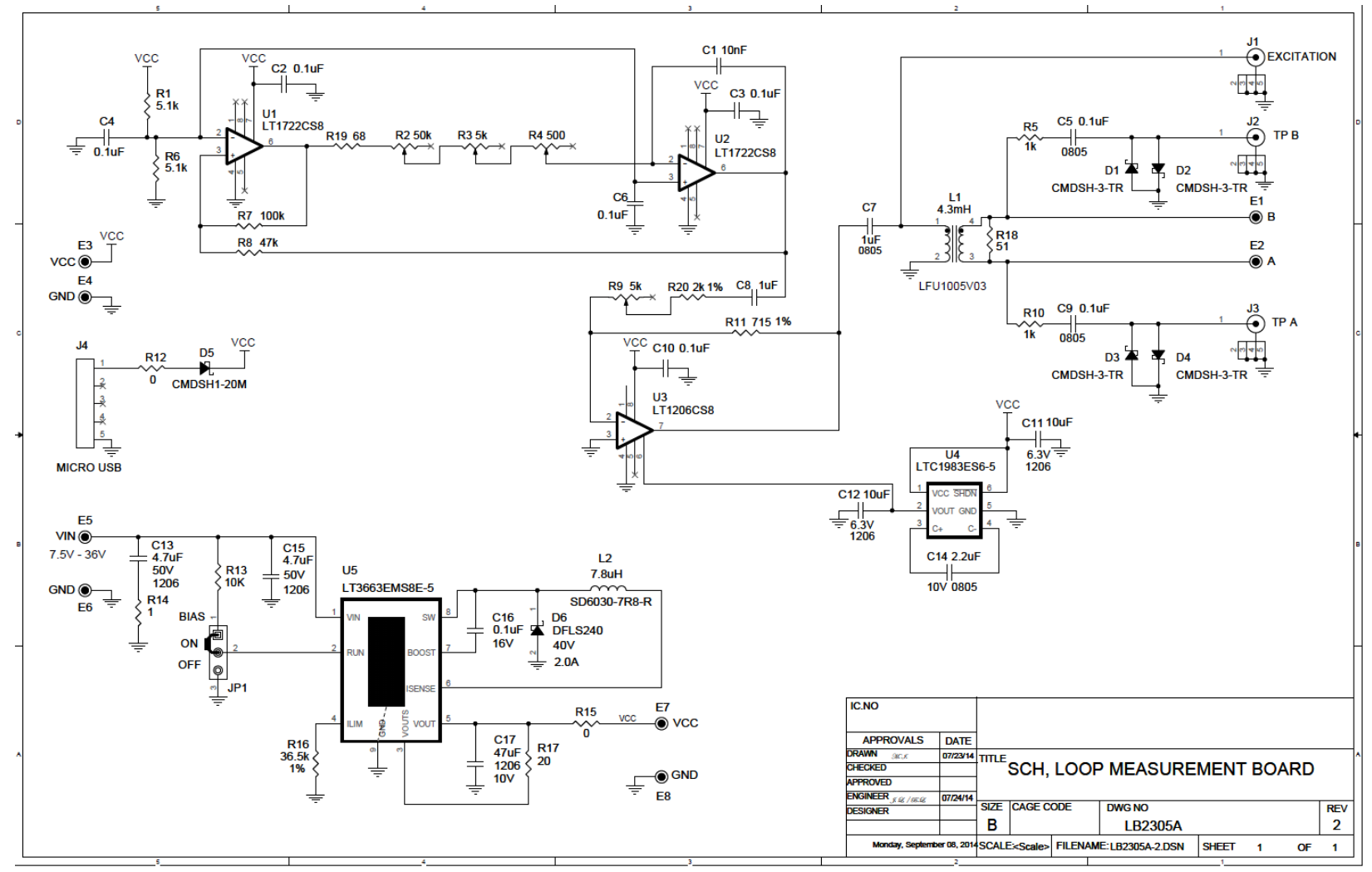

Figure 4-13: Schematic of Loop Measurement Board (Note*: Labeled components do not match with previous schematics)

Figure 4-13 shows the final schematic for the loop measurement tool. To power up the loop measurement tool with a laptop, a micro USB port is used in conjunction with a diode to protect the laptop from possible shorts on the loop measurement tool. Since the standard output of a 
computer's USB port is $5 \mathrm{~V}$, no conversion is required. For the third option, which is to power up the loop measurement tool with a higher supply voltage, a generic buck converter using the LT3663 is used as shown in Figure 4-13. LT3663 can take an input between 7.5V to 36V and output $5 \mathrm{~V}$, thus allowing the board to be powered with a higher input voltage. The buck should have line and load regulations below 5\%, and an output voltage peak to peak ripple of less than $5 \%$. Also, the efficiency under load will ideally be over $80 \%$ over a wide range of load. However, the most important requirement is that the converter can supply $5 \mathrm{~V}$ to the rest of the loop measurement board. This means that even if efficiency under a load condition goes below $80 \%$, the converter can still be used.

It should be noted that to adjust frequency, three separate potentiometers are used, and are labeled R2, R3, and R4. Using three different valued potentiometers allow for an easier adjustment in frequency and better control of the triangle waveform being output by the waveform generator. If only one potentiometer is to be used, the resolution of control for the signal may make it difficult to make fine adjustments to the signal's frequency. The hope is that the use of three potentiometers of different orders will provide the needed resolution to make fine adjustments when necessary. 


\section{Chapter 5 - Hardware Results}

In this chapter, the hardware implementation for the loop measurement board will be explained. The implementation will be in reference to the details outlined in Chapter 3 as well as Chapter 4. Hardware results for various stages of the loop measurement board will be discussed and shown. Afterwards, procedures and data will be presented showing how the loop measurement tool takes accurate loop measurements.

\subsection{Triangle Wave Generator}

The triangle waveform generator was implemented as specified in Chapter 4. The waveform generator was then tested in order to determine its frequency range as well as the maximum voltage it could supply at high and low frequencies. The waveform generator's output was viewed using an oscilloscope. Figures 5-1 and 5-2 show example waveforms exhibiting the range of frequencies that the waveform generator can produce. Figures 5-1 and 5-2 show the lowest frequency and the highest frequency respectively that the loop measurement board can produce.

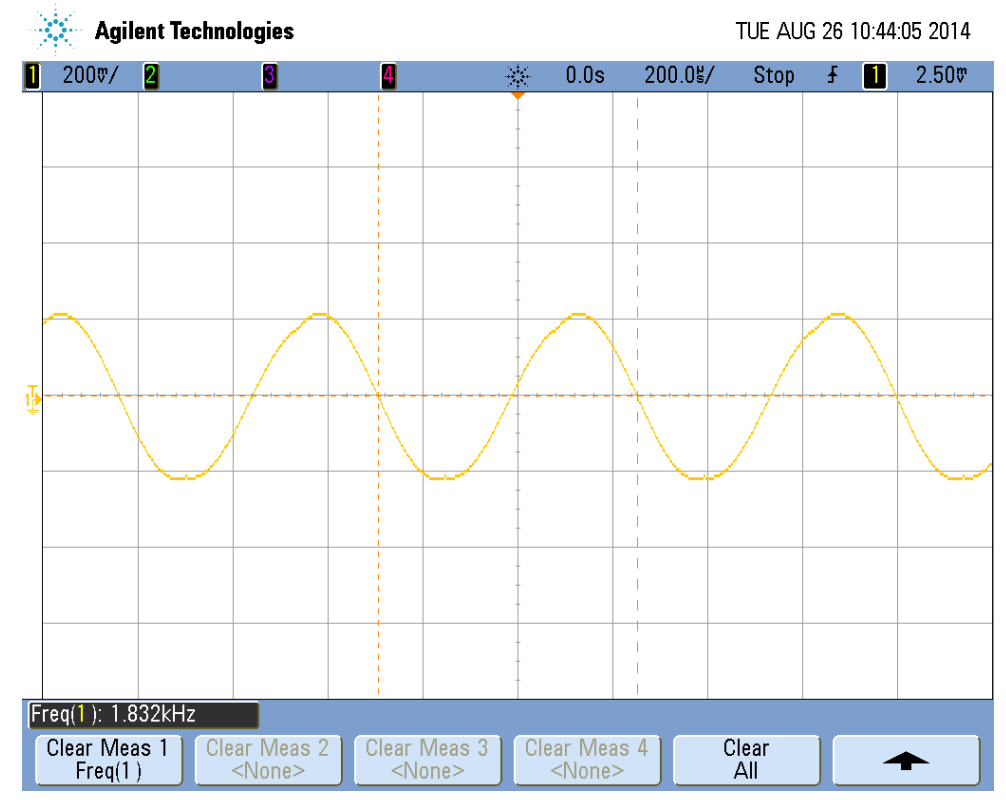

Figure 5-1: Minimum Frequency Waveform 


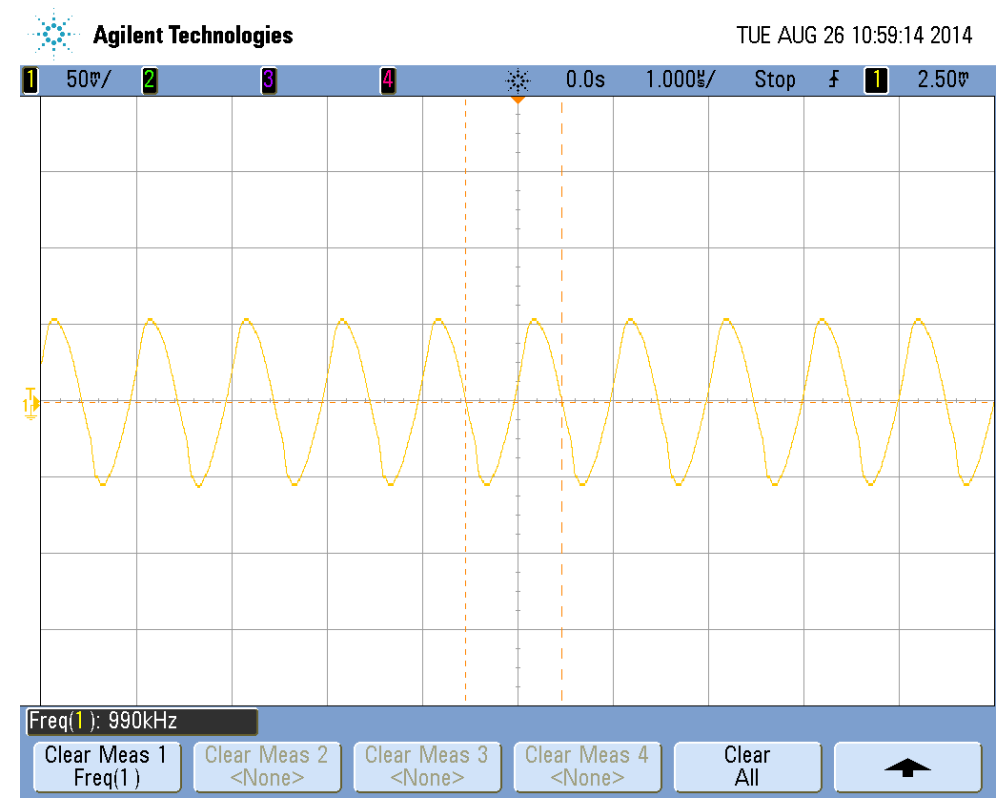

Figure 5-2: Maximum Frequency Waveform

When the waveform generator is implemented in hardware, the minimum frequency was measured to be approximately $1.8 \mathrm{kHz}$ while the maximum frequency was at $990 \mathrm{kHz}$. At $1.8 \mathrm{kHz}$, the maximum peak to peak output voltage is around $400 \mathrm{mV}$. At $990 \mathrm{kHz}$, however, the maximum peak to peak output voltage becomes lower at approximately $100 \mathrm{mV}$. The lower voltage at 990 $\mathrm{kHz}$ is a result of attenuation at higher frequencies.

During testing, resistor values were modified in order to output a $1 \mathrm{kHz}$ signal. However, it was found that with the circuit configured the way it is, signals less than $1.8 \mathrm{kHz}$ were not as clean and more distorted. Because of this, the frequency for the waveform generator remains from approximately $2 \mathrm{kHz}$ to $1 \mathrm{MHz}$. For DC-DC converters, this range is acceptable and thus the waveform generator is considered finished. Table 5-1 summarizes this result. 
Table 5-1: Waveform Generator Summary

\begin{tabular}{|c|c|}
\hline Minimum Frequency & Maximum Frequency \\
\hline $1.8 \mathrm{kHz}$ & $990 \mathrm{kHz}$ \\
\hline Maximum Voltage at & Maximum Voltage at \\
Minimum Frequency & Maximum Frequency \\
\hline $400 \mathrm{mV}$ & $100 \mathrm{mV}$ \\
\hline
\end{tabular}

\subsection{Inverting Charge Pump}

The next stage that underwent testing was the charge pump circuitry, which is shown in Figure 5-3. The charge pump is designed to take 5 VDC and to output -5 VDC. As such, the main concern is whether or not the charge-pump is able to invert the input and output the -5 VDC to provide a negative rail. Therefore the test is as simple as inputting a 5 VDC and seeing if the output is -5 VDC. Using a single power supply, 5 VDC was input to the charge pump, -4.998 VDC was measured at the output. This output is close to the ideal output of $-5 \mathrm{VDC}$, and thus the charge pump works as intended. Table 5-2 summarizes this result.

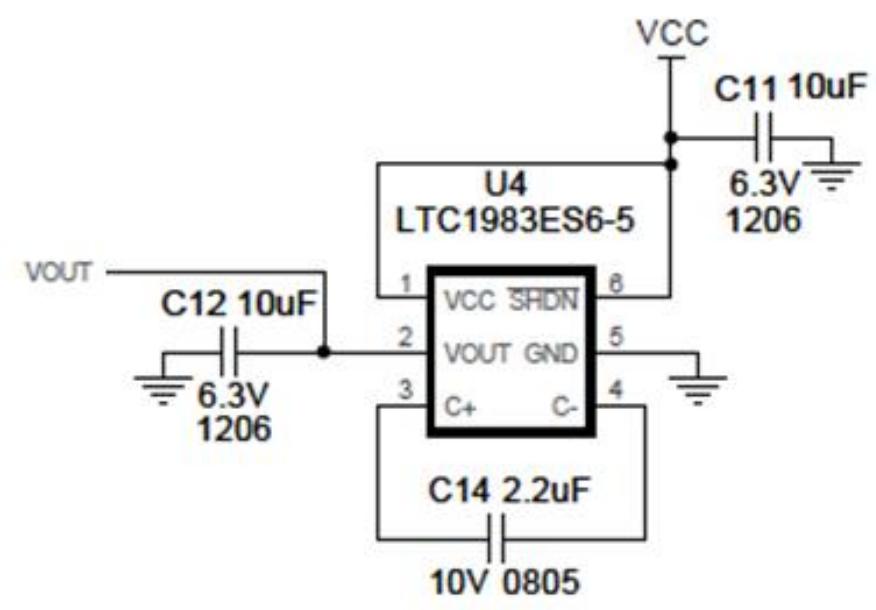

Figure 5-3: Charge Pump Schematic [12] 
Table 5-2: Charge Pump Summary

\begin{tabular}{|c|c|}
\hline Ideal Output & $5.000 \mathrm{~V}$ \\
\hline Actual Output & $4.998 \mathrm{~V}$ \\
\hline \% Difference & $0.2 \%$ \\
\hline
\end{tabular}

\subsection{Step-Down Converter}

Another important part of the loop measurement board is the step-down converter, which is shown in Figure 5-4. As stated in previous chapters, this converter allows for higher supply voltages to power up the loop measurement board and is integral to its flexibility and ease of use.

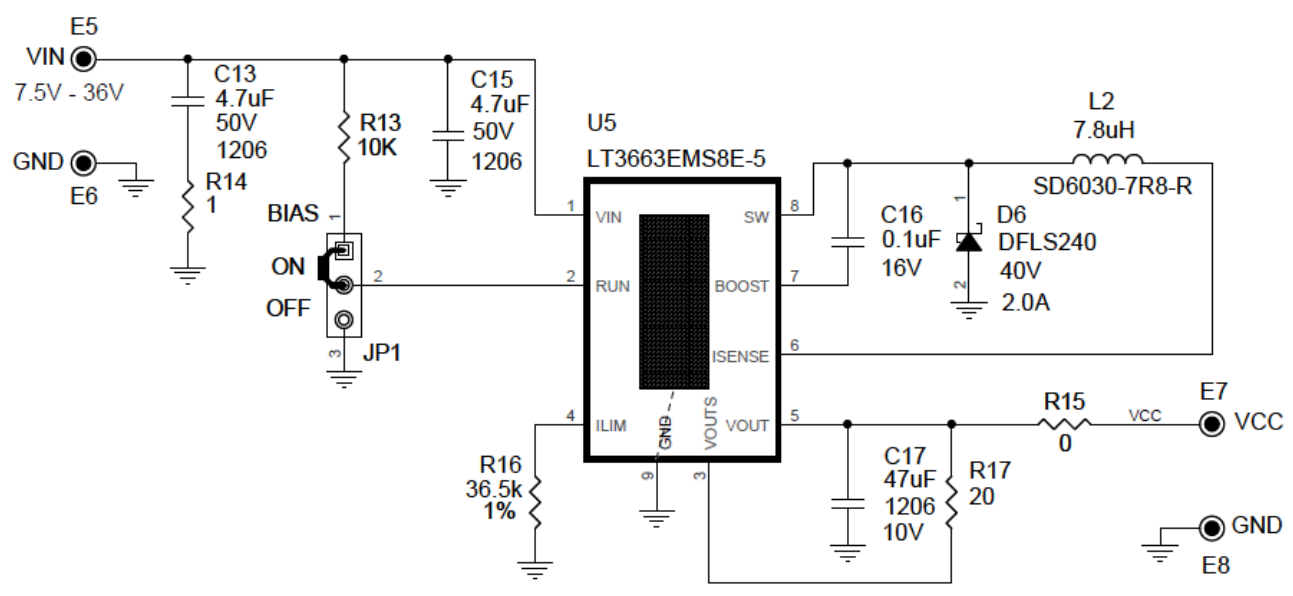

Figure 5-4: Step-Down Converter Schematic [9]

Even though the converter's design and externals were replicated from a Linear Technology demo board, the converter's important parameters still need to be tested. For the purpose of verifying the converter, tests for line regulation, load regulation, efficiency, and voltage ripple were done. The converter is considered acceptable if both line and load regulation are under 5\%, and if output voltage ripple is lower than 5\%. It would also be ideal if efficiency is over $80 \%$ under load. Figure 5-5 shows the test setup for the converter. The main input power supply is connected directly to the power meter to monitor the input power, input voltage, as well as the input current being drawn 
by the converter. However, to more accurately measure input current, a separate digital multimeter is used. An electronic load is connected at the output of the converter which controls the output current sourced by the converter while reading the output power. Due to the wires being used to connect the load to the converter's output is lengthy, a separate multimeter is used to more accurately measure the converter's output voltage.

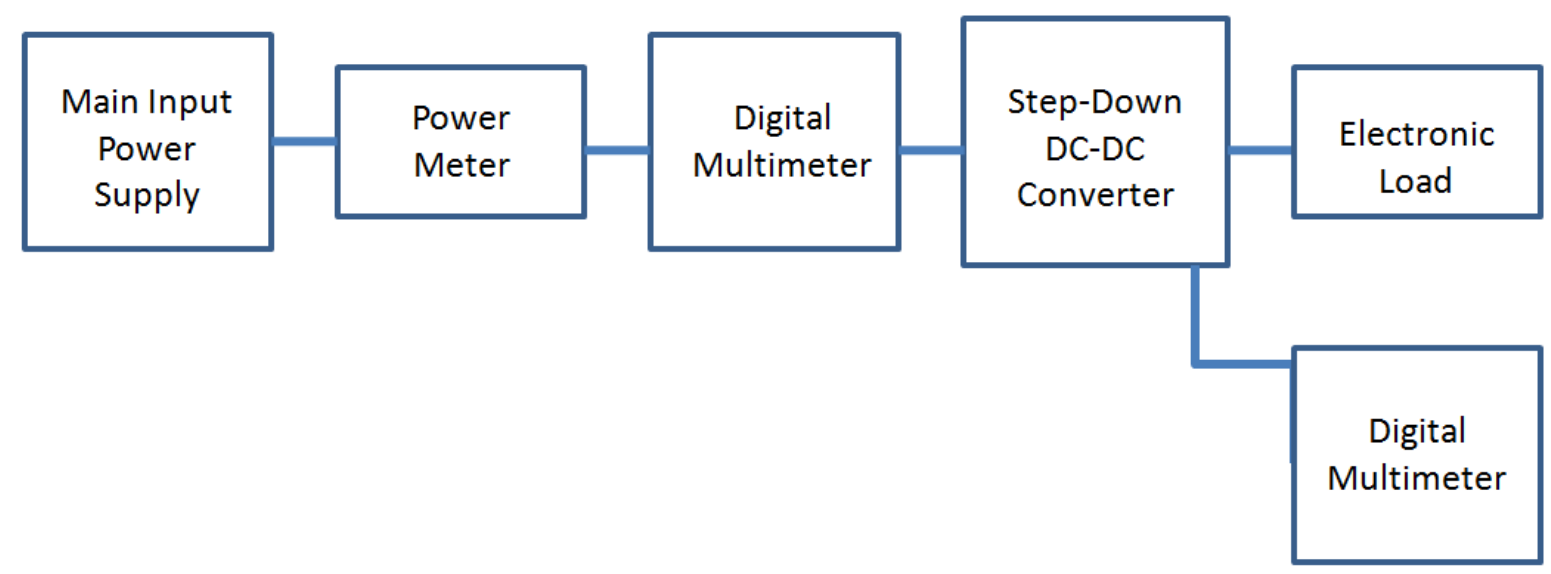

Figure 5-5: Step-Down DC-DC Converter Test Set-Up

The step-down converter is configured to be able to supply a maximum load of $1 \mathrm{~A}$ at a regulated voltage of $5 \mathrm{~V}$. Thus, the converter will be tested in percent of load increments to monitor its efficiency. Table 5-3 shows the output voltages and efficiencies for the step-down converter ranging from no load to a full $1 \mathrm{~A}$ full load. Input power is measured by a power meter and the input current measured by a digital multimeter. Output power is measured from the output voltage measured by a multimeter and the output current displayed on the electronic load. Efficiency was calculated for input voltages of $7.5 \mathrm{~V}, 24 \mathrm{~V}$, and $36 \mathrm{~V}$. 
Table 5-3: Output Voltages and Efficiencies for Percent Load Test of Step-down Converter

\begin{tabular}{|c|c|c|c|c|c|c|}
\hline \multicolumn{7}{|c|}{$\mathrm{V}_{\mathrm{IN}}=7.5 \mathrm{~V}$} \\
\hline $\begin{array}{c}\text { Input } \\
\text { Voltage } \\
\text { (V) }\end{array}$ & $\begin{array}{c}\text { Input } \\
\text { Current (A) }\end{array}$ & $\begin{array}{c}\text { Input Power } \\
\text { (W) }\end{array}$ & $\begin{array}{c}\text { Output } \\
\text { Voltage }(\mathbf{V})\end{array}$ & $\begin{array}{c}\text { Output } \\
\text { Current (A) }\end{array}$ & $\begin{array}{c}\text { Output } \\
\text { Power }(W)\end{array}$ & $\begin{array}{c}\text { Efficiency } \\
(\%)\end{array}$ \\
\hline 7.47 & 0.004 & 0.03 & 4.98 & 0.0 & 0 & 0 \\
\hline 7.45 & 0.091 & 0.68 & 4.97 & 0.1 & 0.50 & 73.65 \\
\hline 7.48 & 0.166 & 1.24 & 4.98 & 0.2 & 1.00 & 80.17 \\
\hline 7.46 & 0.240 & 1.79 & 4.98 & 0.3 & 1.49 & 83.45 \\
\hline 7.50 & 0.312 & 2.34 & 4.98 & 0.4 & 1.99 & 85.13 \\
\hline 7.48 & 0.389 & 2.91 & 4.98 & 0.5 & 2.49 & 85.58 \\
\hline 7.49 & 0.465 & 3.48 & 4.97 & 0.6 & 2.98 & 85.62 \\
\hline 7.46 & 0.546 & 4.07 & 4.97 & 0.7 & 3.48 & 85.41 \\
\hline 7.52 & 0.622 & 4.68 & 4.97 & 0.8 & 3.98 & 85.00 \\
\hline 7.49 & 0.706 & 5.29 & 4.97 & 0.9 & 4.47 & 84.59 \\
\hline 7.47 & 0.795 & 5.94 & 4.97 & 1.0 & 4.97 & 83.69 \\
\hline \multicolumn{7}{|c|}{$V_{\text {IN }}=24 \mathrm{~V}$} \\
\hline $\begin{array}{c}\text { Input } \\
\text { Voltage } \\
\text { (V) }\end{array}$ & $\begin{array}{c}\text { Input } \\
\text { Current }(A)\end{array}$ & $\begin{array}{c}\text { Input Power } \\
\text { (W) }\end{array}$ & $\begin{array}{c}\text { Output } \\
\text { Voltage }(V)\end{array}$ & $\begin{array}{c}\text { Output } \\
\text { Current (A) }\end{array}$ & $\begin{array}{c}\text { Output } \\
\text { Power (W) }\end{array}$ & $\begin{array}{c}\text { Efficiency } \\
(\%)\end{array}$ \\
\hline 24.05 & 0.0031 & 0.08 & 5.00 & 0 & 0 & 0 \\
\hline 24.04 & 0.0345 & 0.83 & 5.00 & 0.1 & 0.50 & 60.29 \\
\hline 24.04 & 0.0641 & 1.54 & 5.00 & 0.2 & 1.00 & 64.89 \\
\hline 24.03 & 0.0914 & 2.20 & 5.00 & 0.3 & 1.50 & 68.30 \\
\hline 24.03 & 0.1170 & 2.81 & 5.00 & 0.4 & 2.00 & 71.14 \\
\hline 24.02 & 0.1410 & 3.39 & 5.00 & 0.5 & 2.50 & 73.82 \\
\hline 24.01 & 0.1660 & 3.99 & 5.00 & 0.6 & 3.00 & 75.27 \\
\hline 24.00 & 0.1900 & 4.56 & 5.00 & 0.7 & 3.50 & 76.75 \\
\hline 23.99 & 0.2150 & 5.16 & 5.00 & 0.8 & 4.00 & 77.55 \\
\hline 23.99 & 0.2400 & 5.76 & 4.99 & 0.9 & 4.49 & 78.00 \\
\hline 23.98 & 0.2670 & 6.40 & 4.99 & 1.0 & 4.99 & 77.94 \\
\hline \multicolumn{7}{|c|}{$V_{I N}=24 V$} \\
\hline $\begin{array}{l}\text { Input } \\
\text { Voltage } \\
\text { (V) }\end{array}$ & $\begin{array}{c}\text { Input } \\
\text { Current (A) }\end{array}$ & $\begin{array}{l}\text { Input Power } \\
\text { (W) }\end{array}$ & $\begin{array}{c}\text { Output } \\
\text { Voltage }(\mathbf{V})\end{array}$ & $\begin{array}{c}\text { Output } \\
\text { Current (A) }\end{array}$ & $\begin{array}{c}\text { Output } \\
\text { Power }(W)\end{array}$ & $\begin{array}{c}\text { Efficiency } \\
(\%)\end{array}$ \\
\hline 36.03 & 0.0032 & 0.115 & 5.01 & 0 & 0 & 0 \\
\hline 36.03 & 0.0260 & 0.937 & 5.01 & 0.1 & 0.50 & 53.48 \\
\hline 36.03 & 0.0470 & 1.693 & 5.01 & 0.2 & 1.00 & 59.17 \\
\hline 36.02 & 0.0680 & 2.449 & 5.01 & 0.3 & 1.50 & 61.36 \\
\hline 36.02 & 0.0860 & 3.098 & 5.01 & 0.4 & 2.00 & 64.69 \\
\hline 36.02 & 0.1030 & 3.710 & 5.01 & 0.5 & 2.51 & 67.52 \\
\hline 36.02 & 0.1200 & 4.322 & 5.01 & 0.6 & 3.01 & 69.54 \\
\hline 36.00 & 0.1370 & 4.932 & 5.01 & 0.7 & 3.51 & 71.11 \\
\hline 36.00 & 0.1550 & 5.580 & 5.01 & 0.8 & 4.01 & 71.83 \\
\hline 36.00 & 0.1720 & 6.192 & 5.01 & 0.9 & 4.51 & 72.82 \\
\hline 36.00 & 0.1910 & 6.876 & 5.00 & 1.0 & 5.01 & 72.86 \\
\hline
\end{tabular}




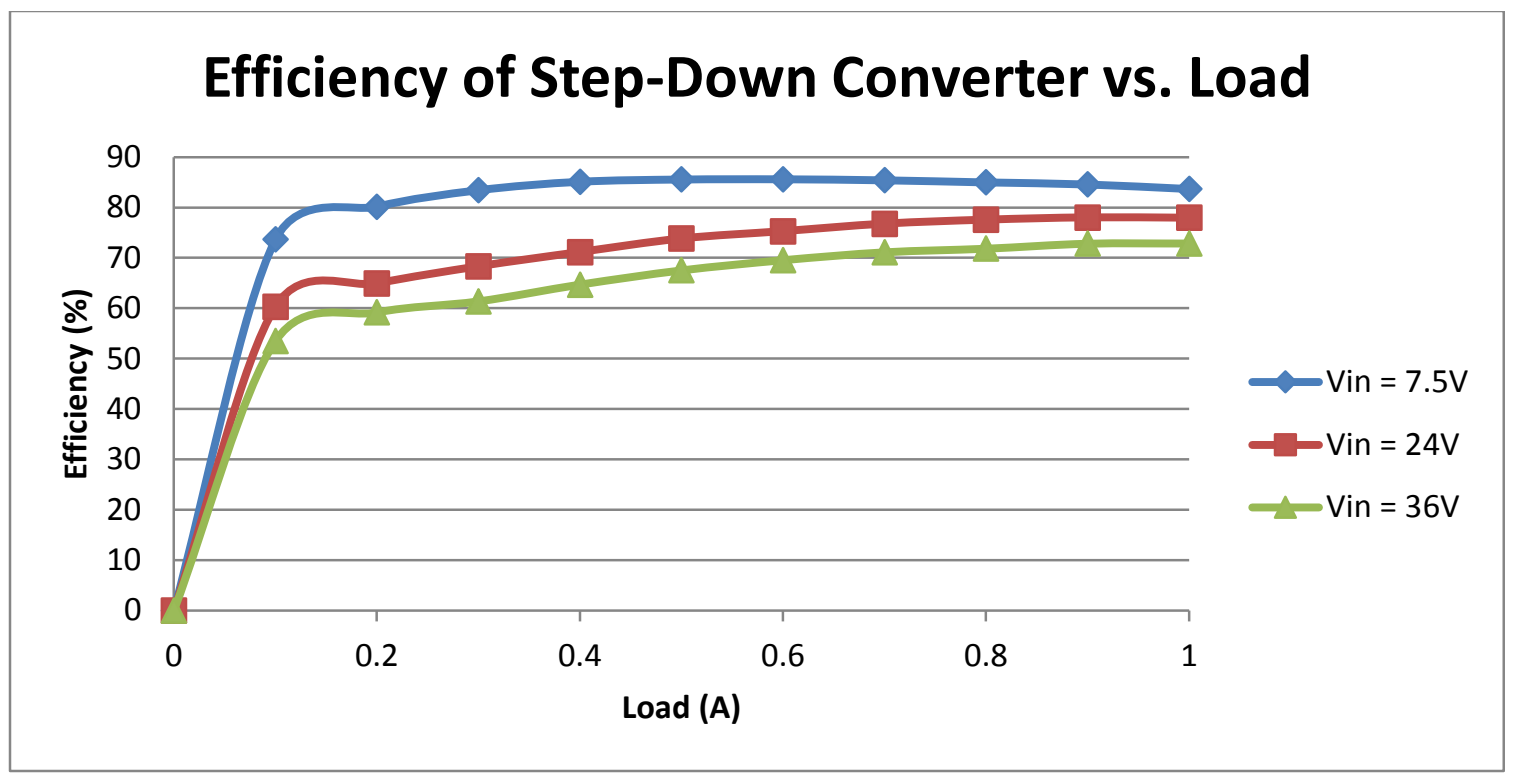

Figure 5-6: Efficiency vs. Load for Step-down Converter for Various Input Voltages

Load regulation was calculated using equation 5.1 shown below. Load regulation was measured and calculated for input voltages of $7.5 \mathrm{~V}, 24 \mathrm{~V}$, and $36 \mathrm{~V}$, respectively:

$$
\text { Load Regulation }(\%)=\frac{\left(V_{o(\min l o a d)}-V_{o(\max l o a d)}\right)}{V_{o(\max l o a d)}} * 100
$$

For an input voltage of $7.5 \mathrm{~V}$ :

$$
\text { Load Regulation }(\%)=\frac{(4.98-4.97)}{4.97 \mathrm{~V}} * 100=0.26 \%
$$

For an input voltage of $12 \mathrm{~V}$ :

$$
\text { Load Regulation }(\%)=\frac{(5.00-4.99)}{4.99 \mathrm{~V}} * 100=0.20 \%
$$

For an input voltage of $12 \mathrm{~V}$ :

$$
\text { Load Regulation }(\%)=\frac{(5.01-5.00)}{5.00 \mathrm{~V}} * 100=0.20 \%
$$

Line regulation was calculated using Equation 5.5 below:

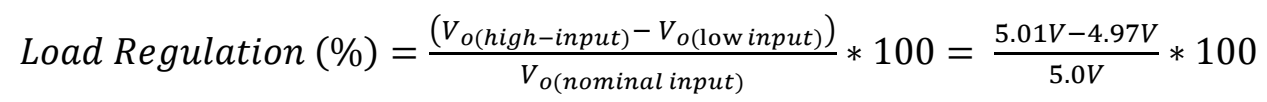

Efficiency was calculated using Equation 5.6 provided below: 


$$
\eta(\%)=\frac{P_{\text {out }}}{P_{\text {in }}} * 100
$$

The load and line regulations for the step-down converter meet the requirement of less than $5 \%$. Figure 5-6 shows a graph of the efficiency of the converter over load. For the input voltages of $7.5 \mathrm{~V}, 24 \mathrm{~V}$, and $36 \mathrm{~V}$, only an input voltage of $7.5 \mathrm{~V}$ produced efficiencies over $80 \%$ for all loads above $20 \%$ of full load. Input voltages of $24 \mathrm{~V}$ and $36 \mathrm{~V}$ did not result in efficiencies over $80 \%$.

Figure 5-7 shows the output voltage peak-to-peak ripple of the converter at full load conditions using an input voltage of $36 \mathrm{~V}$. With a measured peak-to-peak voltage of $10 \mathrm{mV}$, the output voltage ripple can be calculated using Equation 5.7:

$$
\% \frac{\Delta V}{V_{\text {out }}}=\frac{10 \mathrm{mV}}{5.00 \mathrm{~V}}=0.2 \%
$$

With an output voltage ripple of $0.4 \%$, the specification for an output voltage ripple of under $5 \%$ has been met.

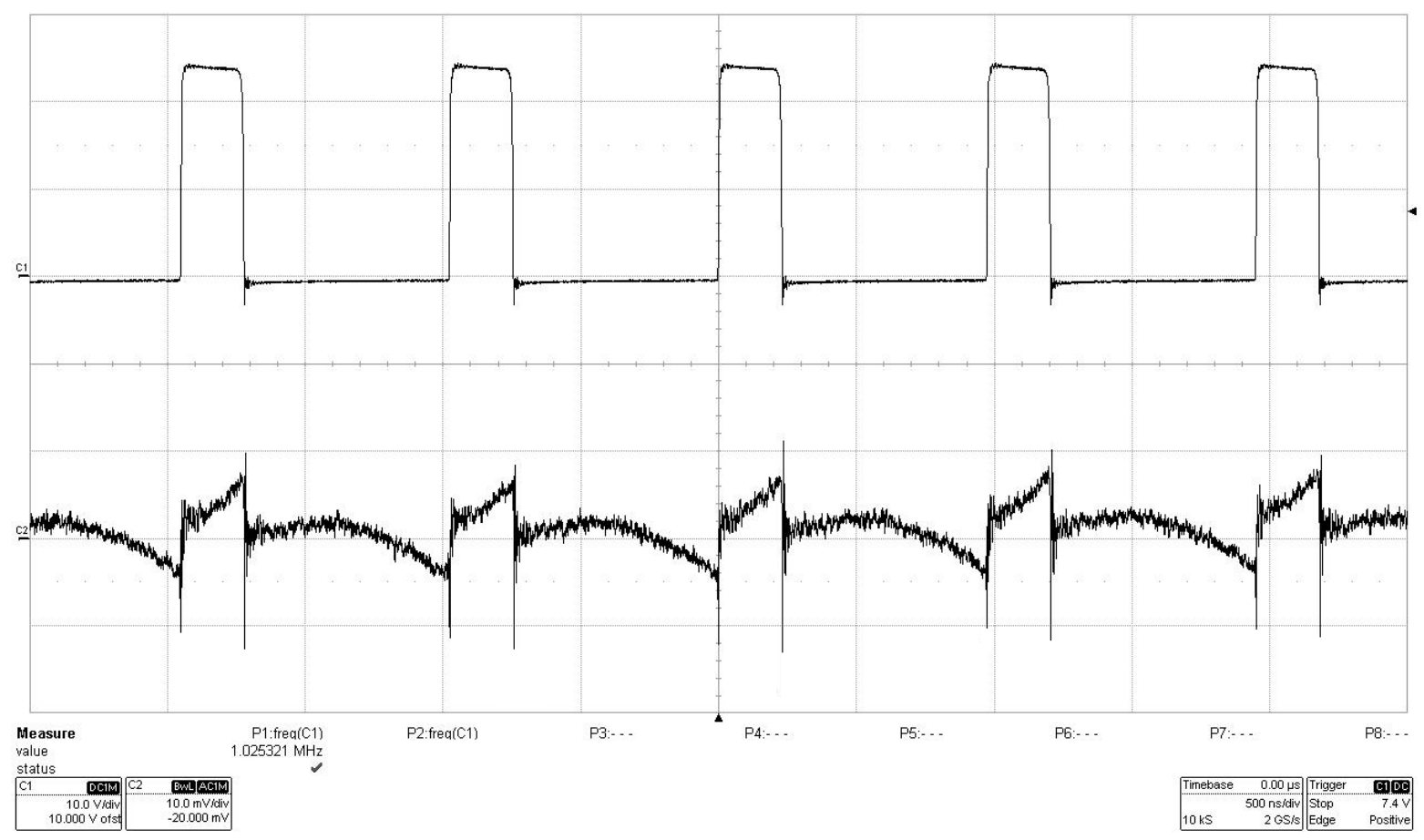

Figure 5-7: Output Voltage Peak-to-Peak Ripple at Full Load Conditions (bottom waveform) 


\subsection{Physical Hardware Implementation}

For the physical hardware implementation of the loop measurement board, there were various details to consider. While the loop measurement board has to provide the functionality required to make loop measurements, it has to be physically easy to use as well. Figure 5-8 shows a schematic of the loop measurement board and how the hardware is laid out. The potentiometers used to adjust the excitation signal's frequency and amplitude (R2, R3, R4, R9) are placed on the bottom so that nothing will obstruct access to them. Inputs to give the loop measurement board power are all on the left in order to be consistent. The high voltage input that includes the stepdown converter circuitry are on the top left of the board where E5 and E6 (ground) can be used for power input. The micro USB input is also on the left of the board, and is labeled as J4 on the schematic. The $5 \mathrm{~V}$ option to power the loop measurement board are on the bottom left and are labeled on the schematic with E3, and E4 as ground. As for the triangle signal produced by the waveform generator, a BNC connector is played on the left side (labeled J1) of the board as well, in order to stay consistent with inputs being on the left. It will be explained later on how J1 is used in loop measurements.

The loop measurement board's right side is on the other hand associated with the board's outputs. The output excitation signals are output on the right to turrets labeled on the schematic as points A and B. BNC connectors labeled TP B (J2) and TP A (J3) are also placed on the right in order to be able to view these output excitation signals on an oscilloscope.

The transformer used in the loop measurement board is placed in the middle of the board. The transformer allows the excitation signal to be injected differentially. The circuit that constitutes the triangle waveform generator is placed right below the transformer. The step-down converter circuitry can be found above the transformer. 


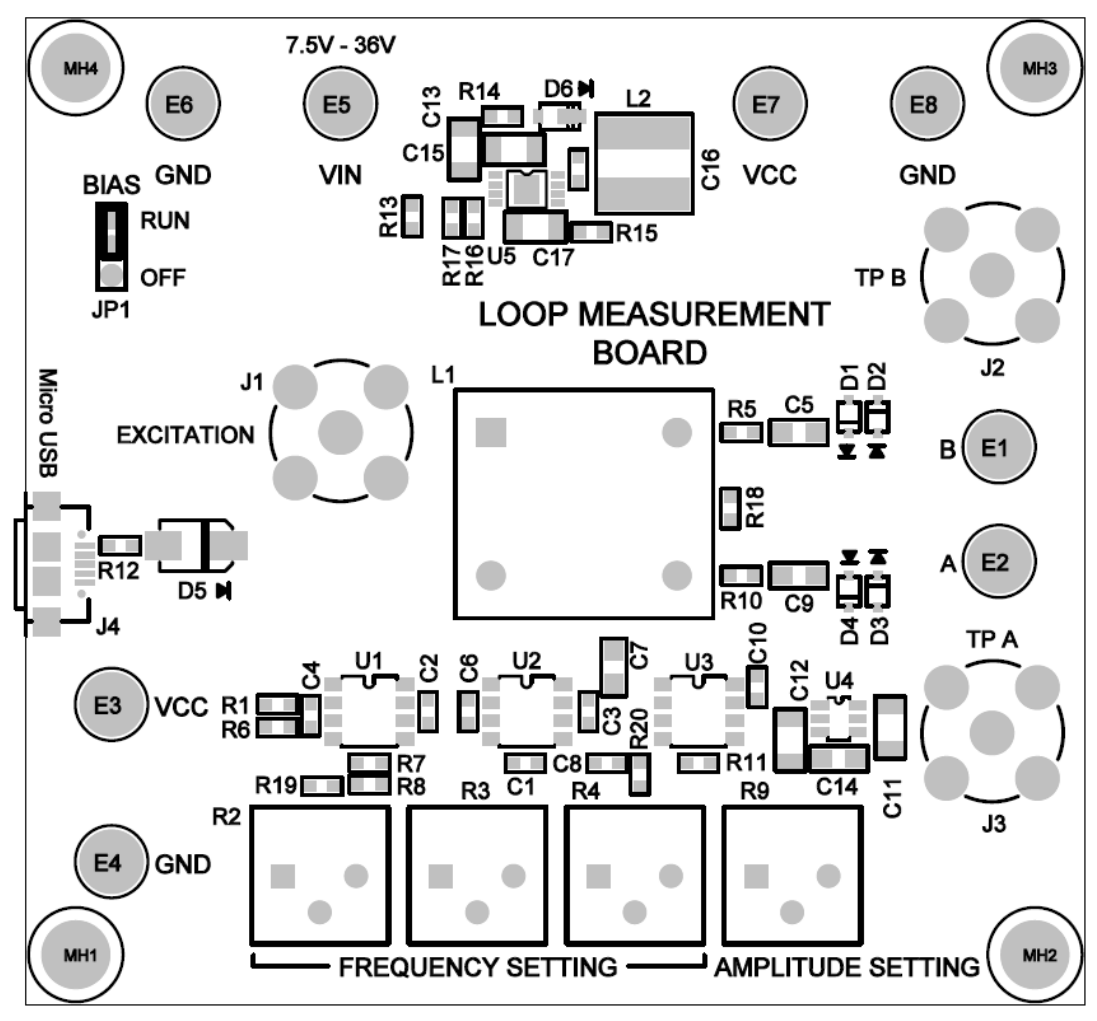

Figure 5-8: Top layer of PCB for Loop Measurement Board

The loop measurement board was designed to be placed on a PCB. The PCB layout was designed using just two layers, a top and bottom layer. Figure 5-9 shows the PCB layout design and its connections. The layout was done with the intention to keep the loop measurement board small while still being large enough that the various BNC connectors, potentiometers, and power inputs are easy to access. On the board, the ground planes of both layers are connected with vias. Vias are also placed close to the power input of the ICs so that bypass capacitors are close to ground. Figure 5-10 shows another view of the PCB layout. On the top of the schematic highlighted in red, are places where there will be exposed grounds. The exposed grounds surround E6 and E8 (in reference to Figure 5-8) and are used to more easily connect with the ground of the DC-DC converter under test. By having these exposed grounds, it is possible to connect the ground of the loop measurement board with the ground of the DC-DC converter being tested. This increases the accuracy of the loop measurements. 


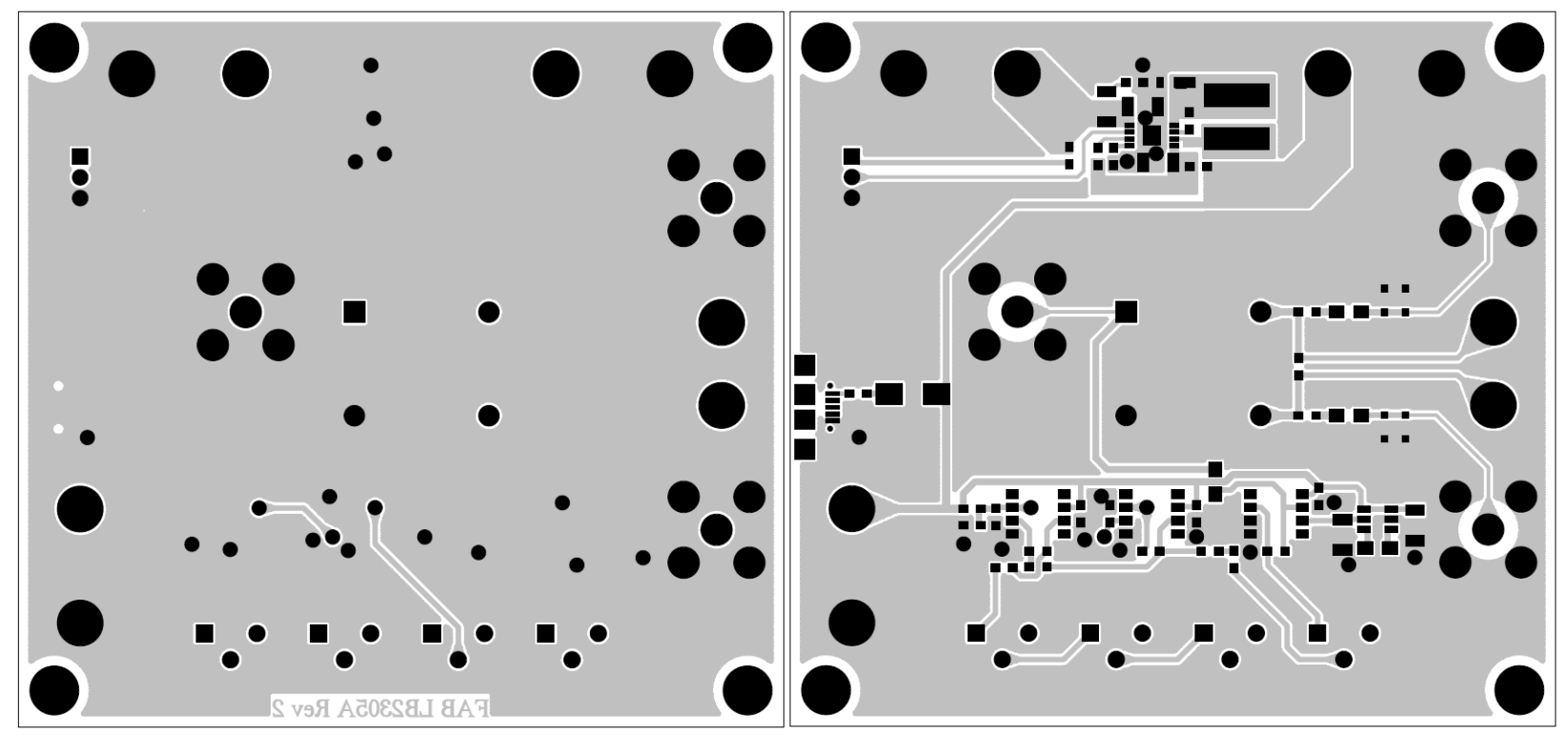

Figure 5-9: Bottom and Top Layer layout of PCB

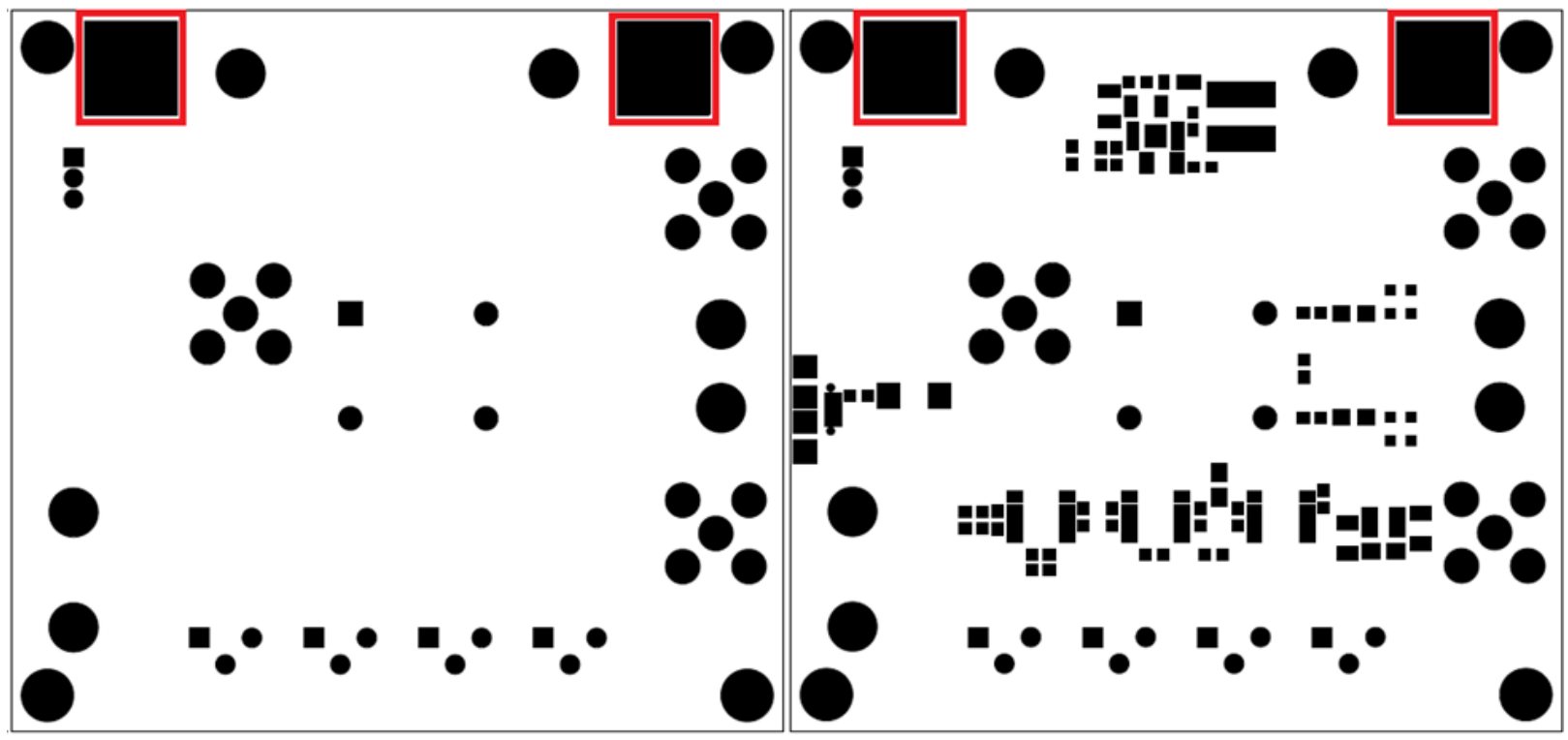

Figure 5-10: PCB layout showing exposed ground planes

Figure 5-11 shows a physical implementation of the loop measurement board. As noted earlier, turrets are placed on various power and ground pins in order to increase ease of use and accessibility. The board's dimensions are 2.9"x2.7"x1.5" (height from top of transformer to bottom of mounts), fulfilling the size requirement of being less than $4 " \mathrm{x} 4$ "x4". The loop measurement board also weighs approximately 50 grams, thus meeting the weight requirement outlined in 
Chapter 3. Finally, the cost of producing the board, including components, PCB, and other materials is approximately $\$ 68.87$, as shown in Appendix A. With this estimated cost, the loop measurement board satisfies the cost requirement of less than $\$ 100$. If the PCB was to be ordered and made in bulk, and if the ICs were ordered in bulk, the price could go even further down.

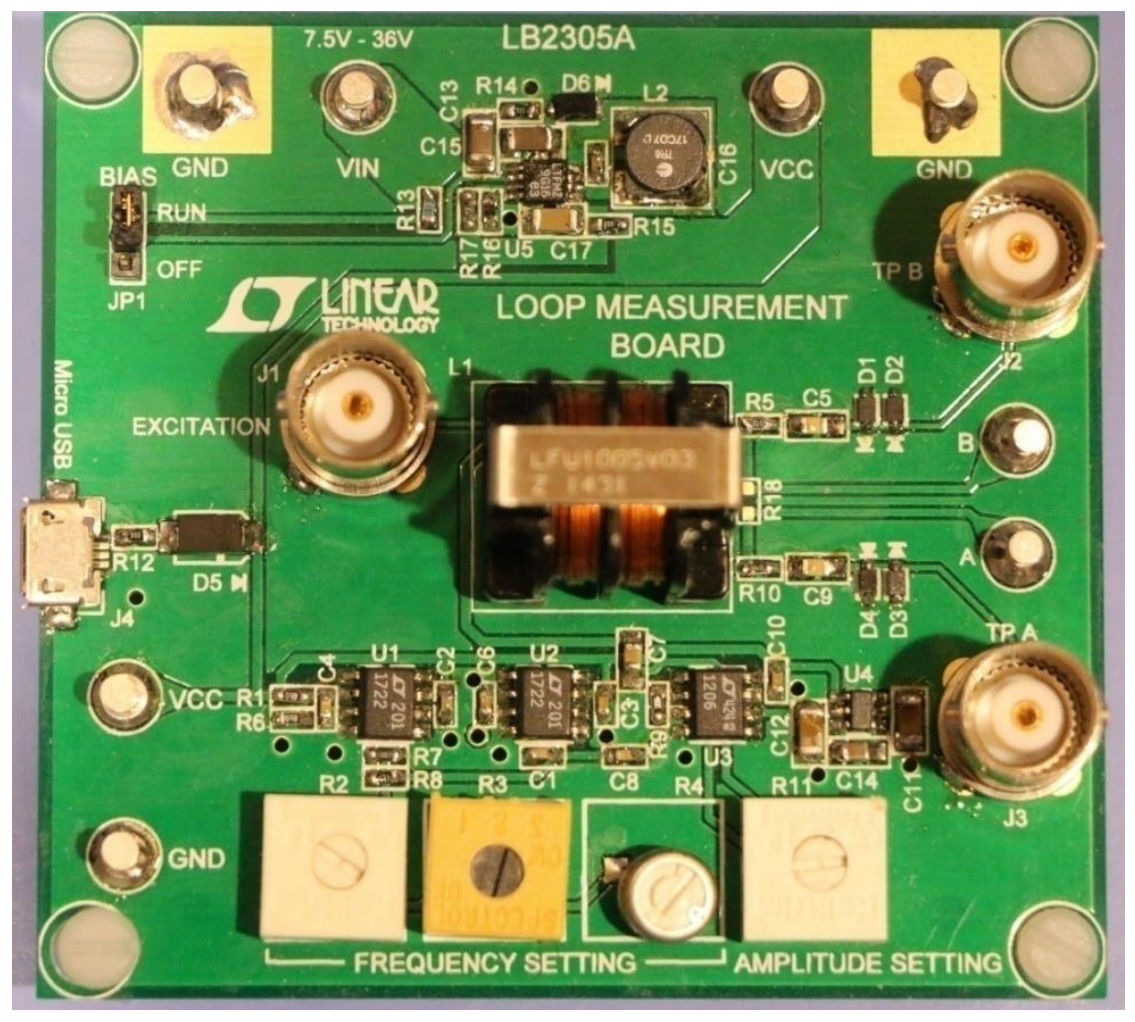

Figure 5-11: Implemented Loop Measurement Board

\subsection{Using The Loop Measurement Board}

The loop measurement board is relatively simple to set up to make measurements on a converter. Referring to Figures 5-12 and Figure 5-10, the loop measurement can be obtained using the following procedure:

1. First, without connecting the loop measurement board to the DC-DC converter, apply input voltage VIN to the measurement board and check the excitation signal, which is labeled on the board as "excitation (J1)", with a scope. Set the excitation signal to about $50 \mathrm{mV}$ PPand $10 \mathrm{kHz}$. 
2. Without power, connect the grounds of the loop measurement board and the converter together. It is strongly recommended that the grounds are soldered together, which can be done on the exposed ground on the loop measurement board, shown in Figure 5-10, boxed in red.

3. Insert a $50 \Omega$ resistor through the converter's voltage feedback path, and connect terminals $\mathrm{A}$ and $\mathrm{B}$ across the resistor.

4. Connect EXCITATION (J1), TP B (J2), and TP A (J3) via BNC connectors to an oscilloscope.

5. Turn on the converter under test. Check for the proper output voltage.

6. Connect the input power supply (5V) to VCC and GND of the loop measurement board.

a. If using a Micro USB, connect to the Micro USB port.

b. If using an input voltage from $7.5 \mathrm{~V}$ to $36 \mathrm{~V}$, connect to VIN and GND.

7. Turn on the input power source and slowly increase the input voltage. Be careful not to exceed $5.25 \mathrm{~V}$. Note that if an input voltage between 7.5 to $36 \mathrm{~V}$ is being used, do not exceed 36V.

8. Observe EXCITATION ( $\mathrm{J} 1)$ via a scope to check if an excitation signal is being output.

9. Once an excitation signal is produced, adjust frequency and amplitude to make measurements on the converter. 


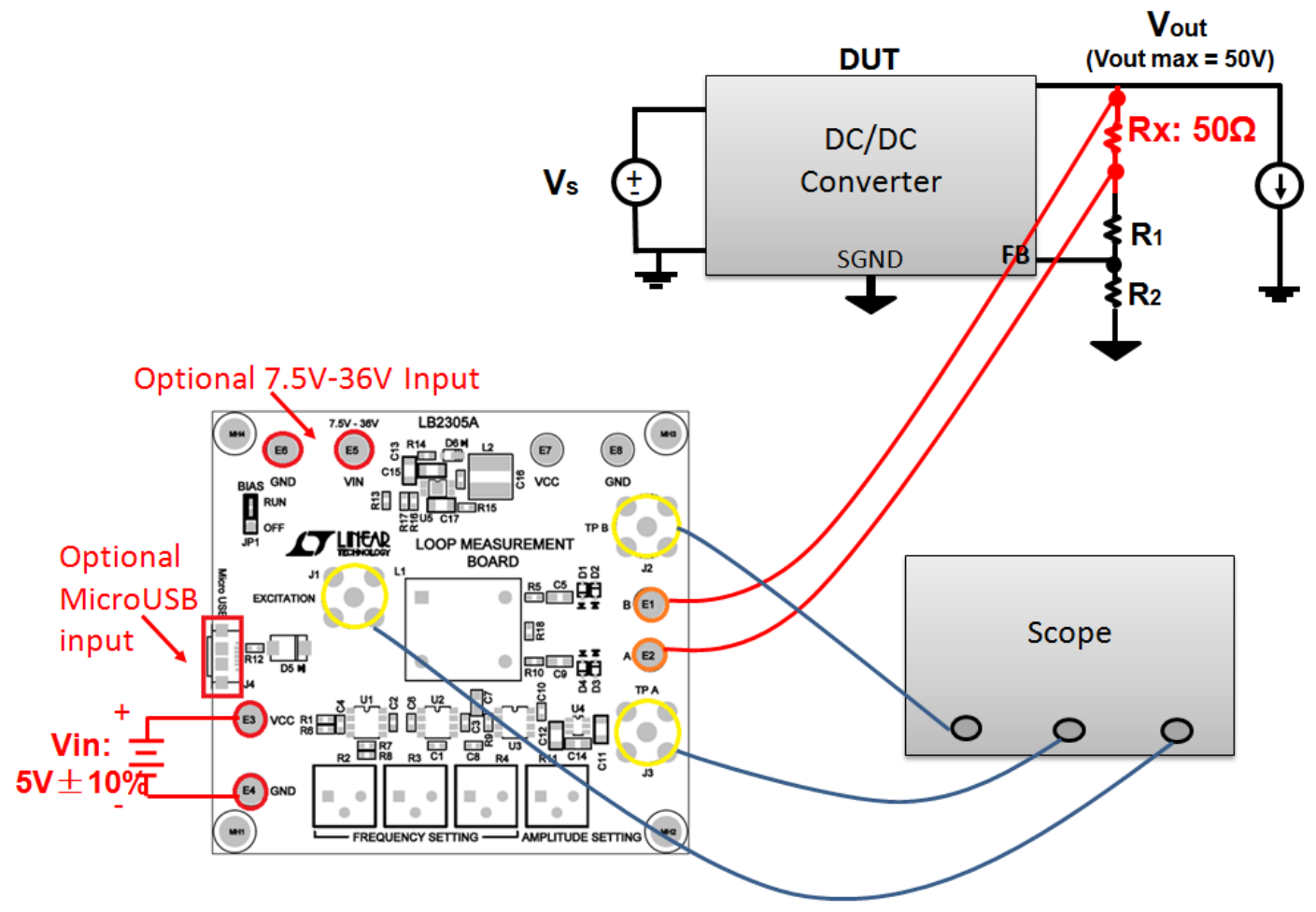

Figure 5-12: Loop Measurement Board Setup

Crossover frequency and phase margin are two valuable pieces of information when it comes to a converter's control loop. In frequency analyzers, crossover frequency and phase margin are observed at the cross-over frequency where the gain crosses $0 \mathrm{~dB}$ (gain of 1.0). What this means for signals A and B, crossover frequency and phase margin can be measured and calculated when both signals are the same amplitude, implying unity gain (as in Figure 5-13 below).

To obtain crossover frequency (bandwidth) and phase margin from signals A and B, adjust the frequency of the excitation signal until the signals monitored on TPA and TPB (shown in Figure 5-13) are equal in amplitude. The crossover frequency is the frequency when the amplitudes of two signals are equal. Phase margin is also determined in this unity gain condition. By calculating the phase difference between signals B and A, phase margin can be determined. When 
finding difference in time dt of the two signals, period $\mathrm{T}$, and the amplitudes of the signals, cursors are preferred as shown in Figure 5-13.

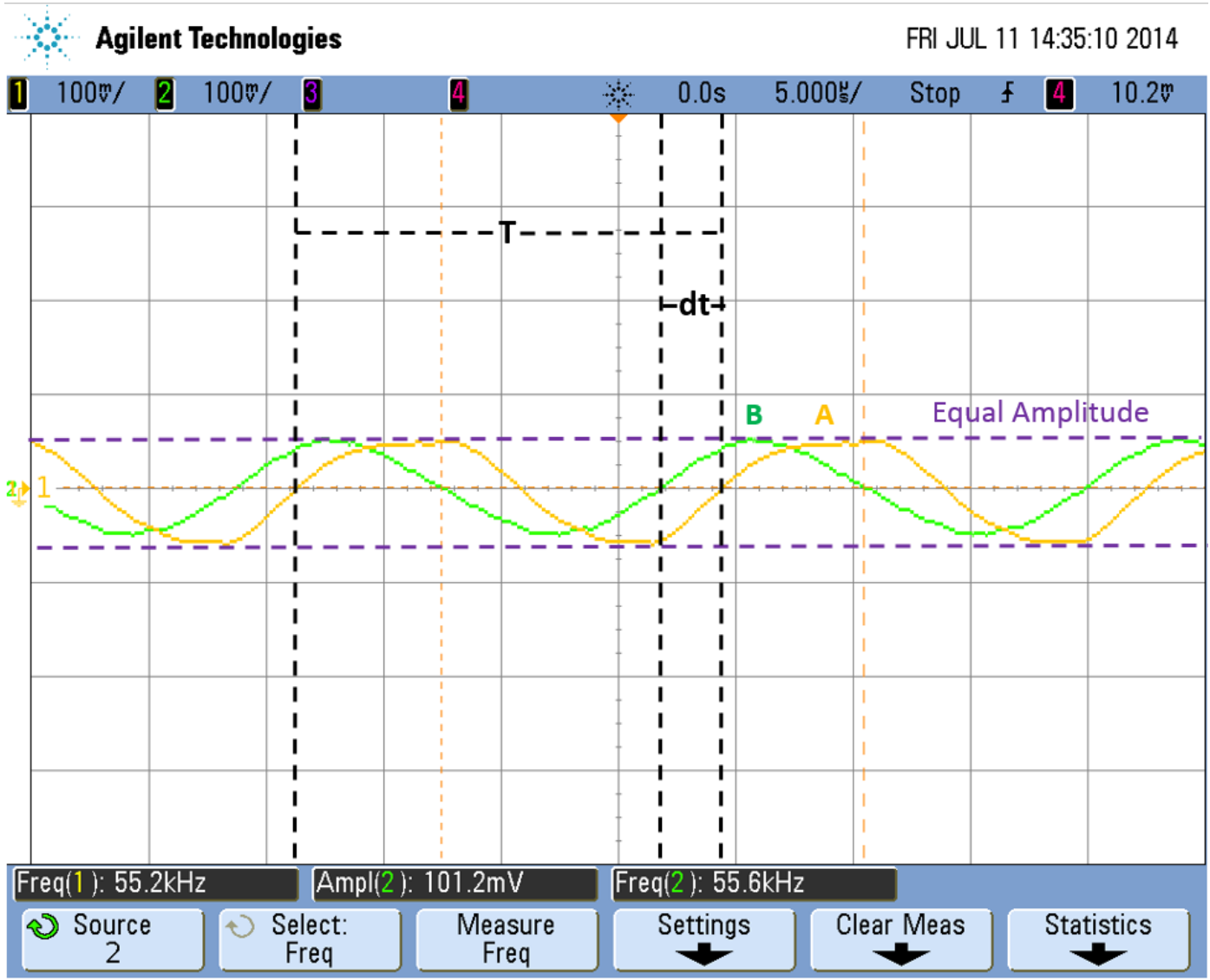

Figure 5-13: Example waveform for Phase Margin and Crossover Frequency

The Phase Margin can then be calculated from:

$$
\text { Phase Margin }=(\mathrm{dt} / \mathrm{T})^{*} 360^{\circ}[(\text { degrees }]
$$

Where again $\mathbf{d t}$ is the time difference between the two waveforms (TPA and TPB). Using their respective zero crossings may make finding dt easier. Finding the period $\mathbf{T}$ by using a signal's zero crossings may make the measurement easier. (1/T) is also crossover frequency, which can otherwise be measured from the excitation signal.

Gain margin is another useful parameter that can be measured. On a frequency analyzer, gain margin is observed at the frequency when the phase difference (B-A) is $0^{\circ}$. If it is kept in mind that the phase difference is zero degrees when gain margin can be found, then it also makes 
sense that gain margin can be found when signals B and A on the loop measurement board are in phase (as in Figure 5-14). To obtain gain margin, adjust the frequency of the excitation signal until the signals monitored on TPA and TPB (shown in Figure 5-12) are in phase of each other by observing their peaks. When the signals are in phase (both peaks coincide), gain margin can be determined. The gain between the waveforms when they are in phase is equal to the converter's gain margin as illustrated in Figure 5-14.

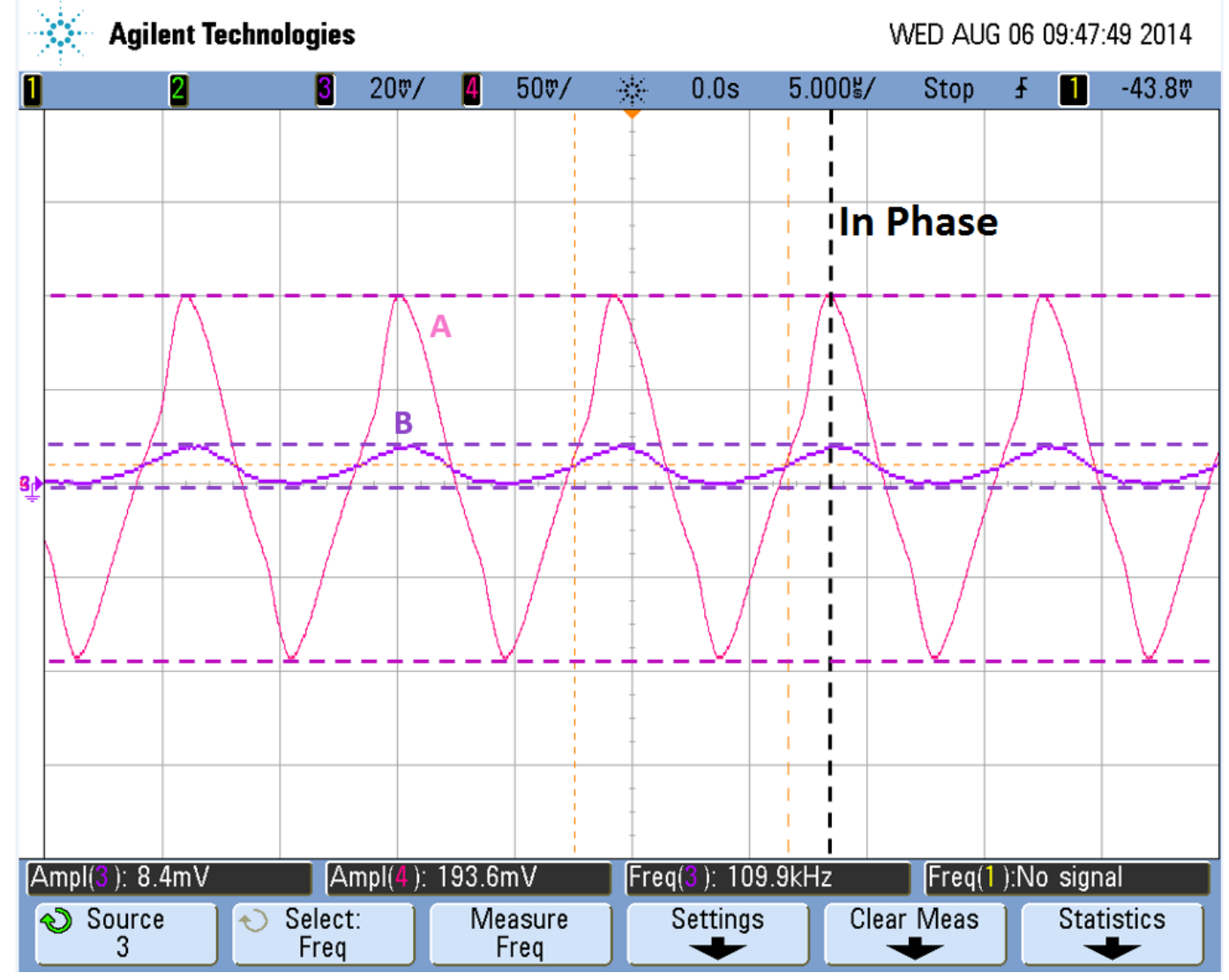

Figure 5-14: Example Waveform for finding gain margin

The Gain Margin is calculated using

$$
\text { Gain Margin }=\left|20 \log \left(\mathrm{V}_{\text {Bpk-pk }} / \mathrm{V}_{\text {Apk-pk }}\right)\right|(\mathrm{dB})
$$

where:

V Bpk-pk is the peak to peak voltage value for signal B.

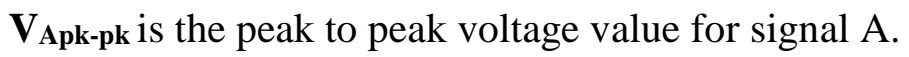


Note that when a converter's gain is high, large amounts of distortion and noise may be observed. Oscilloscopes with averaging functions may be useful to make measurement taking an easier task in this case. Without any modification to the oscilloscope's setup, observing signals A and B can potentially become a difficult task. Often times, signals A and B will be affected by switching ripple, which can cause the waveforms to be noisy, and thus complicate making measurements.

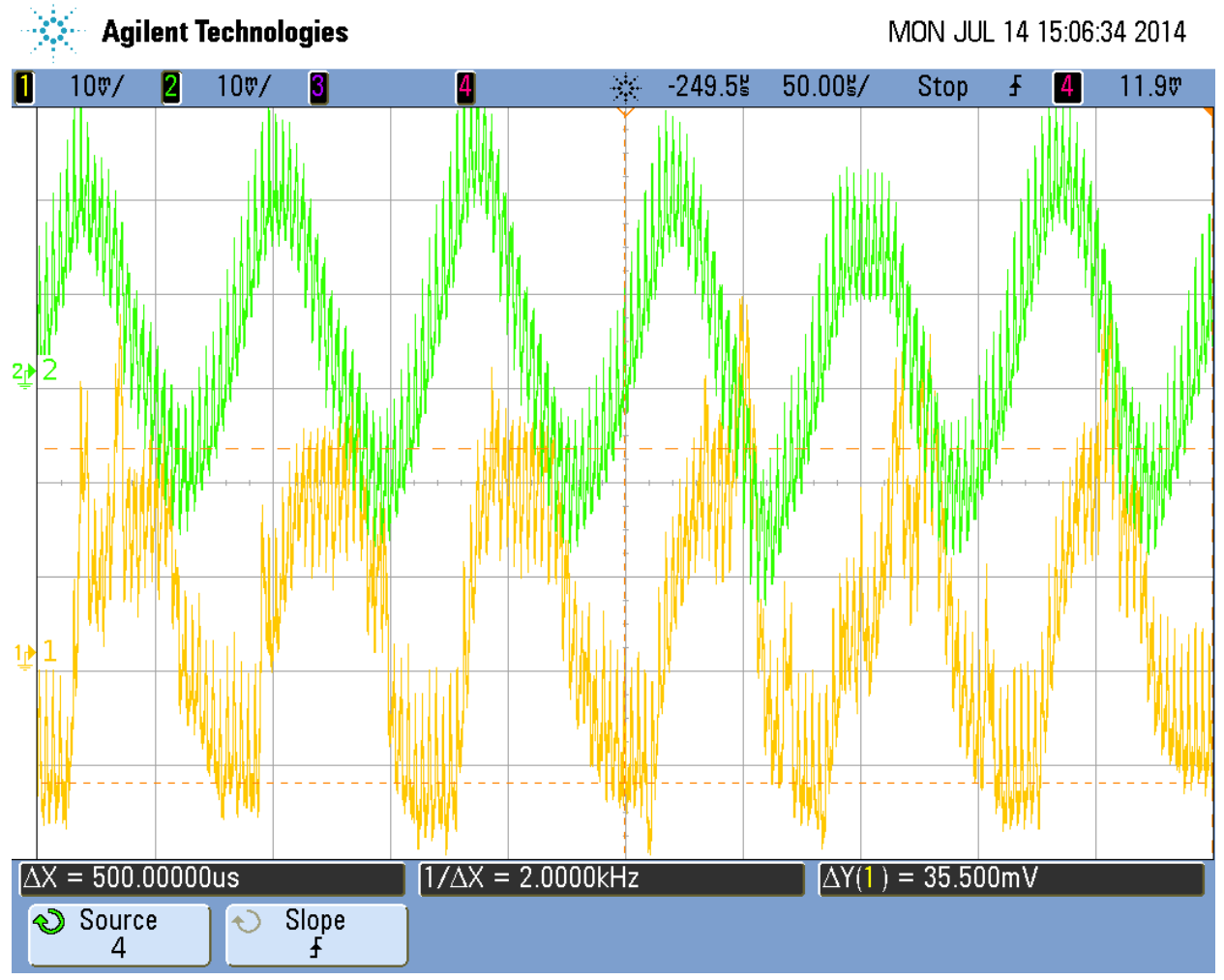

Figure 5-15: Example waveform with switching ripple

As exhibited in Figure 5-15, switching ripple prevents the loop measurement tool to accurately find crossover frequency, gain margin, and phase margin. Without some way to reduce the ripple's effect on measurements, accuracy cannot be relied upon. However, as mentioned previously, oscilloscopes often provide the functions to get around this problem such as persistence and averaging. 
When setting up the oscilloscope, there are a few things to keep in mind. First, the signals should trigger on the excitation signal, as switching ripple and noise may make triggering off the signals on TP A and TP B difficult. It is also recommended to BW Limit the excitation signal to reduce noise. Again as to make the viewing of signals B and A easier, oscilloscope's persistence or averaging function can be utilized. In Figure 5-16, an example of using infinite persistence to find the time difference between two signals is shown. Using the zero crossing as a point of reference for the two signals, and with the assistance of persistence, the midpoint of each signal could be well-estimated. Thus, even with a noisy signal with ripple, time difference can be found with the use of a scope's cursors. When further frequency/amplitude adjustments must be made, persistence can be temporarily turned off and cleared.

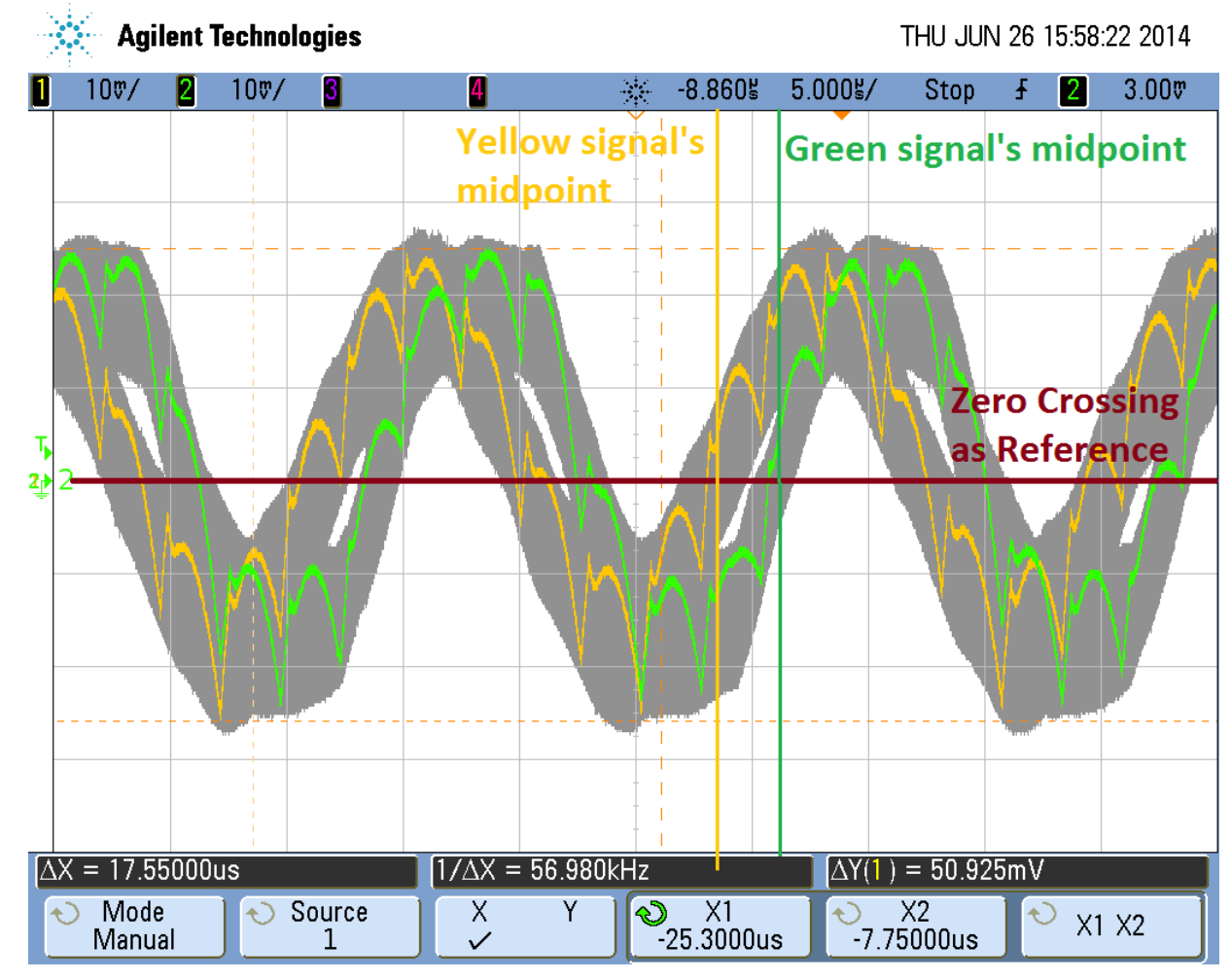

Figure 5-16: Example on using persistence

An example of the use of the Averaging function to help make the proper measurement is shown in Figure 5-17. Unlike in persistence, where the midpoint is found manually in a given area, 
averaging makes the signal's midpoint more obvious. As shown in Figure 5-17, Averaging produces a cleaner waveform on the scope. Sometimes when infinite persistence creates very wide areas (as seen in Figure 5-16 in grey), the room for human-induced error can be greater. Averaging helps to reduce this error.

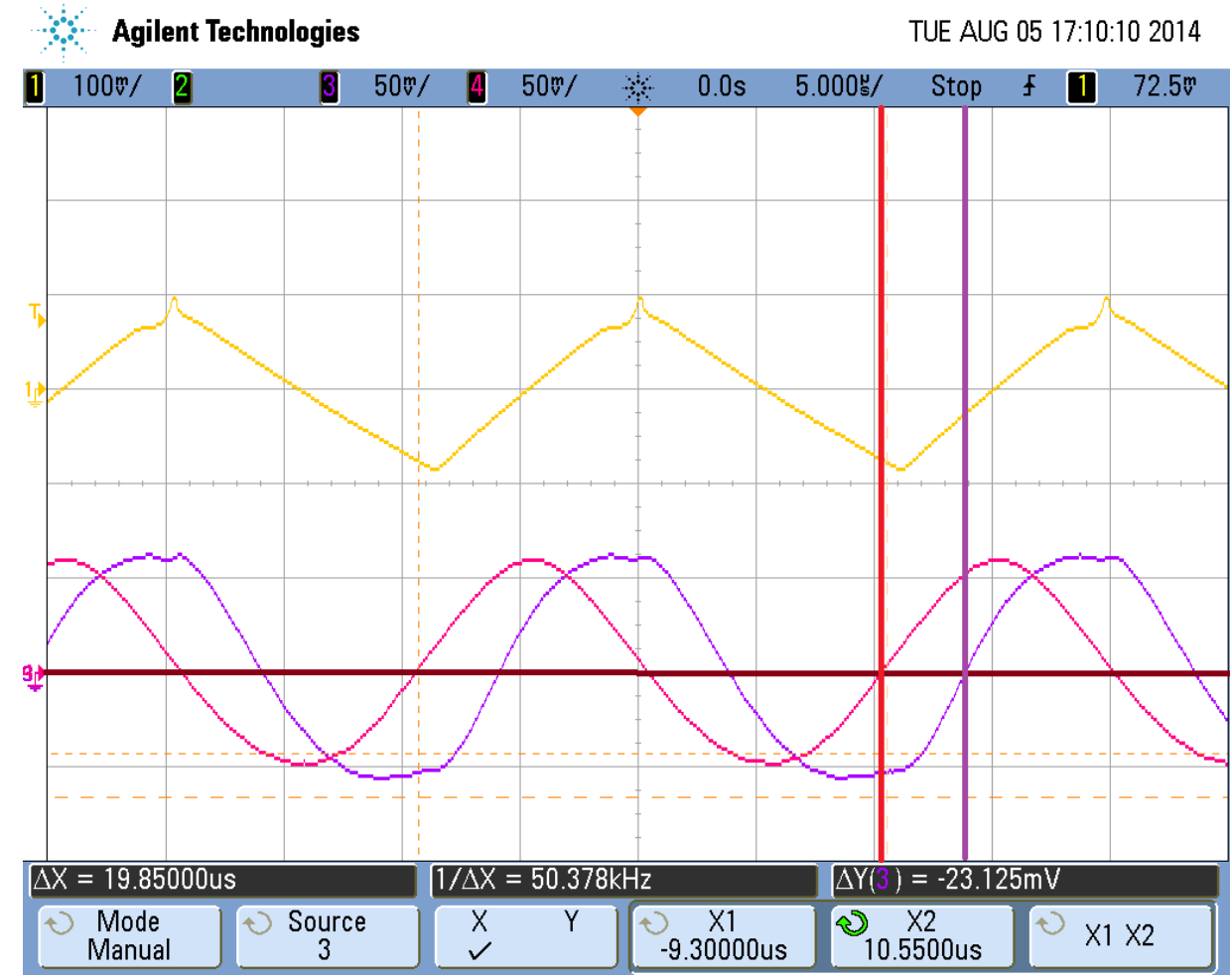

Figure 5-17: Example on using averaging

To verify that the loop measurement board can in fact take loop measurements, hardware verification needs to take place. For the purpose of verification, measurements were done on two of Linear Technology's demo boards, demo circuit 1409A, a boost converter, and demo circuit 1829A, a buck converter. A network analyzer was used on each of these circuits to produce a bode plot that contains measurements for crossover frequency, phase margin, and gain margin. Each circuit was then used in conjunction with the loop measurement board and an oscilloscope to make the same loop measurements. The results are then compared. The hope is that the results from both 
the network analyzer and the loop measurement board are alike. This would show that the loop measurement board can indeed make accurate measurements.

\subsection{Test Results}

For the 1409A boost converter, a network analyzer was used to create a bode plot for the converter at input voltages of $7 \mathrm{~V}$ and $12 \mathrm{~V}$. From these plots, shown in Figure 5-18 and Figure 519, crossover frequency, phase margin, and gain margin were determined. Different input voltages were used in order to have multiple test cases for comparison with the loop measurement board. When the input voltage is $7 \mathrm{~V}$, the crossover frequency was found to be $10.76 \mathrm{kHz}$, with phase margin being 81.89 degrees and gain margin being $28.67 \mathrm{~dB}$. When the input voltage is $12 \mathrm{~V}$, the crossover frequency was found to be $22.15 \mathrm{kHz}$, with phase margin being 76.90 degrees and gain margin being $19.29 \mathrm{~dB}$. Note that 180 degrees is already included in the following plots.

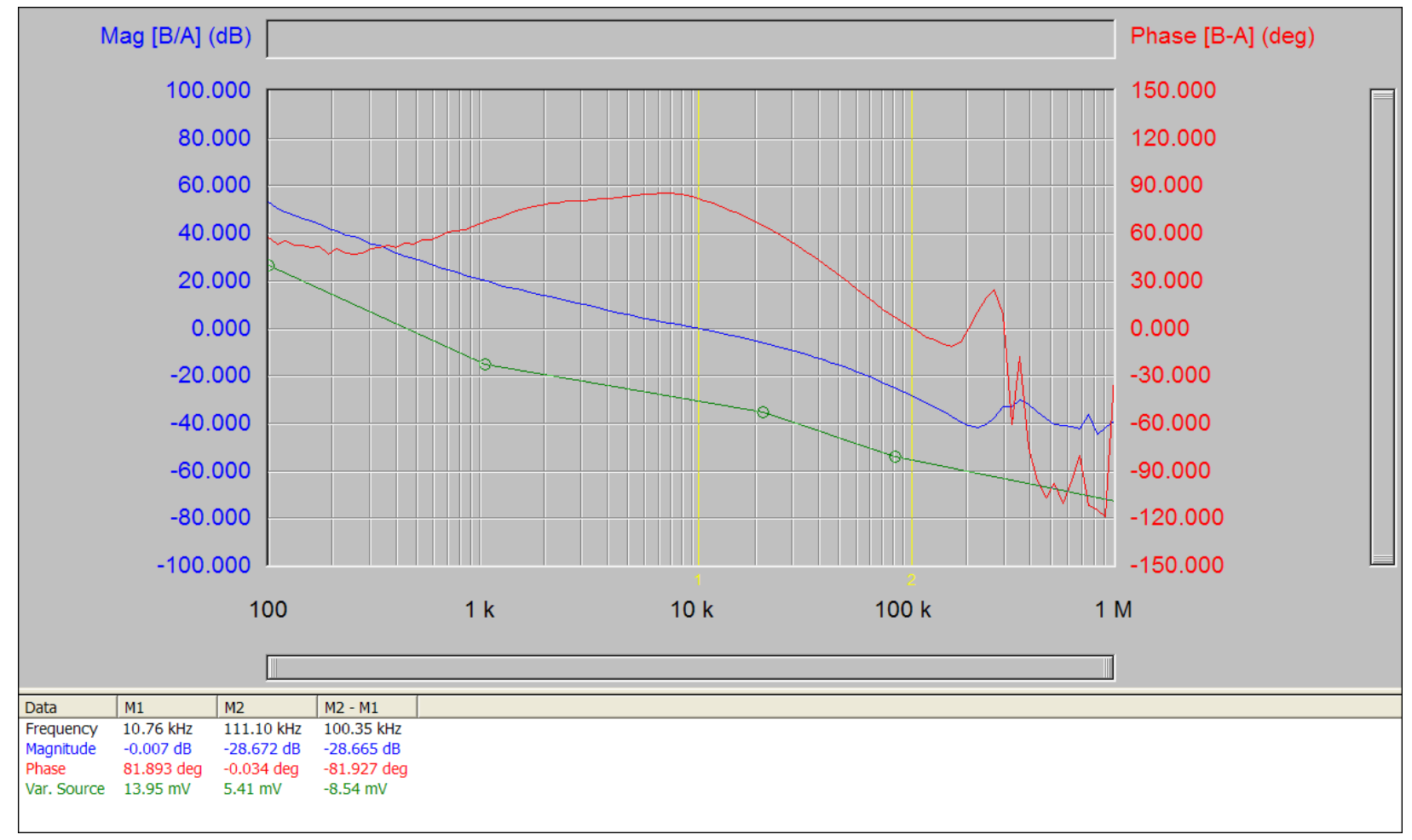

Figure 5-18: Bode plot of 1409A boost at Vin $=7 \mathrm{~V}$ from network analyzer 


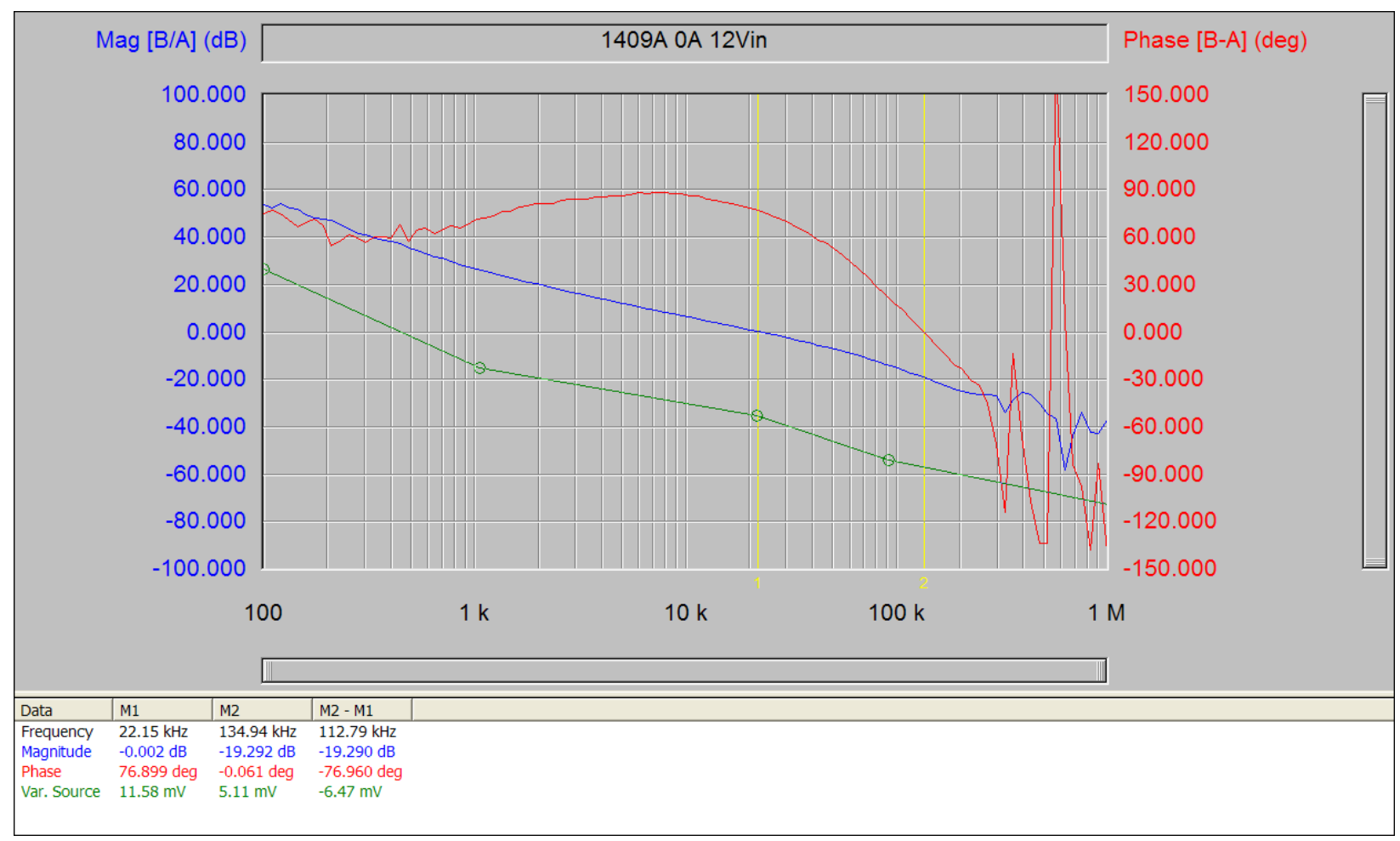

Figure 5-19: Bode plot of 1409A boost at Vin $=12 \mathrm{~V}$ from network analyzer

After the loop measurements were done using the network analyzers, the same measurements were done using the loop measurement board. Using the loop measurement board in conjunction with an oscilloscope, the waveforms needed to find crossover frequency, phase margin, and gain margin could be found. First, the converter was tested at an input voltage of 7V. Figure 5-20 shows the waveform where crossover frequency and phase margin can be measured for the 1409A boost circuit. The loop measurement board's signal frequency was adjusted until signals $\mathrm{A}$ and $\mathrm{B}$ are approximately equal in amplitude. In this case, the converter's crossover frequency, is $11.96 \mathrm{kHz}$. Using the techniques detailed above, the phase margin was measured to be 77.00 degrees and the gain margin (using the waveform in Figure 5-21) was measured to be 27.96dB. Table 5-4 summarizes these results and compares the loop measurement board's results with the network analyzer's measurements. 


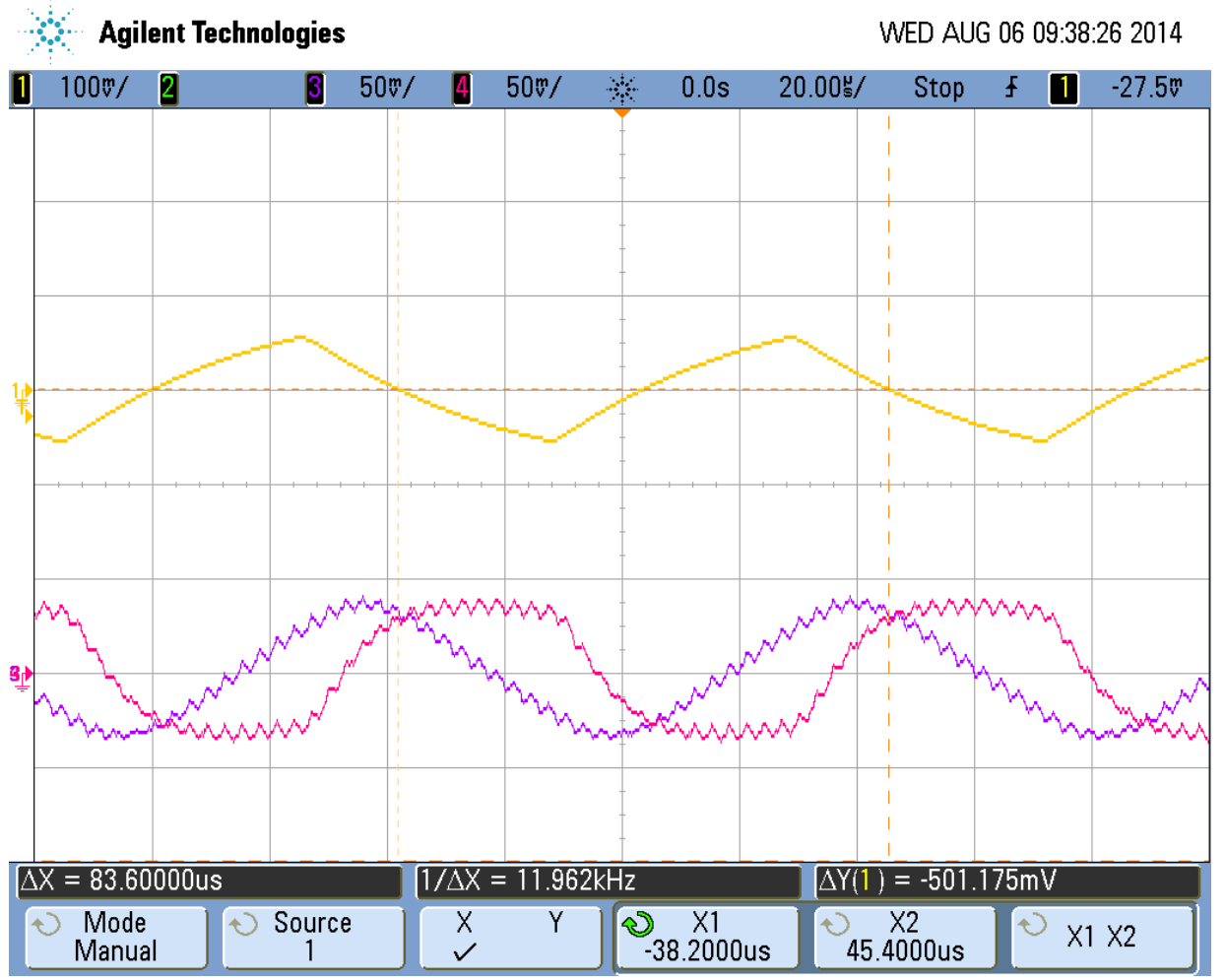

Figure 5-20: Waveform used to measure crossover frequency and phase margin for $1409 \mathrm{~A}$ Vin $=7 \mathrm{~V}$

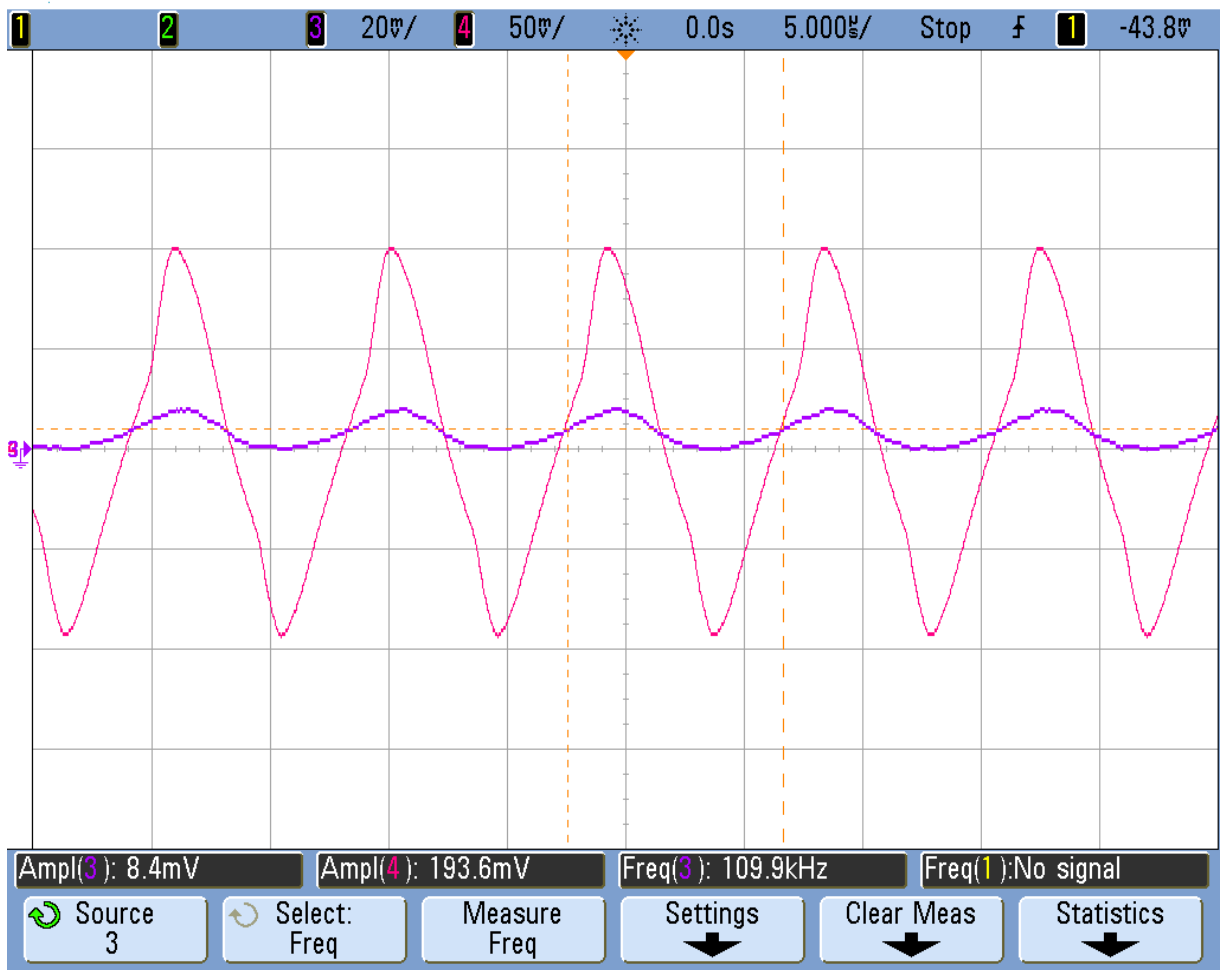

Figure 5-21: Waveform used to measure gain margin for $1409 \mathrm{~A}$ Vin $=7 \mathrm{~V}$ 
Table 5-4: Loop measurement results for 1409A Boost Circuit Vin = 7V

\begin{tabular}{|c|c|c|c|c|c|c|}
\hline $\begin{array}{c}\text { 1409A } \\
\text { VIN }=7 \mathrm{~V} \\
\text { Vout }=24 \mathrm{~V}\end{array}$ & $\begin{array}{c}\text { Cut-Off } \\
\text { Frequency } \\
\text { (Hz) }\end{array}$ & $\begin{array}{c}\text { \% } \\
\text { Difference } \\
\text { to Bode } \\
\text { Plot (fc) }\end{array}$ & $\begin{array}{c}\text { Phase } \\
\text { Margin } \\
\text { (Degree) }\end{array}$ & $\begin{array}{c}\% \\
\text { Difference } \\
\text { to Bode } \\
\text { Plot } \\
\text { (Phase) }\end{array}$ & $\begin{array}{c}\text { Gain } \\
\text { (dB) }\end{array}$ & $\begin{array}{c}\% \\
\text { Difference } \\
\text { to Bode } \\
\text { Plot (Gain) }\end{array}$ \\
\hline $\begin{array}{c}\text { Network } \\
\text { Analyzer }\end{array}$ & $\mathbf{1 0 . 7 6 k}$ & N/A & 81.89 & N/A & 28.67 & N/A \\
\hline $\begin{array}{c}\text { Loop } \\
\text { Measurement } \\
\text { Board }\end{array}$ & $\mathbf{1 1 . 9 6 k}$ & $\mathbf{- 1 1 . 1 5 \%}$ & $\mathbf{7 7 . 0 0}$ & $\mathbf{5 . 9 \%}$ & $\mathbf{2 7 . 9 6}$ & $\mathbf{2 . 4 8 \%}$ \\
\hline
\end{tabular}

On Table 5-4 the results of both methods of loop measurement are shown as well as the percent difference between the network analyzer produced bode plot and the loop measurement board. The crossover frequency found by the loop measurement board is $-11.15 \%$ difference from the cut-off frequency found by the network analyzer. Even though the percent difference seems rather high, the measurement provided by the loop measurement board is still a good estimation. It should be kept in mind that human error can factor into the difference in these measurements. For phase margin and gain margin, the loop measurement board produced measurements that were $5.9 \%$ and $2.48 \%$ difference from the network analyzer measurements. In these two cases, the measurements are very close the network analyzer results.

Next, the loop measurement board was used to find the same measurements when the 1409A boost circuit has an input voltage of $12 \mathrm{~V}$. Figure 5-22 shows the waveform where crossover frequency and phase margin can be measured for the 1409A boost circuit. In this case, crossover frequency is $22.80 \mathrm{kHz}$. The phase margin was measured to be 73.00 degrees and the gain margin (using the waveform in Figure 5-23) was measured to be $18.66 \mathrm{~dB}$. Table 5-5 summarizes these results and compares the loop measurement board's results with the network analyzer's measurements. 


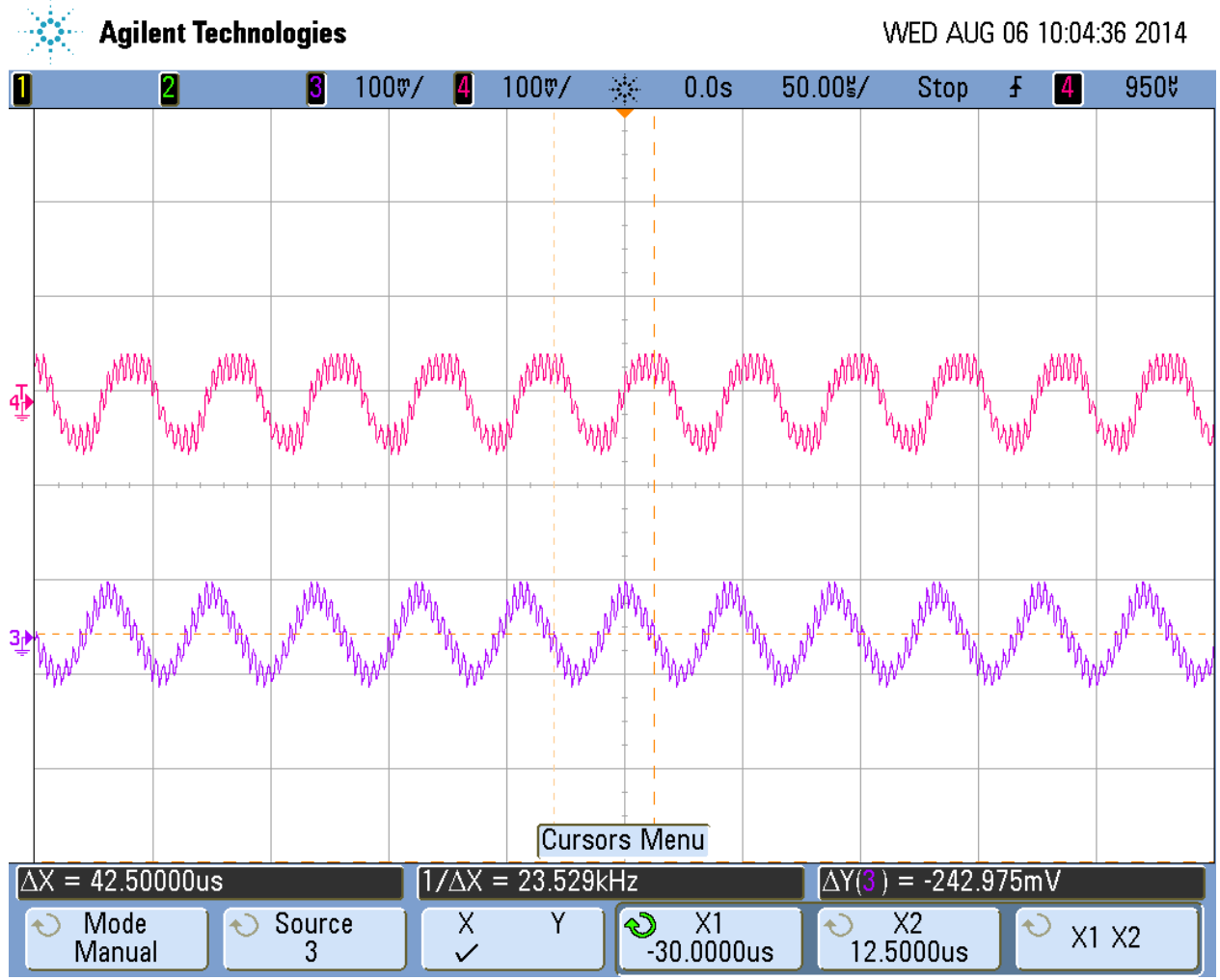

Figure 5-22: Waveform used to measure crossover frequency and phase margin for $1409 \mathrm{~A}$ Vin $=12 \mathrm{~V}$

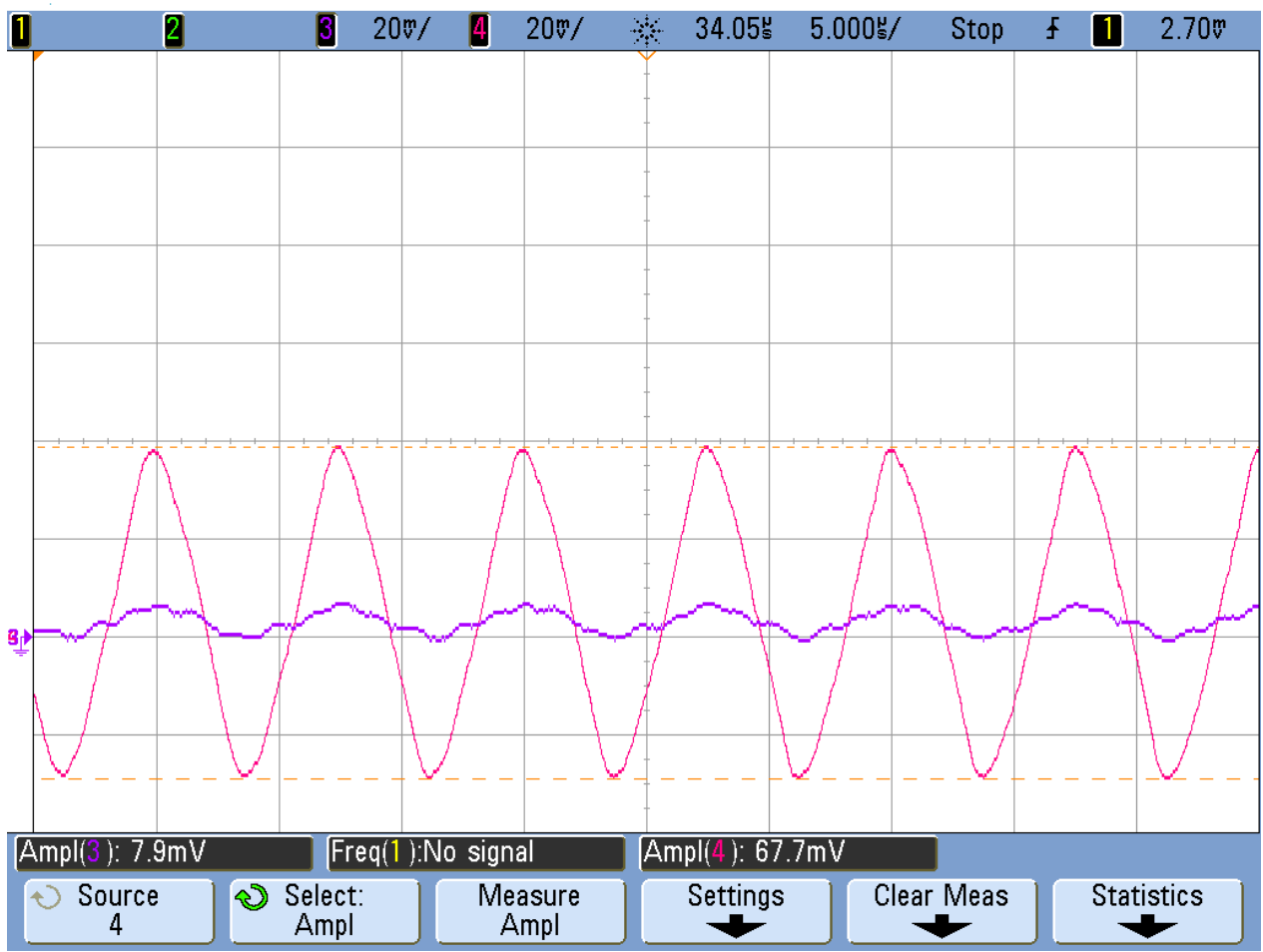

Figure 5-23: Waveform used to measure gain margin for 1409A Vin $=12 \mathrm{~V}$ 
Table 5-5: Loop measurement results for 1409A Boost Circuit Vin $=12 \mathrm{~V}$

\begin{tabular}{|c|c|c|c|c|c|c|}
\hline $\begin{array}{c}\text { 1409A } \\
\text { VIN }=12 \mathrm{~V} \\
\text { Vout }=24 \mathrm{~V}\end{array}$ & $\begin{array}{c}\text { Cut-Off } \\
\text { Frequency } \\
\text { (Hz) }\end{array}$ & $\begin{array}{c}\text { \% } \\
\text { Difference } \\
\text { to Bode } \\
\text { Plot (fc) }\end{array}$ & $\begin{array}{c}\text { Phase } \\
\text { Margin } \\
\text { (Degree) }\end{array}$ & $\begin{array}{c}\% \\
\text { Difference } \\
\text { to Bode } \\
\text { Plot } \\
\text { (Phase) }\end{array}$ & $\begin{array}{c}\text { Gain } \\
\text { (dB) }\end{array}$ & $\begin{array}{c}\% \\
\text { Difference } \\
\text { to Bode } \\
\text { Plot (Gain) }\end{array}$ \\
\hline $\begin{array}{c}\text { Network } \\
\text { Analyzer }\end{array}$ & $22.15 \mathrm{k}$ & N/A & 76.90 & N/A & 19.29 & N/A \\
\hline $\begin{array}{c}\text { Loop } \\
\text { Measurement } \\
\text { Board }\end{array}$ & $\mathbf{2 2 . 8 0 k}$ & $-2.96 \%$ & 73.00 & $5.07 \%$ & 18.66 & $3.27 \%$ \\
\hline
\end{tabular}

On Table 5-5 the results of both methods of loop measurement are shown as well as the percent difference between measurements taken from the network analyzer and the loop measurement board. The crossover frequency found by the loop measurement board is $-2.96 \%$ difference from the cut-off frequency found by the network analyzer. For phase margin and gain margin, the loop measurement board produced measurements that were $5.07 \%$ and $3.27 \%$ difference from the network analyzer measurements. In all three measurements, the loop measurement board produces accurate measurements that are close to the measurements found by the network analyzer.

Next, the same measurements were done using Linear Technology's 1829A buck circuit. The buck is set up with an input voltage of $12 \mathrm{~V}$, an output voltage of $1.5 \mathrm{~V}$, and no load. As with the previous test, loop measurements were first done with a network analyzer and then done with the loop measurement board. Figure 5-24 shows the bode plot made by the network analyzer that is used to measure crossover frequency, phase margin, and gain margin. When the input voltage is $12 \mathrm{~V}$, the crossover frequency was found to be $52.40 \mathrm{kHz}$, with phase margin being 61.17 degrees and gain margin being $8.62 \mathrm{~dB}$. 


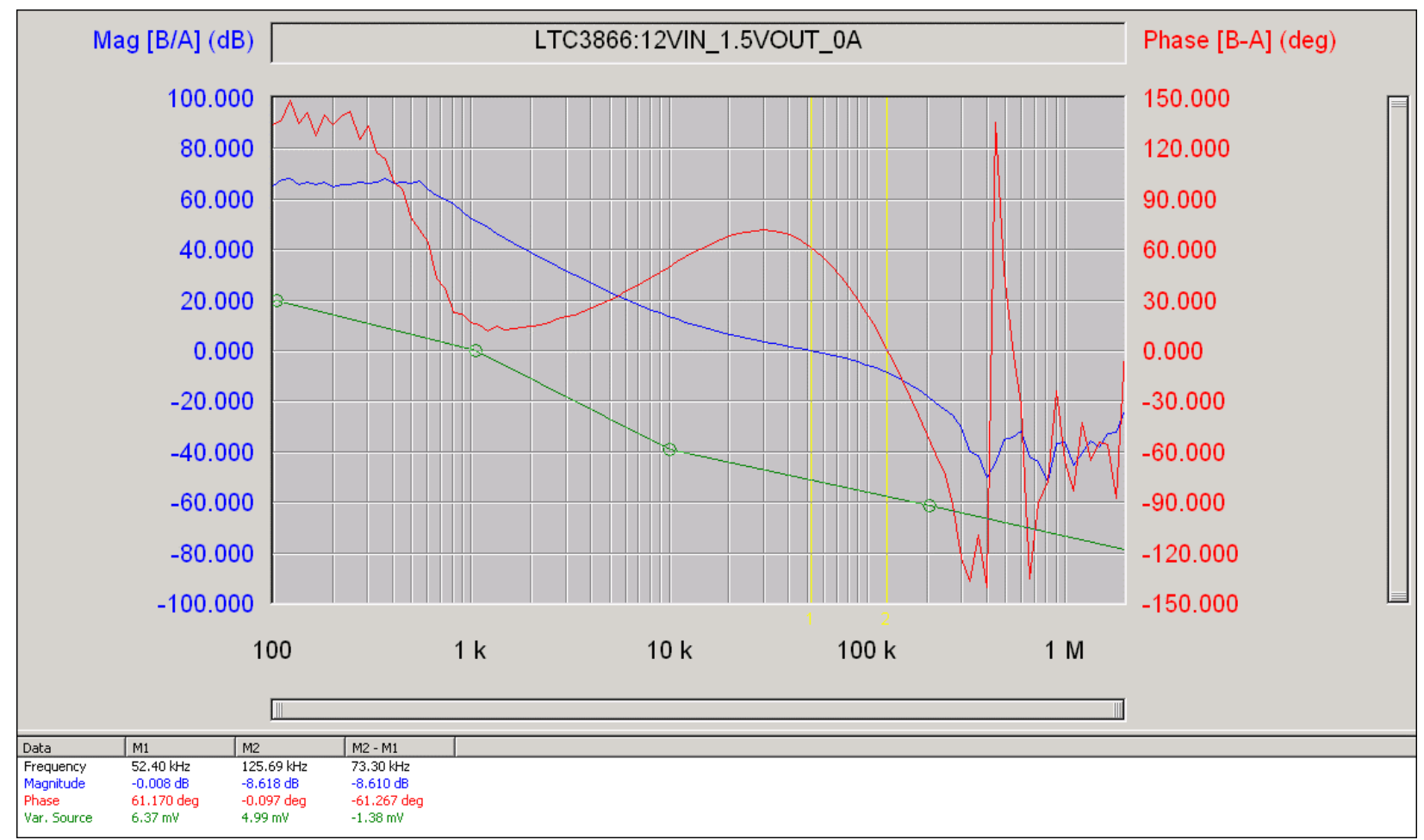

Figure 5-24: Bode plot of 1829A buck at Vin $=12 \mathrm{~V}$ from network analyzer

Next, loop measurements were done using the loop measurement board. Figure 5-25 and Figure 5-26 show the waveforms used to find crossover frequency, phase margin, and gain margin for the 1829A buck. With this particular converter, the crossover frequency was found to be $50.60 \mathrm{kHz}$, with phase margin being 62.00 degrees and gain margin being 8.20dB. Table 5-6 summarizes these results and compares the loop measurement board's results with the network analyzer's measurements. 


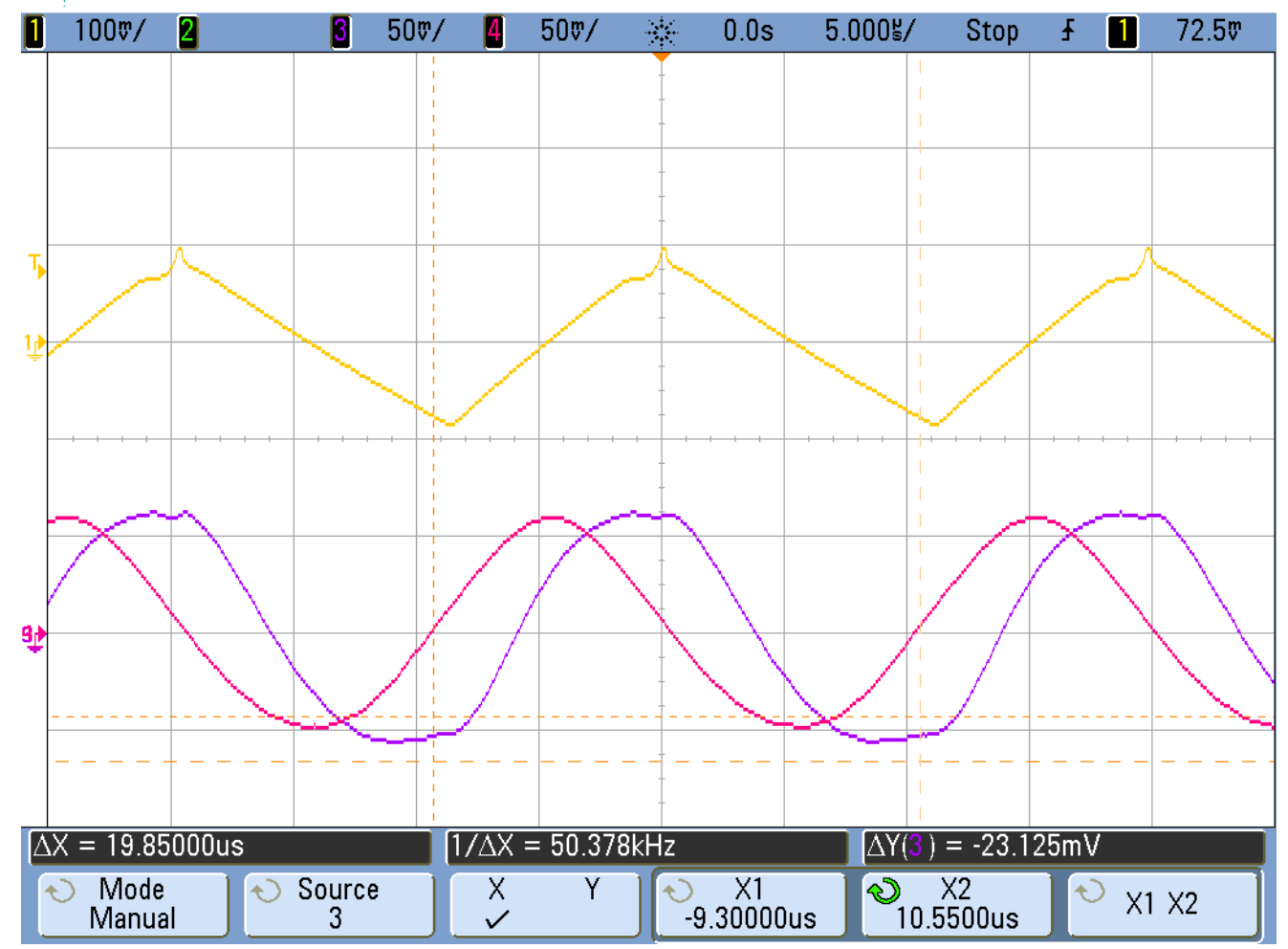

Figure 5-25: Waveform used to measure crossover frequency and phase margin for 1829A $\mathrm{Vin}=12 \mathrm{~V}$

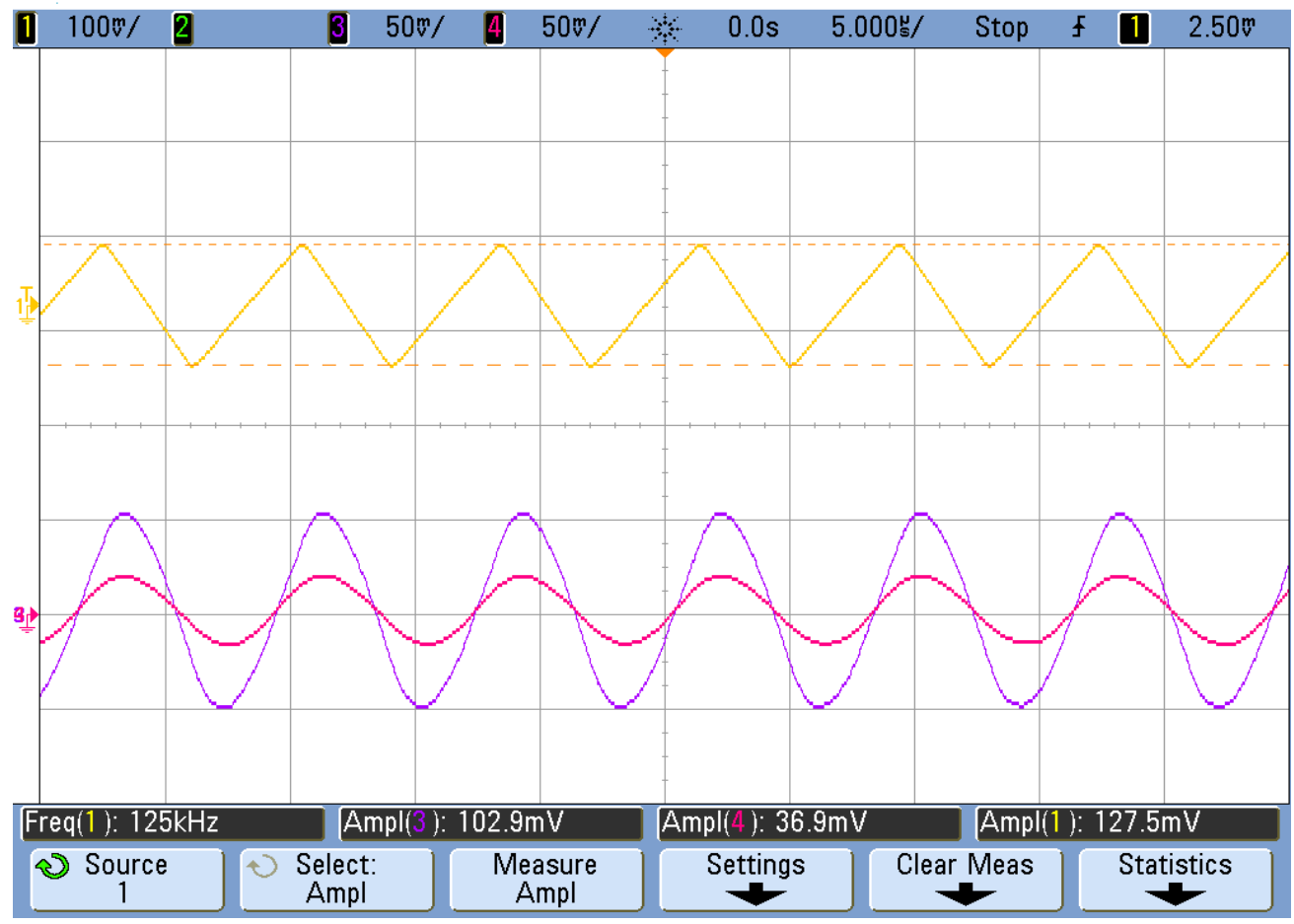

Figure 5-26: Waveform used to measure gain margin for 1829A Vin $=12 \mathrm{~V}$ 
Table 5-6: Loop measurement results for 1829A Boost Circuit Vin = 12V

\begin{tabular}{|c|c|c|c|c|c|c|}
\hline $\begin{array}{c}\text { 1829A } \\
\text { VIN }=12 V \\
\text { Vout }=1.5 V\end{array}$ & $\begin{array}{c}\text { Cut-Off } \\
\text { Frequency } \\
\text { (Hz) }\end{array}$ & $\begin{array}{c}\text { \% } \\
\text { Difference } \\
\text { to Bode } \\
\text { Plot (fc) }\end{array}$ & $\begin{array}{c}\text { Phase } \\
\text { Margin } \\
\text { (Degree) }\end{array}$ & $\begin{array}{c}\% \\
\text { Difference } \\
\text { to Bode } \\
\text { Plot } \\
\text { (Phase) }\end{array}$ & $\begin{array}{c}\text { Gain } \\
\text { (dB) }\end{array}$ & $\begin{array}{c}\text { \% } \\
\text { Difference } \\
\text { to Bode } \\
\text { Plot (Gain) }\end{array}$ \\
\hline $\begin{array}{c}\text { Network } \\
\text { Analyzer }\end{array}$ & $52.40 \mathrm{k}$ & N/A & 61.17 & N/A & 8.62 & N/A \\
\hline $\begin{array}{c}\text { Loop } \\
\text { Measurement } \\
\text { Board }\end{array}$ & $50.60 \mathrm{k}$ & $3.40 \%$ & 62.00 & $-1.36 \%$ & 8.20 & $4.87 \%$ \\
\hline
\end{tabular}

On Table 5-6 the results of both methods of loop measurement are shown as well as the percent difference between the network analyzer produced bode plot and the loop measurement board. The crossover frequency found by the loop measurement board is $3.40 \%$ difference from the cut-off frequency found by the network analyzer. For phase margin and gain margin, the loop measurement board produced measurements that were $-1.36 \%$ and $4.87 \%$ difference from the network analyzer measurements. In all three measurements, the loop measurement board produces accurate measurements that are close to the measurements found by the network analyzer.

\subsection{Different Excitation Signals: Sine vs. Triangle}

Initially, before the design of the triangle waveform generator, testing was done to see if a triangular waveform would give measurements similar to what a sine wave would get. In order to see if using a triangular excitation signal would give accurate measurements, loop measurements would have to be done using both types of signals. First, using Linear Technology's demo circuit DC1829A, a step-down converter, along with a network analyzer, the converter's cut-off frequency, phase margin, and gain margin were measured to be used as a point of reference. The DC1829A step-down converter was set to take an input of 12 VDC and to output 1.5 VDC at no load. Figure 5-27 shows the bode plot produced by the network analyzer. 


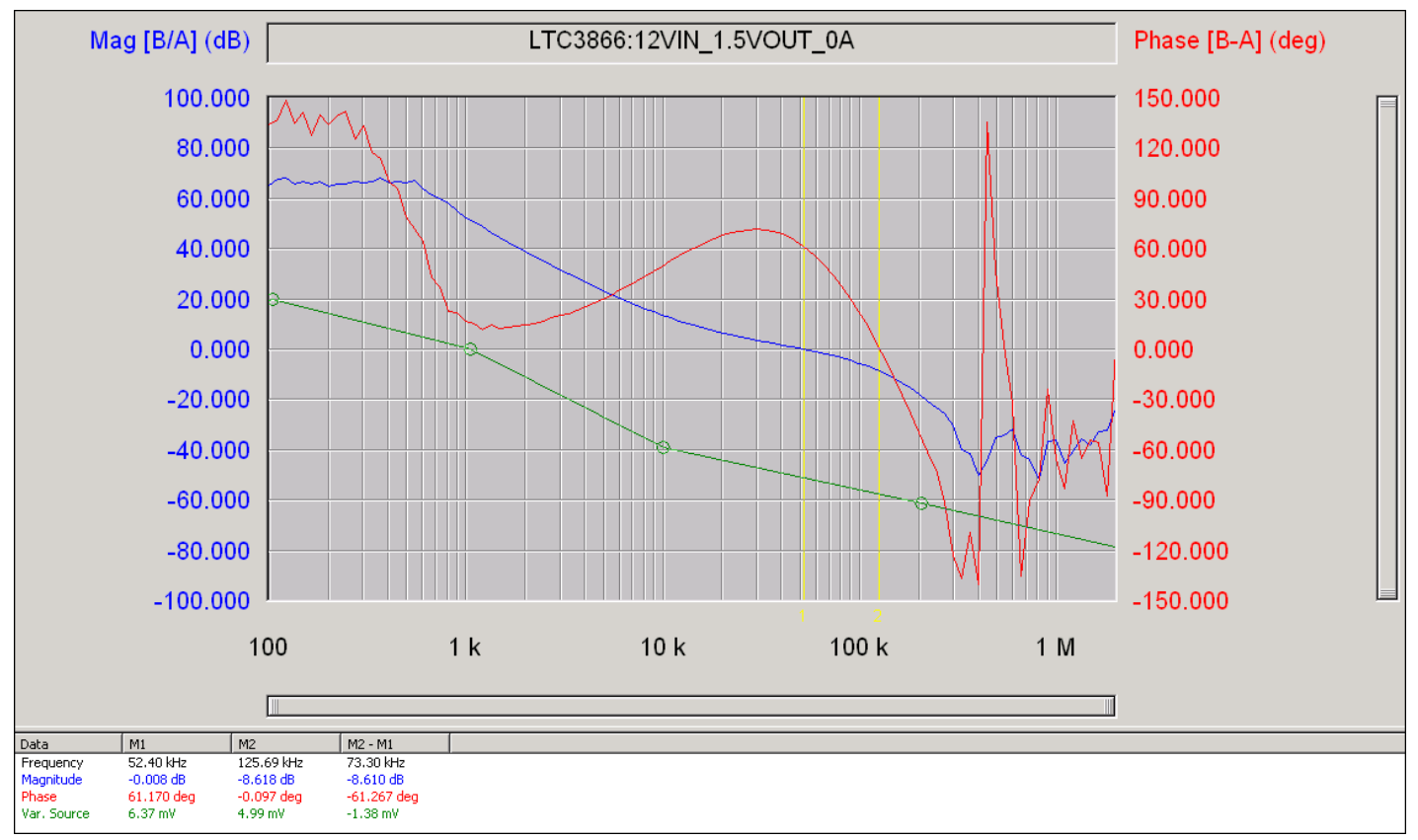

Figure 5-27: Bode Plot produced by Network Analyzer

Next, to compare the use of a sine wave to a triangle wave, a function generator was connected to a signal injection board, which is shown in Figure 5-28. The signal injection board consists of just an isolation transformer and some circuitry that allows for a signal that is input to be output and injected into a DC-DC converter's feedback loop, thus allowing for loop measurements. The signal injection circuitry has test points (represented by TPB and TPA) that allows for oscilloscopes to monitor the input and output signals via BNC ports. Figure 5-30 shows the test setup.

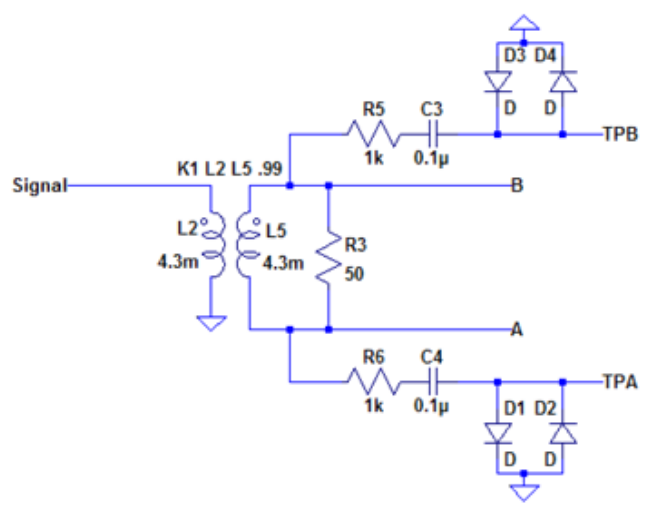

Figure 5-28: Schematic for signal injection board 

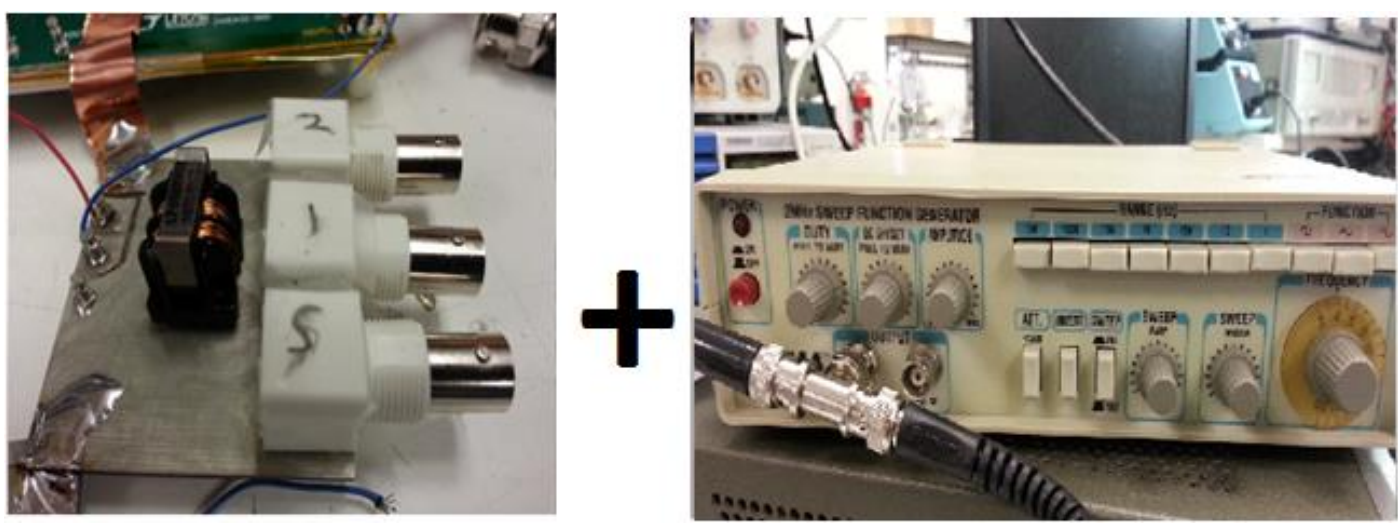

Figure 5-29: Equipment used

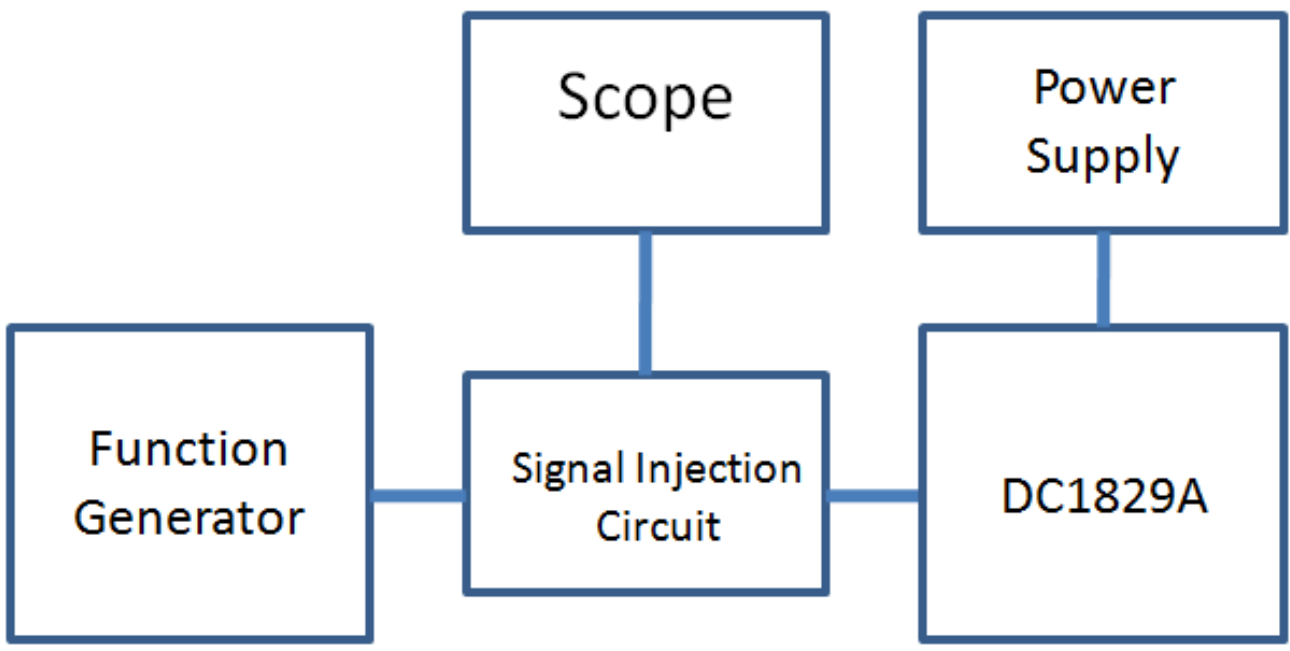

Figure 5-30: Test setup to compare Triangle and Sine excitation signals

Using the function generator to provide a sine wave, cut-off frequency, phase margin, and gain margin for the converter were measured. After these measurements were taken, the same measurements were taken as previously done using a triangle wave. The results are shown below in Table 5-7. The network analyzer measured a cut-off frequency of $52 \mathrm{kHz}$, a phase margin of 61 degrees, and a gain margin of $8.6 \mathrm{~dB}$. Using a sine wave from the function generator, a cut-off frequency of $53.0 \mathrm{kHz}$, a phase margin of 59 degrees, and a gain margin of $8.0 \mathrm{~dB}$ were measured. Using a triangle waveform from the function generator, a cut-off frequency of 55.0 
$\mathrm{kHz}$, a phase margin of 58 degrees, and a gain margin of $8.4 \mathrm{~dB}$ was measured. When comparing these last two sets of measurements to the network analyzer's measurements, the triangle waveform produces measurements that are close to those of the network analyzer. In fact, the triangle waveform produced measurements that were within $5 \%$ of the network analyzer's measurements. It could then be concluded that the triangle wave should be used to make reasonably accurate loop measurements.

Table 5-7: Different Excitation, Sine vs. Triangle

\begin{tabular}{|c|c|c|c|c|c|c|}
\hline 1829A & $\begin{array}{c}\text { Cut-Off } \\
\text { Frequency } \\
(\mathbf{H z})\end{array}$ & $\begin{array}{c}\% \\
\text { Difference } \\
\text { to Network } \\
\text { Analyzer } \\
\text { (fc) }\end{array}$ & $\begin{array}{c}\text { Phase } \\
\text { Margin } \\
\text { (Degree) }\end{array}$ & $\begin{array}{c}\% \\
\text { Difference } \\
\text { to Network } \\
\text { Analyzer } \\
\text { (Phase) }\end{array}$ & $\begin{array}{l}\text { Gain } \\
\text { Margin } \\
\text { (dB) }\end{array}$ & $\begin{array}{c}\% \\
\text { Difference } \\
\text { to Network } \\
\text { Analyzer } \\
\text { (Gain) }\end{array}$ \\
\hline $\begin{array}{l}\text { Network } \\
\text { Analyzer }\end{array}$ & $52.4 \mathrm{k}$ & N/A & 61 & $\mathbf{N} / \mathbf{A}$ & 8.6 & N/A \\
\hline $\begin{array}{l}\text { Sig. Inject } \\
\text { (Sine) }\end{array}$ & $53.0 \mathrm{k}$ & $1.14 \%$ & 59 & $-3.38 \%$ & 8.0 & $-6.97 \%$ \\
\hline $\begin{array}{l}\text { Sig. Inject } \\
\text { (Tri.) }\end{array}$ & $55.0 \mathrm{k}$ & $4.96 \%$ & 58 & $-4.92 \%$ & 8.4 & $-2.32 \%$ \\
\hline
\end{tabular}




\section{Chapter 6 - Conclusion and Future Improvement}

The purpose of this thesis is to design and construct a low-cost, small, and portable loop measurement tool for DC-DC converters. Such a tool will be very useful in the situation where a network analyzer is not available. The tool could be used to make quick loop measurements of phase margin, gain margin, and crossover frequency of standard DC-DC converters with maximum output voltage of $50 \mathrm{~V}$.

Results from hardware implementation of the loop measurement tool show that the tool meets target electrical and physical requirements and constraints as outlined in Chapter 3. The finished board has dimension of 2.9"x2.7"x1.5" while weighing 50 grams. This allows the board to be portable and easily transportable. Another goal was to make the board cost less than $\$ 100$. The completed board was calculated to cost approximately $\$ 67.87$, making it an affordable tool. The board was also designed to have three options to power the board: a $5 \mathrm{~V}$ input (such as from bench power supply), a 5V input via Micro USB, and a 7.5V-36V input with the use of a buck circuit. This gives the loop measurement board more flexibility with its use.

A requirement that was not completely met was the frequency range that the loop measurement board should be able to operate in. Originally, the objective was to design the tool to be able to measure frequencies anywhere from 0 to $1 \mathrm{MHz}$. However, when the excitation signal generator was implemented in hardware, the minimum frequency was found to be approximately $1.8 \mathrm{kHz}$ and the maximum frequency was measured to be $990 \mathrm{kHz}$. Despite the narrower range, the loop measurement tool should still be acceptable for the majority of DC-DC converter applications.

Further tests on the proposed tool using buck and boost demo circuits demonstrated that the loop measurement board was able to make measurements almost as accurately as those 
obtained from a network analyzer. More specifically, results from the loop measurement board were in many instances found to be far less than $10 \%$ difference from measurements made by a network analyzer.

Aside from the benefits offered by the proposed loop measurement tool, one point of concern is that since everything with this board is manual, there could potentially be some margin for human error when making loop measurements. A user has to manually set up the board to make the measurements and makes real time readings off an oscilloscope using his or her good judgment. The manual nature of the loop measurement board is both a strength and potential weakness.

Although the board can be used in its current configuration, further development can be done in the future to improve the board. Examples of further enhancements include a wider frequency of operation of the board, the ability to make measurements on DC-DC converters with higher output voltages, and refinement in the waveform generation. Currently, the loop measurement board can only make measurements from approximately $1.8 \mathrm{kHz}$ to $990 \mathrm{kHz}$. Even though this specification is acceptable for the majority of DC-DC converter applications, there are cases where DC-DC converter loop measurements may need to be done below $1.8 \mathrm{kHz}$. Such improvement could be achieved by a better waveform generator. Another improvement that will make the board more versatile is by increasing its ability to handle measurements for DC-DC converters with higher output voltages. This may be done for example by changing the passive components at the output of the loop measurement board. In its current state, the waveform generator for creating the triangular waveform uses a comparator, integrator, and inverting amplifier. This design works but may not be the best way to produce the excitation signal, and so a better method should be investigated to create the excitation signal. Different design choices 
could potentially lower the cost of the system and/or save space on the board itself. Refining the design could also allow for a wider frequency range for the board.

Overall, this thesis successfully demonstrated an alternative way to make a low-cost, compact, and portable loop measurements on DC-DC converters. 


\section{BIBLIOGRAPHY}

[1] Linear Technology, Application Note 140

[2] Linear Technology, Application Note 76

[3] Texas Instruments. (2002). Designing Stable Control Loops [Online]. Available: http://www.ti.com/lit/ml/slup173/slup173.pdf

[4] Omicron Lab. (2011). Loop Gain Measurement. [Online]. Available: http://www.omicron.com/fileadmin/assets/customer_examples/Bode_Info_LoopGain_V1_0.pdf

[5] Sachs, J.; Kmec, M.; Herrmann, R.; Helbig, M.; Schilling, K., "Integrated pseudo-noise device with network analyzer performance for UWB sensing and component test," Signals, Systems, and Electronics (ISSSE), 2012 International Symposium on , vol., no., pp.1,6, 3-5 Oct. 2012

[6] Agilent. (2004). Network Analyzer Basics. [Online]. Available: http://cp.literature.agilent.com/litweb/pdf/5965-7917E.pdf

[7] Texas Instruments. (2011). A Quick Sine Wave Generator. [Online] Available: http://www.ti.com/lit/wp/snoa839/snoa839.pdf

[8] Linear Technology. "Single, Dual, Quad 200MHz Low Noise Precision Op Amps." LT1722 datasheet. 2014.

[9] Linear Technology. "LT3663EDCB-3.3/5.0 1.2A, 1MHz Step-Down Switching Regulator with Output Current Limit." Demo Circuit 1570A-A/B quick start guide. 2014.

[10] Linear Technology. "250mA/60MHz Current Feedback Amplifier." LT1206 datasheet. 2014 
[11] Linear Technology. "100mA Regulated Charge-Pump Inverters in ThinSOT." LT1983 datasheet. 2014.

[12] Linear Technology. "100mA Regulated Charge Pump Inverter." Demo Circuit 482 quick start guide. 2014.

[13] Texas Instruments. (2001). Closing the Feedback Loop [Online]. Available: http://www.ti.com/lit/ml/slup068/slup068.pdf

[14] Taufik. Introduction to Power Electronics. San Luis Obispo, CA: Cal Poly State University. 2013. 


\section{APPENDICES}

\section{Appendix A - Bill of Materials}

\section{The following information covers the cost of materials needed to implement the loop}

\section{measurement board in hardware:}

\begin{tabular}{|c|c|c|c|c|c|c|}
\hline & A & B & C & D & $\mathrm{E}$ & $\mathrm{F}$ \\
\hline 1 & Item & Qty & Ref-Des & Desc & Manufacturer's Part Number & Cost \\
\hline 2 & 1 & 2 & $\mathrm{Cl}, \mathrm{C} 8$ & CAP, 0603 10nF 10\% 25V X7R & AVX 06033 C103KAT2A & $\$ 0.32$ \\
\hline 3 & 2 & 6 & $\mathrm{C} 2, \mathrm{C} 3, \mathrm{C} 4, \mathrm{C} 6, \mathrm{C} 10, \mathrm{C} 16$ & CAP, 06030.1 UF 10\% 16V X7R & AVX 0603YC104K4T2A & $\$ 0.60$ \\
\hline 4 & 3 & 2 & C5,C9 & CAP, 08050.1 UF 10\% 50V X7R & AVX 08055C104K4T2A & $\$ 0.58$ \\
\hline 5 & 4 & 1 & C7 & CAP, 0805 lUF 20\% 10V X7R & TAIYO YUDEN LMK212BJ105MG-T & $\$ 0.41$ \\
\hline 6 & 5 & 2 & $\mathrm{C} 11, \mathrm{C} 12$ & CAP, 1206 10UF 10\% 6.3V X5R & AVX 12066D106KAT2A & $\$ 0.56$ \\
\hline 7 & 6 & 2 & $\mathrm{C} 13, \mathrm{C} 15$ & CAP, 1206 4.7UF 20\% 50V X7R & AVX 12065C475KAT2A & $\$ 0.32$ \\
\hline 8 & 7 & 1 & $\mathrm{C} 14$ & CAP, 0805 2.2UF 10\% 10V X7R & AVX 0805ZC225KAT2A & $\$ 0.36$ \\
\hline 9 & 8 & 1 & $\mathrm{C} 17$ & CAP, 1206 47UF $20 \%$ 10V X5R & MURATA GRM31CR61A476ME15L & $\$ 0.81$ \\
\hline 10 & 9 & 4 & D1,D2,D3,D4 & DIODE, SCHOTTKY 30V, 100mA & CENTRAL SEMI CMSH-3 TR & $\$ 6.64$ \\
\hline 11 & 10 & 1 & D5 & DIODE, SCHOTTKY RECTIFIER 20V, IA SMA & CENTRAL SEMI CMSHI-2OM & $\$ 0.13$ \\
\hline 12 & 11 & 1 & D6 & DIODE, SCHOTTKY BARRIER RECTIFIER 40V 2A & DIODES INC.DFLS240-7 & $\$ 0.70$ \\
\hline 13 & 12 & 8 & $\mathrm{El}, \mathrm{E} 2, \mathrm{E} 3, \mathrm{E} 4, \mathrm{E} 5, \mathrm{E} 6, \mathrm{E} 7, \mathrm{E} 8$ & TURRET & MILL MAX 250 1-2-00-80-00-00-07-0 & $\$ 4.88$ \\
\hline 14 & 13 & 1 & JPl & HEADER, 3 PIN $2 \mathrm{~mm}$ & SULLINS NRPN031PAEN-RC & $\$ 0.35$ \\
\hline 15 & 14 & 3 & $\mathrm{Jl}, \mathrm{J} 2, \mathrm{~J} 3$ & CONN,BNC,5 PINS & CONNEX 112404 & $\$ 7.77$ \\
\hline 16 & 15 & 1 & $\mathrm{~J} 4$ & CONN MICRO USB RCPT RA TYPE B SMD & WURTH 629105136821 & $\$ 0.25$ \\
\hline 17 & 16 & 1 & Ll & CHOKE, $4.3 \mathrm{mH}$ & DELTA ELECTRONICS INC. LFU1005V03 & $\$ 1.30$ \\
\hline 18 & 17 & 1 & L2 & IND, 7.8uH & COILTRONICS SD6030-7R8-R & $\$ 1.01$ \\
\hline 19 & 18 & 4 & $\mathrm{MHI}, \mathrm{MH} 2, \mathrm{MH} 3, \mathrm{MH} 4$ & STANDOFF, SNAP ON & KEYSTONE 8831 & $\$ 1.12$ \\
\hline 20 & 19 & 2 & $\mathrm{R} 1, \mathrm{R} 6$ & RES, 0603 5.1K OHMS 1\% 1/10W & VISHAY CRCW06035K 10FKEA & $\$ 0.16$ \\
\hline 21 & 20 & 1 & R2 & RES, VARIABLE 50k & BOURNS 3386P-1-503LF & $\$ 1.54$ \\
\hline 22 & 21 & 1 & R3 & RES, VARIABLE $5 \mathrm{k}$ & BOURNS 3386P-1-502LF & $\$ 1.54$ \\
\hline 23 & 22 & 1 & R4 & RES, VARIABLE 500 OHMS & BOURNS 3386P-1-501LF & $\$ 1.54$ \\
\hline 24 & 23 & 2 & R5,R10 & RES, 0603 1K OHMS 5\% 1/16W & VISHAY CRCW06031KO0JNED & $\$ 0.16$ \\
\hline 25 & 24 & 1 & R7 & RES, 0603 100K OHMS 5\% 1/16W & VISHAY CRCW0603100KJNEA & $\$ 0.08$ \\
\hline 26 & 25 & 1 & R8 & RES, 0603 47K OHMS 5\% 1/10W & VISHAY CRCW060347KOJNEA & $\$ 0.08$ \\
\hline 27 & 26 & 1 & R9 & RES, 0603 200K OHMS 5\% 1/16W & VISHAY CRCW0603200KJNEA & $\$ 0.08$ \\
\hline 28 & 27 & 1 & R11 & RES, VARIABLE 100k & BOURNS 3386P-1-104LF & $\$ 1.70$ \\
\hline 29 & 28 & 2 & R12,R15 & RES, 06030 OHMS JUMPER & VISHAY CRCW06030000ZOEA & $\$ 0.20$ \\
\hline 30 & 29 & 1 & R13 & RES, 0603 10K OHMS 5\% 1/10W & VISHAY CRCW060310KOJNEA & $\$ 0.08$ \\
\hline 31 & 30 & 1 & R14 & RES, 06031 OHMS 5\% 1/10W & VISHAY CRCW0603IRO0JNEA & $\$ 0.08$ \\
\hline 32 & 31 & 1 & R16 & RES. 0603 36.5k OHMS 1\% 1/10W & VISHAY CRCW060336K5FKEA & $\$ 0.08$ \\
\hline 33 & 32 & 1 & R17 & RES, 060320 OHMS 5\% 0.1W & VISHAY CRCW060320ROJNEA & $\$ 0.08$ \\
\hline 34 & 33 & 1 & R18 & RES, 060351 OHMS 5\% 1/10W & VISHAY CRCW060351ROJNEA & $\$ 0.08$ \\
\hline 35 & 34 & 2 & U1,U2 & IC, OP AMP & LINEAR TECH. LT1722CS8\#PBF & $\$ 2.12$ \\
\hline 36 & 35 & 1 & U3 & IC, 250MA/60MHz CURRENT FEEDBACK AMP & LINEAR TECH. LT1206CS8\#PBF & $\$ 4.83$ \\
\hline 37 & 36 & 1 & U4 & IC, 100mA REGULATED CHARGE-PUMP INVERTER & LINEAR TECH. LTC1983ES6-5 & $\$ 2.17$ \\
\hline 38 & 37 & 1 & U5 & IC, 1.2A STEP-DOWN SWITCHING REGULATOR & LINEAR TECH. LT3663EMS8E-5\#PBF & $\$ 3.71$ \\
\hline 39 & 38 & 1 & XJP1 & SHUNT & SAMTEC 2SN-BK-G & $\$ 0.45$ \\
\hline 40 & & & & & & \\
\hline 41 & & & & PCB & & $\$ 20.00$ \\
\hline 42 & & & & & Total Cost: & $\$ 68.87$ \\
\hline
\end{tabular}

